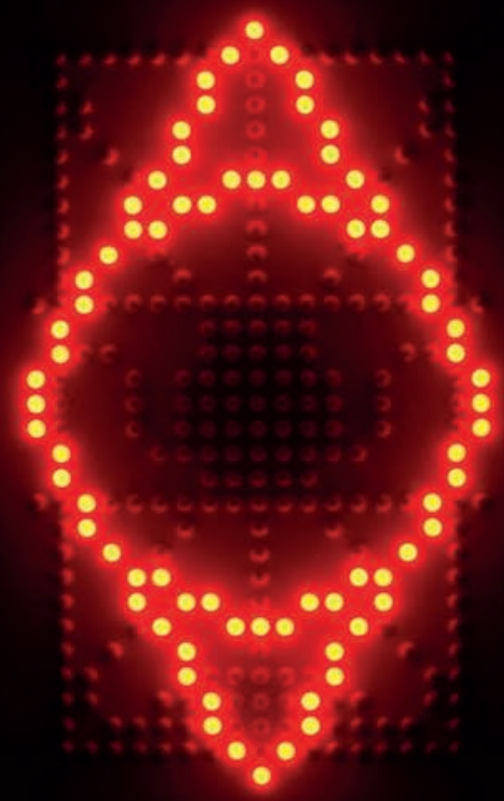

Theo Hug, Michael Schorner, Josef Mitterer (Hg.)

\title{
Ernst-von-Glasersfeld-Lectures 2015
}

innsbruck university press 


\section{EDITED VOLUME SERIES}

innsbruck university press

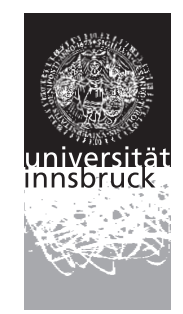



Theo Hug, Michael Schorner, Josef Mitterer (Hg.)

\section{Ernst-von-Glasersfeld-Lectures 2015}




\section{Theo Hug}

Institut für Psychosoziale Intervention und Kommunikationsforschung, Universität Innsbruck

\section{Josef Mitterer}

Institut für Philosophie, Alpen-Adria-Universität Klagenfurt

\section{Michael Schorner}

Ernst-von-Glasersfeld-Archiv am Forschungsinstitut Brenner-Archiv, Universität Innsbruck

Diese Publikation wurde mit finanzieller Unterstützung des Vizerektorats für Forschung, des Forschungsinstituts Brenner-Archiv und des Instituts für Psychosoziale Intervention und Kommunikationsforschung der Universität Innsbruck gedruckt.

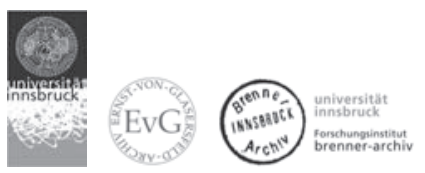

(C) innsbruck university press, 2015

Universität Innsbruck

1. Auflage

Alle Rechte vorbehalten.

Fotos (wenn nicht anders angegeben): Ernst-von-Glasersfeld-Archiv

www.uibk.ac.at/iup

ISBN 978-3-902936-93-6 


\section{Inhaltsverzeichnis}

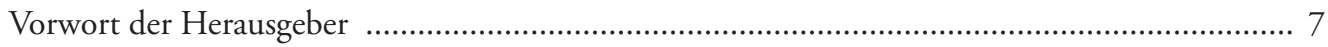

\section{Grußwort}

Wolfgang Meixner, Vizerektor für Personal der Universität Innsbruck

\section{Ernst-von-Glasersfeld-Lectures}

Siegfried J. Schmidt

vorläufig endgültig vorläufig - Philosophieren nach Ernst von Glasersfeld

Gebhard Rusch

Sicherheit und Freiheit

\section{Aus dem Archiv}

Jona Hoier, Markus Murschitz und Theo Hug

BANANA PERIOD - Ein Lichtprojekt an den Nahtstellen von

Medienkunst und Wissenschaftskommunikation

Michael Schorner

Sprechen Sie Yerkish? - Ernst von Glasersfelds Beitrag zum LANA Projekt zwischen Operationalismus und Radikalem Konstruktivismus 



\section{Vorwort der Herausgeber}

Am 2. März 2015 fanden im Claudiasaal der Universität Innsbruck die Ernst-von-GlasersfeldLectures statt. Nach den Beiträgen zur offiziellen Eröffnung des Ernst-von-Glasersfeld-Archivs am 22. März 2013 konnten mit dieser Veranstaltung weitere Vorlesungen von Weggefährten und Mitstreitern von Ernst von Glasersfeld realisiert werden. Der vorliegende Band dokumentiert die beiden Vorträge von Siegfried J. Schmidt und Gebhard Rusch sowie darüber hinaus das Grußwort von Vizerektor Wolfgang Meixner und zwei weitere Beiträge aus dem Ernst-von-Glasersfeld-Archiv. Letztere befassen sich in dokumentarischer und medienkünstlerischer Absicht mit dem LanaProjekt und „Yerkish“, der ersten Zeichensprache für nicht-menschliche Primaten, die der Philosoph und Kommunikationswissenschaftler Ernst von Glasersfeld (1917-2010) zusammen mit Piero Pisani Anfang der 70er Jahre an der University of Georgia entwickelte.In der Lecture von Siegfried J. Schmidt zum Thema „vorläufig endgültig vorläufig" geht es darum, Konsequenzen aus der Veränderung des philosophischen Argumentationsstils zu ziehen, die Ernst von Glasersfeld initiiert hat. Schmidt erörtert den Umstieg von Objekt-bezogenen Argumentationen auf eine konsequente Prozess-Orientierung und diskutiert die Folgen dieses Umstiegs auf Dauerthemen der Philosophie wie Wissen und Wahrheit, Erfahrung und Gedächtnis, Kommunikation, Verstehen und Kontingenz. In seiner Lecture zum Thema "Sicherheit und Freiheit“ skizziert Gebhard Rusch zunächst jene politischen Interpretationen von ,Freiheit' und ,Sicherheit', die den rhetorischen Referenzrahmen für legitimatorische und agitatorische Diskurse, Wahlkampfrhetorik und Parlamentsdebatten, Zivilgesellschaft und politische Administration in westlichen Demokratien nach Innen und Außen abstecken. Einerseits werden dabei die Begrifflichkeiten häufig in ein oppositionelles Verhältnis zueinander im Sinne von beispielsweise mehr innenpolitische Sicherheit und weniger persönliche Freiheit (oder umgekehrt) gesetzt. Andererseits gelangen jedoch die operationalen Wurzeln dieser Begrifflichkeiten in der Wahrnehmung, im Verhalten und Handeln zunehmend aus dem Blick. Im Beitrag wird insbesondere nach operationalen Evidenzen gefragt, die Wahrnehmung und Verhalten für die Begriffe ,Sicherheit' und ,Freiheit' vor all ihren ideologischen Aufladungen, historischen Interpretationen und philosophischen Explikationen bieten.

Jona Hoier, Markus Murschitz und Theo Hug beschreiben in ihrem Beitrag ein aktuelles Projekt des Ernst-von-Glasersfeld-Archivs, das auf die Gestaltung neuer Formen der Wissenschaftskommunikation im Spannungsfeld von Technik, Wissenschaft und Kunst zielt. Die vielfältigen Zusammenhänge von Technisierungsschüben und Kulturwandel betreffen nicht zuletzt auch die Technologien und Ästhetiken des Lichts. Hand in Hand mit den digitalen Entwicklungen sind neue Spielräume der Programmierung von Beleuchtungskörpern sowie responsiven Infrastrukturen und Interaktionsräumen entstanden. Das Ernst-von-Glasersfeld-Archiv setzt mit seinem EvG-Lichtprojekt bei diesen Entwicklungen an. BANANA PERIOD ist eine Medieninstallation von Jona Hoier und Markus Murschitz. Sie thematisiert die Bildsprache Yerkish und deren Anwendung in sprachwis- 
senschaftlichen Experimenten mit Schimpansen. Die Lichtinstallation lässt die Symbole der Bildsprache mittels moderner LED-Technologie auf ästhetische Weise aufleuchten und belebt so aus dem Schaufenster des Ernst-von-Glasersfeld-Archivs den Innsbrucker Stadtkern.

Während sich die markanten Symbole von Yerkish bestens dazu eignen, das Interesse von Passanten im Vorübergehen auf das Archiv zu lenken, fällt es auf den ersten Blick nicht leicht, diesen Beitrag zum LANGuage Analogue Project in Glasersfelds Gesamtwerk einzuordnen. Der Beitrag von Michael Schorner verortet Yerkish im Kontext des Operationalismus von Silvio Ceccatos Scuola Operativa Italiana und Glasersfelds ab den späten 1970er Jahren unter dem Namen Radikaler Konstruktivismus bekannt gewordenen Theorie des Wissens und Lernens. Dabei werden auch der erkenntnistheoretische Hintergrund und Glasersfelds Auffassung von Sprache und Kommunikation beleuchtet.

Wir bedanken uns bei all jenen, die zum Gelingen der Veranstaltung sowie zur Realisierung dieses Bandes beigetragen haben: Barbara Halder und Jennifer Moritz vom Sekretariat des Forschungsinstituts Brenner-Archiv sowie Mathias Schennach und Burkhard Hager vom International Relations Office für die organisatorische Unterstützung. Catharina Walli vom Büro für Öffentlichkeitsarbeit und Kulturservice für die Flyer-Gestaltung. Birgit Holzner und Carmen Drolshagen von innsbruck university press (iup) für das Layout und die verlegerische Betreuung.

Ebenso gilt unser Dank dem Forschungsinstitut Brenner-Archiv, dem Vizerektorat für Forschung und dem Institut für Psychosoziale Intervention und Kommunikationsforschung, die durch ihre finanzielle Unterstützung die Veranstaltung und diese Publikation ermöglicht haben.

Ulrike Tanzer, Professorin für österreichische Literatur am Institut für Germanistik, leitet seit Herbst vergangenen Jahres das Brenner-Archiv und hat damit die Nachfolge von Johann Holzner angetreten. Beiden sei an dieser Stelle für die gute Zusammenarbeit gedankt.

Aktuelle Informationen des Ernst-von-Glasersfeld-Archivs sind im Internet unter der Adresse www.evg-archive.net abrufbar.

Innsbruck, im September 2015

Die Herausgeber 
Grußwort 

Seit 2011 beheimatet die Universität Innsbruck den wissenschaftlichen Nachlass Ernst von Glasersfelds, seit 2013 als Ernst-von-Glasersfeld-Archiv innerhalb des Brenner-Archivs, in dem diese Bestände aufbewahrt und für die Nachwelt und Interessierte erschlossen werden. Es war der ausdrückliche Wunsch von Ernst von Glasersfeld, dass sein Nachlass nach Österreich kommt und dort für die Forschung zur Verfügung gestellt werden soll.

Die Universität Innsbruck hält die Erinnerung an Ernst von Glasersfeld, dem sie 2008 das Ehrendoktorat verliehen und der damals in launigen Dankesworten ausgeführt hatte, dass „normalerweise [...] Studenten vier bis fünf Jahre [benötigen], manchmal sogar weniger, um einen Doktortitel zu erlangen. Bei mir hat es über 60 Jahre gedauert", auch durch eine jährlich stattfindende und ihm gewidmete Veranstaltung aufrecht. Die Ernst-von-Glasersfeld-Lectures 2015 wurden von Prof.em. Dr. Dr.h.c. Siegfried J. Schmidt und Prof. Dr. Gebhard Rusch bestritten, die beide mit Ernst von Glasersfeld wissenschaftlich wie persönlich eng verbunden waren. Es geht um Themen und Problembereiche wie „vorläufig endgültig vorläufig“ (S. J. Schmidt) und um „Sicherheit und Freiheit" (G. Rusch), die Ernst von Glaserfeld sicher nicht nur sehr interessiert hätten, sondern zu denen er auch einiges beizutragen gehabt hätte, würde er noch unter uns weilen. Ernst von Glasersfeld war ein Autodidakt, der aufgrund der Zeit- und seiner Lebensumstände keine wissenschaftliche Karriere im herkömmlichen Sinne durchlaufen hat und es dennoch zu höchster Anerkennung und auch Würden (als Professur für Kognitive Psychologie an der University of Georgia) gebracht hatte. Er selbst betonte wiederholt, dass er durch Wittgensteins Tractatus und Freuds Traumdeutung den „Schubs in der Erkenntnistheorie“ erhalten hatte. Diese lässt sich - in seinen Worten - in etwa so zusammenfassen: „wir können die Bilder, die wir uns von der Welt machen, nur mit anderen von uns gemachten Bildern vergleichen“ und „das Weltbild, das wir uns im Bewusstsein machen, kann letzten Endes nur von uns selbst interpretiert werden“.

Wolfgang Meixner

Vizerektor für Personal der Universität Innsbruck 

Ernst-von-Glasersfeld-Lectures 



\title{
vorläufig endgültig vorläufig - Philosophieren nach Ernst von Glasersfeld
}

\author{
Siegfried J. Schmidt
}

\begin{abstract}
Zusammenfassung
Im Beitrag geht es darum, Konsequenzen aus der Veränderung des philosophischen Argumentationsstils zu ziehen, die Ernst von Glasersfeld initiiert hat. Versucht wird der Umstieg von Objektbezogenen Argumentationen auf eine konsequente Prozess-Orientierung. Diskutiert werden die Folgen dieses Umstiegs auf Dauerthemen der Philosophie wie Wissen und Wahrheit, Erfahrung und Gedächtnis, Kommunikation, Verstehen und Kontingenz.
\end{abstract}

\section{Neue Stichwörter}

Eine der wichtigsten Konsequenzen der theoretischen Überzeugungen von Autoren wie Ernst von Glasersfeld, Heinz von Foerster, Humberto R. Maturana oder Francisco Varela - und ich spreche aus vielen Gründen bewusst nicht von „Konstruktivisten“ - kann gesehen werden in einer Veränderung des philosophischen Argumentationsstils. Fast schon automatisch vertretene philosophische Überzeugungen wie Objektivität, Wahrheit, Repräsentation der Wirklichkeit im Erkennen oder sprachliche Referenz auf eine außersprachliche Wirklichkeit wurden in Frage gestellt. Neue Stichwörter bestimmten den Argumentationsprozess:

- Viabilität ${ }^{1}$ statt Wahrheit

- Erfahrungsprozess statt Objektivität

- Wissen statt Erkenntnis

- Beobachterkonstruktionen statt Wirklichkeitsrepräsentation

- Theorien als Problemlösungsinstrumente statt als Annäherungen an die Wahrheit

- Kommunikation als Bedeutungskonstruktion statt als Bedeutungsübertragung

- Kognition als Organisation der Erfahrungswelt statt als Erkenntnis einer objektiven Realität.

Im Folgenden unternehme ich den Versuch, einige dieser neuen Stichwörter auszubuchstabieren, und zwar auf der Grundlage einer konsequenten Prozessorientierung. Diese Orientierung kann - wie ich an anderer Stelle formuliert habe (Schmidt 2010) - bestimmt werden als Verflüssigung oder als

1 „Der Begriff der Viabilität ersetzt jenen der ontischen Wahrheit; das heißt, die Bestätigung des Wissens wird nicht in einem unmöglichen Vergleich mit der Realität gesucht, sondern in seiner Brauchbarkeit angesichts der Hindernisse, denen wir beim Verfolgen unserer Ziele begegnen." (von Glasersfeld 1998, S. 510) 
Pragmatisierung der Hauptwörter (wie z. B. ,Wirklichkeit', ,Wahrheit', ,Bedeutung'), die immer Referenzansprüche stellen und ein dualistisches Denken (vgl. Mitterer 1992, 2001) voraussetzen bzw. zumindest fördern.

\section{Theoretische Voraussetzungen}

Die theoretischen Voraussetzungen der folgenden Überlegungen lassen sich wie folgt zusammenfassen:

(a) Angestrebt wird ein konsequenter Verzicht auf ontologische Behauptungen oder Negationen des Typs: die Wirklichkeit ist...., Wahrheit ist..., wir können die Wirklichkeit (nicht) erkennen... usw.

(b) Angestrebt wird ein Umstieg von Objekten auf Prozesse. Das bedeutet z. B. für die theoretische Modellierung von Wahrnehmung, dass konsequent vom Zusammenwirken von Wahrnehmungsträger, Wahrnehmungsperformanz und Wahrnehmungsresultat gesprochen wird. Objekte, heißt das, sind Resultate eines komplexen Wahrnehmungsprozesses in einer konkreten Wahrnehmenssituation. Und statt der Bejahung oder Verneinung „der Wirklichkeit“ wird gefragt, was für wen auf Grund welcher Prozesse und Kriterien als wirklich gilt, womit in alle Argumentationen der Beobachter als konstitutive Größe einbezogen wird. Gegenstände, so kann man dann formulieren, sind Referenten für Bezugnahmen bzw. Resultate der Differenz von Selbstreferenz und Fremdreferenz. M. a. W. sie sind beobachterspezifisch.

(c) Im Hinblick auf Prozesse des Wahrnehmens, Beobachtens, Denkens oder Beschreibens lassen sich zwei Feststellungen treffen: (1),Wahrnehmen', ,Denken', ,Beobachten` oder ,Beschreiben' sind transitive Verben, die Handlungen i. w. S. bestimmen, bei denen nur analytisch (also durch eine Vereinseitigung von Beobachtung) zwischen Aktant, Handlungsvollzug und Handlungsresultat getrennt werden kann. Eine Beobachtung ist notwendig die Beobachtungshandlung eines Beobachters, der in einer konkreten Situation etwas als etwas beobachtet; eine Wahrnehmung ist die Wahrnehmungshandlung eines Aktanten, in deren Verlauf in einer Situation etwas als etwas wahrgenommen wird usw. (2) Die drei nur analytisch voneinander unterscheidbaren Komponenten bilden also ein Prozesssystem bzw. einen Wirkungszusammenhang im Sinne der Allgemeinen Systemtheorie, der autokonstitutiv gedacht werden muss. Wenn hier von ,Wirkungszusammenhang' gesprochen wird, dann darf nicht an Kausalverhältnisse gedacht werden; vielmehr geht es um eine sich selbst konstituierende Komplementarität von Bedingungen von Möglichkeiten, also um Ermöglichungsverhältnisse.

Die genannten Handlungen des Wahrnehmens, Erkennens, Sprechens usw. operieren mit Unterscheidungen und Benennungen, die aus einem Pool von Optionen selegieren. Das bedeutet: Im Unterscheiden und Benennen wird eine Setzung vollzogen (a und nicht b oder c), die zugleich eine Voraussetzung konstituiert ( $\mathrm{a}$, b oder c wären möglich gewesen, in Anspruch genommen wurde nur 
b). Jede Setzung konstituiert eine Gleichzeitigkeit von Setzung und Voraussetzung, die nicht ontologisierend voneinander getrennt werden können. Handeln lässt sich in dieser Perspektive konzipieren als die Einheit der Differenz von Setzung und Voraussetzung. Der Mechanismus von Setzung und Voraussetzung kann als grundlegend für alle menschlichen Handlungen postuliert werden. Er setzt Freiheitsgrade bzw. Optionsmöglichkeiten voraus, die in/durch Setzungen implementiert und zugleich bestätigt werden. Dieser generelle Mechanismus kann auch auf sich selbst angewandt werden, womit Handlungen Reflexivität erreichen, die eine Selbstbeobachtung dieses Mechanismus erlaubt: Ich kann wissen, dass ich den Mechanismus von Setzung und Voraussetzung setze und voraussetze. Damit eröffne ich mir als Aktanten, und das heißt als handelndem System aus Systemen (Gehirn, Bewusstsein, Körper) die Möglichkeit der Anwendung der Differenz Selbstreferenz/Fremdreferenz auf meine eigenen Operationen und garantiere mir damit gewissermaßen die Welthaltigkeit meiner Operationen: Handeln führt zu Wissen und Wissen verkörpert sich im Handeln in Geschichten und Diskursen. Dabei verstehe ich unter, Geschichten' den sich selbst organisierenden Zusammenhang der Handlungen von Aktanten, unter ,Diskursen' den sich selbst organisierenden Sinnzusammenhang von Kommunikationen. Konzentrieren wir uns auf die genannten Prozesse der Wahrnehmung, Beobachtung oder Beschreibung, dann erkennen wir in ihnen dieselbe Grundstruktur: Um uns in unserer Umwelt, mit Handlungspartnern und im Hinblick auf soziale Institutionen erfolgreich orientieren zu können, brauchen wir Sinnorientierungen, von denen wir (stillschweigend) annehmen, dass sie von allen anderen geteilt werden (= operative Fiktionen).

(d) Setzungen als Vollzug von Unterscheidungen setzen Raum und Zeit. Sie können bestimmt werden als ununterbrochene Transformation von Zuständen in Situationen. Wirklichkeit und Gegenwart sind nur komplementär zu denken; d. h. Wirklichkeit, genauer: Wirkliches erscheint uns immer in der Gegenwart bzw. im Alltag, der zeitlich und situativ bestimmt ist. Alltag operiert auf der Grundlage von Muttersprache und Common Sense (= operativen Fiktionen). Alltag: das sind gemachte Erfahrungen und Erlebnisse, immer schon geleistete Unterscheidungen und Beschreibungen, immer wieder bestätigte Urteile und Bewertungen. Alltag: das sind die Prozessvoraussetzungen für Setzungen, das, worüber wir als wirklich reden. Anders formuliert: Wo wir sind, ist Wirklichkeit. Oder in der bekannten Formulierung C. Fr. von Weizsäckers: „Sprechen wir sinnvoll von Realität, so sprechen wirvon Realität; spricht niemand von Realität, so ist von Realität nicht die Rede." (1980, S. 42)

(e) Setzungshandlungen sind die Existenzform für/von Aktanten. Was Aktanten handelnd für wirklich halten, ist wirklich in seinen Erfolgen und Misserfolgen. Oder mit den Worten P. Janichs: Tatsachen sind eine Sache der Tat (2015, S. 162). Wirklichkeitssicherheit setzt eine Handlungs- und Kommunikationsgemeinschaft voraus. Wir leben in Geschichten und Diskursen. ${ }^{2}$ Kriterium für Wirklichkeit ist die zeitliche Stabilität folgenreicher Erfahrungen - das ist

2 Vgl. dazu ausführlich Schmidt 2003. 
meine Lesart des von Glasersfeld'schen Begriffs, Viabilität'. Zusammenfassend gesagt: ProzessOrientierung macht ontologische Existenzfragen obsolet. ${ }^{3}$ Oder anders formuliert: Wir kommen als Kinder auf die Welt, nicht auf die Wirklichkeit.

\section{3. erfahren und wissen}

Der Umstieg von einer dualistisch geprägten Ontologie auf Prozess-Orientierung macht das Erfahrungen-Machen zu einem zentralen Thema. Erfahrungen-Machen kann theoretisch modelliert werden als das Zusammenwirken von Begrifflichkeiten, theoretischen Annahmen, Wissen, Handlungen und verbindlichen Traditionen. Dabei spielen kognitive, emotionale, moralische und sensumotorische Komponenten zusammen. In diesem Prozess wirken Vererbung, Reifen und Lernen als wichtige Bestimmungsgrößen.

Prozesse des Erfahrungen-Machens sagen in erster Linie etwas aus über uns, nicht über „die Wirklichkeit".

Beim Thema Wissen kann zwischen ganz verschiedenen Aspekten unterschieden werden. Allgemein kann Wissen beschrieben werden als Handeln-Können, Herstellen-Können bzw. Problemlösen-Können. Wissen resultiert aus Handeln, setzt soziale Interaktion voraus und ermöglicht Anschlussinteraktionen. Bei Wissen sind die Aspekte Herstellung, Darstellung, Anwendung, Reflexion und Bewertung voneinander zu unterscheiden. In der Literatur werden ganz unterschiedliche Arten von Wissen diskutiert, so z. B. implizites, explizites, empirisches, ontologisches, enzyklopädisches, historisches, praktisches oder theoretisches Wissen. Damit wird auf die verschiedenen Formen des Erwerbs, der Anwendung und Bewertung von Wissen verwiesen. Wissen ist sozusagen verkörpert in Aktanten und gebunden an deren Handeln in konkreten Situationen.

Die Herstellung und die Darstellung von Wissen sind gebunden an Sprache und Kommunikation, und das heißt, sie sind immer gesellschaftlich und kulturell geprägt. Wissen ist stets verbunden mit einer Wahrheitsvermutung bzw. -unterstellung, die sich ausdrückt in den Wissensgarantien, die Aktanten in der Interaktion auf Anfrage zu erläutern haben. Diese Erläuterungspflicht gehört gewissermaßen zum moralischen Aspekt des gesellschaftlichen Diskurses.

Das Wissen, das sich Aktanten in einer Gesellschaft gegenseitig unterstellen bzw. voneinander erwarten, kann als kollektives Wissen bezeichnet werden. Wegen der kognitiven Autonomie der Aktanten kann diese Unterstellung nie direkt überprüft werden, sondern nur in Folgehandlungen i. w. S. eingeschätzt werden. Gleichwohl erlaubt es als aus Reflexivität entstandene operative Fiktion, die in der Sozialisation erworben wird, erfolgreiche Kooperation und Kommunikation in gesellschaftlichen Zusammenhängen.

3 Das gilt m. E. auch für die von vielen Autoren vorgeschlagene Unterscheidung zwischen Wirklichkeit und Realität, die zum dualistischen Ontologisieren verführt. 
Generell kann wohl gesagt werden, dass sich Wissen an Wissen misst und deshalb als selbstreferentiell modelliert werden kann.

\section{Gedächtnis und Erinnern}

Der Wissensdiskurs war und ist stets eng verbunden mit dem Thema Gedächtnis. Im Unterschied zu traditionellen Gedächtnismodellen, die durchwegs Orts- bzw. Speicher-zentriert waren, operiert die heutige Neurobiologie und Kognitionstheorie nach dem aktuellen Stand des Wissens mit Prozess-orientierten Modellen. ${ }^{4}$ Die Grundannahme besagt, dass der neuronale Apparat des Menschen durch Konnektivitäten der Nervenzellen bestimmt ist, die in komplexen Netzwerken zusammengeschlossen sind. Genom und Erfahrung bestimmen also gemeinsam die Konnektivität der Bestandteile des neuronalen Systems. Erfahrungen modifizieren die Konnektivität aufgrund von Aktivitäten, die sowohl auf Ereignisse in der Systemumwelt als auch auf systeminterne Prozesse zurückgehen können. Komplexe Nervensysteme vernetzen kortikale, sensorische und motorische Prozesse und können auf diese Weise dauerhafte, im Prinzip aber auch auf Veränderbarkeit angelegte Wege für Erregungsverläufe und Ereignisausbreitungen in den Nervennetzen „bahnen“. Solche durch Lernprozesse gebahnten Wege bestehen als dauerhafte Eigenschaften des Gehirns weiter und stabilisieren nachfolgende kortikale Prozesse. Erregungsverläufe außerhalb solcher markierter Bahnen werden als „neu“ empfunden und emotional mit Unsicherheit konnotiert.

H. R. Maturana (1982, S. 62) hat aus solchen Überlegungen den Schluss gezogen, das Gedächtnis nicht als einen Speicher an einem im Gehirn lokalisierbaren Ort zu modellieren, sondern als Etablierung verhaltenssynthetisch relevanter dauerhafter Kognitionsstrukturen, die für weitere Ordnungs-bildende Kognitionsprozesse zur Verfügung stehen. Solche Strukturen haben mit Vergangenheit nur so viel zu tun, dass sie zu einem Zeitpunkt vor der jeweils abgelaufenen Verhaltenssynthese entstanden sind. Nach diesen Überlegungen liegt die Funktion des Gedächtnisses nicht in der kurzoder langfristigen Aufbewahrung von vergangenen Ereignissen, sondern in der Verhaltensbewertung für alle kognitiven Prozesse auf der Grundlage bisher gemachter Erfahrungen. Seine Funktion geht also weit über die Speicherfunktion hinaus, die ihm üblicherweise zugeschrieben wird, und betrifft Wahrnehmung, Erinnerung, Aufmerksamkeit, Erkennen, Handeln und Bewerten. Durch Ordnungs-bildende Leistungen wie Vor- und Schemawissen sowie die Einschätzungsmöglichkeit als bekannt bzw. neu verhilft es solchen Prozessen zu Prägnanz und Sicherheit. ${ }^{5}$

Das Gedächtnis als eine über das gesamte neuronale System verteilte Funktion des Gehirns organisiert sich selbst auf der Basis seiner eigenen Geschichte, woraus folgt, dass es nicht abbildend,

4 Vgl. dazu die Beiträge in Schmidt (Hg.) 1991.

5 Auf die zahlreichen Vorschläge zur zeitlichen oder funktionalen Typologisierung von Gedächtnissen gehe ich an dieser Stelle nicht ein, da sie in der Regel spekulativ sind. 
Ernst-von-Glasersfeld-Lectures | Siegfried J. Schmidt

sondern konstruktiv (aber deshalb keineswegs willkürlich) operiert. Die dabei wirksamen Kriterien sind angeboren, frühkindlich erworben oder durch spätere Erfahrungen geprägt. Das Gedächtnis ist weitgehend nicht bewusstseinsfähig oder gar bewusstseinspflichtig.

Die Bahnung dauerhafter Wege für Erregungsausbreitung und Verhaltenssynthese ist offenbar eng verbunden mit Emotionen, und zwar mit der nicht zuletzt auch normativ geprägten Intensität von Emotionen. Wie dieser Zusammenhang im Detail bestimmt werden kann, ist allerdings bis heute noch nicht klar, obwohl wichtige Beiträge zu diesem Thema vorliegen (vgl. dazu etwa Roth 2001).

\section{5. wahr}

Wie ,Wirklichkeit' gehört auch ,Wahrheit' zu den zugleich unverzichtbaren wie semantisch vagen Begriffen. Und vergleichbar dem sogenannten und vorgeblich unvermeidbaren wie unverzichtbaren Alltagsrealismus gilt auch für Wahrheit die generelle Annahme eines Wahrheitspostulats auf allen Ebenen gesellschaftlicher Interaktion. Niemand würde (zumindest öffentlich) bestreiten, dass für ihn Wahrheit eine wichtige Rolle spielt und dass die Unterscheidung zwischen Wahrheit und Irrtum unverzichtbar für die Aufrechterhaltung jeder Gesellschaft ist. Das Wahrheitsideal bzw. -postulat ermöglicht allererst menschliche Kooperation als Mittel zum Zweck, indem es als operative Fiktion die Aktanten in eine verbindliche Pflicht nimmt.

Dabei spielt es im Alltag keine Rolle, dass es für ,Wahrheit' keine allgemein gültige Definition gibt - zumindest hat sich keines der zahlreichen philosophischen Definitionsangebote durchsetzen können; denn im Alltagshandeln geht es nie um „die Wahrheit“, sondern darum, ob Etwas i. w. S. für wahr oder nicht für wahr gehalten wird. Das heißt, die Attribution des Wahrheitsprädikats ist eingebunden in menschliche Praxen im Hinblick auf deren Gelingen oder Misslingen, auf Erfolg oder Misserfolg, die stets eine emotionale wie eine moralische Dimension aufweisen.

Auch im Falle der Wahrheit scheinen Philosophen seit der Antike sich unlösbare Probleme dadurch eingehandelt zu haben, dass sie das Attribut „wahr“ substantiviert haben und sich damit in die Pflicht genommen haben, nun auch einen Referenten für den Ausdruck „Wahrheit“ zu finden. Geht man dagegen vom Alltagshandeln aus, dann kann man eine Fülle von praktizierten Verwendungsweisen für das Adjektiv ,wahr' sowie eine ganze Reihe äquivalent funktionierender Bezeichnungen wie ,richtig', ,gültig', ,zutreffend' usw. finden. Hinzu kommt, dass es so viele verschiedene Typen von Wahrheit oder Geltung gibt, wie es Sprechtypen gibt (vgl. Janich 2009, S. 34). Dabei ist es immer praktisch wichtig herauszufinden, wer in welcher Situation und in welchem gesellschaftlichem Handlungszusammenhang nach wahr/falsch fragt und wem diese Frage nützt. Machtaspekte spielen dabei in aller Regel eine wichtige Rolle.

Kurzum: die Frage nach wahr/falsch ist ein praktisch unverzichtbares Instrument zur Beurteilung menschlicher Kommunikation und zur Einschätzung der im Kommunikationsprozess ermittelten Möglichkeiten von passenden Anschlusskommunikationen. Ist man überzeugt, dass die Antwort 
des Befragten rebus sic stantibus wahr ist, endet die Befragung - und zwar zu Recht und emotional befriedigend.

Mit der Frage nach wahr/falsch ist immer ein Aufforderungscharakter verbunden. Die Frage wird bei Dissens oder aufgrund begründeter Vermutung gestellt und verlangt dem Befragten ab, sich zu rechtfertigen, Geltungsansprüche argumentativ einzulösen, erfolgreiche Handlungen durchzuführen usw. ${ }^{6}$ Nicht zufällig hielt H. von Foerster Wahrheit für eine Erfindung eines Lügners. Erfolgreiches Handeln wird damit zum Definiens von Wahrheit (= für wahr gehalten werden) im praktischen wie im kommunikativen Bereich. Dabei können - wie P. Janich ausgeführt hat - Wahrheiten durch Sprachregelung, als Handlungsfolgewissen oder aus Erfahrung bestimmt werden. „Externe Wahrmacher" wie Wirklichkeiten oder Tatsachen bleiben überflüssig, „(...) weil das Spiel des Sprechens und Handelns (...) auf sich selbst bezogen bleibt.“ (2001, S. 158)

Wahrheit ist stets mit einem (zumindest impliziten) Zeitindex versehen: Die Aussage p gilt zu Recht als wahr, wenn $\mathrm{p}$ mit unserem gegenwärtig nicht infrage gestellten Wissen übereinstimmt, und Wahrheit bezieht sich auf sozial unterschiedliches Wissen und Regeln der Attribution des Prädikats „wahr": $p$ ist wahr für Alle, die sich in ihren jeweiligen Geschichten und Diskursen auf dasselbe Wissen beziehen und diesen Bezug auch bei allen Anderen unterstellen. Mit anderen Worten, Wahrheit wird als funktionierende Reflexivität der Wissensbewertung im Diskurs vollzogen. Auch hier könnte man sagen: „Die Wahrheit“ gibt es nicht, aber wir brauchen Wahrheitszuschreibungen als unverzichtbares Diskursregulativ zur Eröffnung, zur Durchführung und zum friedlichen Abschluss unserer Kommunikationsprozesse.

Die Unterscheidung wahr/falsch spielt nicht nur im Alltag eine emotional und moralisch hochgradig besetzte zentrale Rolle, sondern auch im wissenschaftlichen Handeln. Und auch dort erfüllt sie die Funktion eines Regulativs des Handelns und Kommunizierens. Deshalb ist es unplausibel, einen fundamentalen Unterschied zwischen dem Wahrheitsproblem im Alltag und in der Wissenschaft oder der Philosophie zu postulieren; denn in allen Fällen geht es darum, ob im Konflikt- oder Dissensfall eine Aussage für wahr oder falsch gehalten wird, was von den Kriterien abhängt, die Aktanten qua Beobachter mit jeweils guten aber nicht objektiven Gründen eingeführt haben und im Gelingensfall beibehalten.

Die bisher angestellten Überlegungen machen es plausibel, dass im Wahrheitsdiskurs ein bestimmtes Cluster von Begriffen eine zentrale Rolle spielt, das Begriffe umfasst wie Aufrichtigkeit, Wahrhaftigkeit, Glaubwürdigkeit, Verlässlichkeit, Nützlichkeit, Gültigkeit, Kohärenz oder Konsens. Diese Begriffe - unter denen die ersten fünf genannten moralische Begriffe sind - können nicht aufeinander reduziert werden, weil sie in wechselnden Handlungs- und Kommunikationssituationen unterschiedliche pragmatische Aufgaben übernehmen. Sie regulieren unterschiedliche Prozesse in unterschiedlichen Bereichen. So hat etwa P. Finke (2005) darauf verwiesen, dass Wahrheit als

6 „Ob eine Aussage wahr oder falsch ist, kann nur relativ zum Zweck der Handlung ihrer Überprüfung festgestellt werden." (Janich 2001, S. 188) 
Ernst-von-Glasersfeld-Lectures | Siegfried J. Schmidt

regulatives Prinzip kulturell entstanden ist und Wissenschaft und Philosophie allererst ermöglicht hat, indem durch Anwendung dieses regulativen Prinzips die Produktion neuen Wissens aus alten Bestandteilen im Sinne eines kohärenten Gleichgewichtssystems möglich wurde.

Wenn, wie hier vorgeschlagen, die Anwendung des Wahrheitsprädikates konsequent prozessualisiert wird (A hält p für wahr in der Situation S aus den Gründen G bis X), dann werden dualistisch angesetzte Modelle von Wahrheit als Übereinstimmung mit der Realität vermieden. Die Rede von „Wahrheit" wird ersetzt durch eine Vielzahl verschiedener Redeweisen wie wahr-machen, für-wahrhalten, als-wahr-nachweisen, als-wahr-voraussetzen, sich-als-wahr-herausstellen usw. C. F. von Weizsäcker hat dafür folgende Formulierung gefunden: „Ein pragmatischer Wahrheitsbegriff kann die Prädikate >richtig< oder > falsch< nur ganzen Handlungsweisen zuschreiben. " (1980, S. 152) Dabei gilt erfolgreiches Handeln als Bestimmungsgröße für die Zuerteilung des Prädikats „wahr“. Diese Zuerteilung stabilisiert Handlungen und Kommunikationen durch Bezug auf geglaubtes Wissen. Insofern sind gewusstes und geglaubtes Wissen und der Umgang mit dem Prädikat ,wahr' nicht voneinander zu trennen.

Wahrheit sollte also nicht bestimmt werden als eine (wie auch immer objektive) Bezugsgröße bzw. Beziehungsqualität zwischen Aussagen (i. S. von Propositionen) und Tatsachen jenseits der Sprache und unabhängig von Beobachtern, sondern als wirksames soziales Regulativ in Prozess-Systemen, das Koordinationsaufgaben zu lösen und deren Handlungserfolg zu beurteilen erlaubt. Wahrheit kann bestimmt werden als Resultat eines Attributionsprozesses, das alle am Attributionsprozess Beteiligten zur Zustimmung aber auch zur Begründung verpflichtet und nicht etwa eine frei wählbare Attitüde, die individuell wählbar und abwählbar ist.

Wahrheit als Produkt von Attributionsprozessen in Geschichten und Diskursen invisibilisiert die Kontingenz alles Gewussten und dient als Argumentationsunterbrecher durch die Legitimität der Bezugnahme auf den Status quo als gemeinsam unterstelltes Wissen. Zugleich gilt, dass nach Beendigung der Argumentation zu jeder Zeit eine Wiederaufnahme der Wahrheitsbegründung eingefordert werden kann, die in der Regel von den Kommunikationspartnern nicht verweigert werden darf. Wahrheit als Strategie kontingenter aber situationsspezifisch durchaus plausibler und akzeptabler kontingenter Kontingenzbearbeitung integriert kognitive, affektive und moralische Aspekte. Unbefragt akzeptiertes Wissen erlaubt kognitives wie kommunikatives Operieren, das eine positive Lust-Unlust-Äquilibrierung (im Sinne von L. Ciompi) ermöglicht. Über wahres Wissen zu verfügen, ist emotional befriedigend. Im Alltag - abgesehen von speziellen Kommunikationsformen wie Humor oder Werbung - im Prinzip immer die Wahrheit zu sagen, gehört zu den (wie auch immer kontrafaktischen) moralischen Erwartungen an jeden Aktanten - Notlügen sind das Äußerste an entschuldbarem Zuwiderhandeln. Und besonders Wissenschaftler stehen unter dem hohen moralischen Anspruch, wahres Wissen und nur solches zu erzeugen und zu verbreiten, wollen sie nicht ihre Reputation verlieren. Umgekehrt beziehen sie aus der Erfüllung dieser Erwartung zugleich kognitive und emotionale Befriedigung. 
Würde die Wissenschaft Wahrheitssuche im Sinne einer Suche nach Beobachter-unabhängigen (objektiven) Fakten anstreben, würde sie sich wohl selbst aufheben.

\section{6. kommunizieren}

So wie ,Wahrheit' und, Wirklichkeit' ist auch ,Kommunikation' ein unverzichtbarer aber streng genommen semantisch vager Begriff. Hinzu kommt das Autologieproblem, das besagt, dass Kommunikation nur in der Kommunikation beschrieben werden kann, also in Kommunikationshandlungen in konkreten sozialen Einbettungssettings. Darum halte ich es für problematisch, von „der Kommunikation“ zu sprechen oder davon zu reden, dass „die Kommunikation“ dieses oder jenes tut. Stattdessen spreche ich von Kommunikationshandlungen bzw. von Kommunikationsprozessen, die zu größeren Einheiten aggregiert werden können, so z. B. zu Diskursen als thematisch und stilistisch selektiven Systemen bestehend aus Kommunikationsprozessen.

Aus diesen Überlegungen ergibt sich für mich die Empfehlung, kommunikatives Handeln als soziale Interaktion zu beschreiben, die nur möglich wird durch Anwendung gesellschaftlich verbreiteter und sprachlich bestimmter Handlungsmuster. Kommunikation organisiert gemeinschaftliches Handeln durch Reden; das heißt, ein Prozess organisiert einen anderen.

Im Rahmen dieser Beschreibung wird plausibel, warum beim Kommunizieren zwei Aspekte zu berücksichtigen sind: Zum einen der propositionale Aspekt (= Wovon ist die Rede?) und zum anderen der Beziehungsaspekt (= Wie wird das Verhältnis der Kommunikationspartner zueinander modelliert?). ${ }^{7}$

Kommunikations-Prozess-Systeme können abstrakt konzipiert werden als dynamische, raumzeitlich bestimmbare Systeme, die aus sich wandelnden Kommunikationshandlungen bzw. Kommunikationsprozessen bestehen. Ein Kommunikations-Prozess-System konstituiert seine Eigenschaften aus wirksamen Beziehungen zwischen seinen Bestandteilen.

Die Redeweise von „System“ lässt sich wie folgt konkretisieren: In unseren Kommunikationshandlungen beziehen wir uns im Alltag auf vorausgegangene oder erwartete Kommunikationshandlungen - eine Beziehung, die man auch als Frage-Antwort-Mechanismus beschreiben kann. Dabei wissen wir aus Erfahrung, dass es eine Unmenge von Kommunikationshandlungen gibt, die wir nicht kennen und an denen wir nicht teilnehmen, auf die wir uns aber im Prinzip (etwa durch intensive Nutzung des Internets) beziehen könnten.

Wir erfahren, was wir mit unseren Kommunikationshandlungen erreichen (können) und justieren unsere Kommunikationsmotivation und -strategie im Handlungsverlauf gegebenenfalls mehr oder weniger automatisch nach, um unsere Erfolgsaussichten zu verbessern. Auch hierbei sind wir auf die Antworten bzw. Reaktionen von Handlungspartnern in einer Sprech- und Handlungsgemein-

7 Vgl. dazu grundlegend Watzlawick et al. (1967). 
Ernst-von-Glasersfeld-Lectures | Siegfried J. Schmidt

schaft angewiesen, die wir - als kluge Kommunikationspartner - möglichst genau zu antizipieren versuchen. Wir selber reagieren dann in einer uns geeignet erscheinenden Weise auf Antworten und Reaktionen von Handlungspartnern, wobei wir versuchen, im Modus des Verstehens zu operieren, und zwar sowohl in propositionaler Hinsicht als auch in Hinsicht auf Beziehungsaspekte.

Durch den Bezug all dieser Prozesse aufeinander bildet sich das heraus, was ich als „Prozess-System“ bezeichne und was sich in erster Linie reflexiven Relationen verdankt, deren Wahrnehmung und Beurteilung zu einer ständigen Modifikation und Oszillation dieser Prozesse führt und ihre Beobachtung und Beschreibung erschwert.

Die Grundlage für alle Arten von Kommunikation bildet also die Reflexivität von Wahrnehmen und Wissen (vgl. dazu ausführlich Merten 1977, 1999). Im Vollzug des Aufbaus dieser Reflexivität bilden sich bei den Kommunikationspartnern Erwartungen an das Wissen und Annahmen über Motive und Intentionen des Handelns von Alter heraus, die als Erwartungs-Erwartungen (in Bezug auf Wissen) und Unterstellungs-Unterstellungen (in Bezug auf Intentionen und Motivationen) bezeichnet werden können. Diese reflexiven Strukturen wirken wie operative Fiktionen, die zwar nicht empirisch überprüft bzw. beobachtet werden können, die aber durch ihre reflexive Attribution erfolgreiches soziales Handeln individueller Aktanten ermöglichen.

Reflexivität (Wahrnehmung der Wahrnehmung, Denken des Denkens, Kommunikation über Kommunikation, Beobachtung der Beobachtung und so fort) ist offensichtlich das Instrument, das den Menschen - historisch gesehen - aus seiner Verstricktheit in Tätigkeiten gelöst hat und löst. Reflexivität erlaubt Unterbrechungen und Übergänge und damit Distanz, Intentionalität, Reflexion, Motivverdacht, Täuschung und so weiter, die alle wieder kognitiv und kommunikativ bearbeitet werden (können oder müssen), was wiederum beobachtet und kommentiert wird/werden kann und so weiter. Damit werden Aktanten wie Gesellschaften von Umwelten abgelöst. Damit wird von aktivem Sachbezug im Handeln umgestellt auf Wissen und selbstbezügliche Kommunikation. Insofern bildet Reflexivität die Grundlage der Autonomisierung von Gesellschaft und a fortiori von Mediengesellschaften durch Selbstreferenz und Selbstorganisation des Wissens.

Kommunikationshandlungen sind kontingent, $d$. h. sie sind inhaltlich unbestimmt, unsicher und unvorhersehbar, weil der thematische Auswahlbereich sowie der Frage-Antwort-Verlauf unbestimmt sind. Erst in ihrem Verlauf erfolgt eine temporäre Bestimmung des Unbestimmten: der Prozess reduziert Unsicherheit. Um diese Unbestimmtheit zu bearbeiten, haben sich in Gesellschaften restriktive Regularien herausgebildet; so z. B. situative Routinen, institutionalisierte Routinen oder institutionelle Routinen als kommunikative Formen institutioneller Akte (vgl. Feilke 1996. S. 258). Daneben spielen relevante Faktoren der Umwelt von Kommunikationsprozessen eine wichtige Rolle. Es ist durchaus bedeutsam, in welcher sozialen Rolle ein Kommunikator handelt, welcher Institution oder Organisation er angehört und welchen sozialen, wirtschaftlichen oder politischen Einfluss er besitzt. Eine Kommunikationsofferte eines Mächtigen wird ein einflussloserer Aktant ganz anders behandeln als die eines Gleichgestellten oder Untergebenen. Das heißt, Kommunikation ist immer auch ein Instrument des Handelns und der Macht; Sozial- und Herrschaftsbeziehungen können - wie 
P. Bourdieu (1982, S. 11) und Vertreter der Cultural Studies immer betont und empirisch gezeigt haben - als symbolische Interaktion modelliert werden. Gesellschaftliche Organisationen und Institutionen, Macht- und Herrschaftsverhältnisse, Generations- und Geschlechterbeziehungen entstehen auf der Grundlage von Kommunikationsprozessen und wirken sich nach ihrer Institutionalisierung prägend auf Kommunikationsprozesse aus. Handeln lässt sich in dieser Perspektive konzipieren als die Einheit der Differenz von Setzung und Voraussetzung im Hinblick auf die Herstellung und Durchsetzung bekannter oder neuer Setzungen zum Zwecke der Bekräftigung bekannter Einheiten von Setzungen und Voraussetzungen oder zur Schaffung neuer Konstellationen, die von jetzt an als Orientierungsdirectricen fungieren.

Historisch gesehen ist Kommunikation wesentlich weiterentwickelt worden durch die Entstehung und Verwendung von Sprache, die symbolisches Handeln erlaubte, und zwar in der Sozial-, in der Sach- und in der Zeitdimension. Symbolisches Handeln wurde dann sozusagen verdoppelt durch die Entwicklung der Negation (vgl. Schmidt 1973), die ein Zurückweisen von Meinungen bzw. von Behauptungen als Setzungen wie eine Korrektur von Voraussetzungen ermöglichte und damit für jede sprachliche Kommunikationsmöglichkeit eine positive wie eine negative Version zuließ. Diese Weiterentwicklungen von Kommunikationsmöglichkeiten durch Sprache und Negation haben die Komplexität von Kommunikation vervielfacht aber auch die Möglichkeiten der Be- bzw. Verarbeitung von Komplexität erweitert.

Mittels sprachlicher Kommunikation wird es nun möglich, nicht nur die aktuelle Situation symbolisch zu steuern, sondern künftige Kommunikationen vorzustrukturieren, darauf vorzubereiten oder dafür zu werben bzw. vergangene Kommunikationen zu kommentieren. Mittels sprachlicher Kommunikation können Handlungen Aktanten zugesprochen oder abgesprochen werden, können Handlungsziele festgelegt und von anderen unterschieden werden. Mittels sprachlicher Kommunikation können sich Handlungsstrukturen herausbilden, die schematisiert werden und damit Sinnorientierungen ermöglichen, die Zeit und Aktanten übergreifen und zu kollektivem Wissen "gerinnen". Und alles das kann wieder beobachtet und beschrieben werden.

Kommunikationshandlungen reagieren als Prozesse selektiv auf Selektionen, d. h. sie sind notwendigerweise kontingent. Diese Kontingenz wird noch dadurch verstärkt, dass Sprecher Kommunikationshandlungen selektionsverstärkend auf sich selbst beziehen können (= Metakommunikation). Wenn Kommunikationshandlungen, wie oben entwickelt, auf der Grundlage sozialisatorisch erzeugter operativer Fiktionen in den Bereichen Wissen und Meinen operieren, dann kann Reflexivität als der Grundmechanismus kommunikativer Ordnungsbildung angesehen werden. Dabei resultiert diese Ordnungsbildung aus dem gemeinsamen Bezug aller Aktanten auf gesellschaftlich erzeugtes Wissen soziokultureller Art (soziale Schemata, kulturelle Orientierungsschemata, Sprache), das als kollektives Wissen die Voraussetzung jeder Kommunikationshandlung bildet und durch Bezugnahmen bestätigt und verstetigt wird, wodurch die Kontingenz allen Handelns zwar invisibilisiert werden kann aber nicht etwa zum Verschwinden gebracht wird. 
Ernst-von-Glasersfeld-Lectures | Siegfried J. Schmidt

Prozesse der Ordnungsbildung lassen sich auf allen Ebenen sprachlicher bzw. medienvermittelter Kommunikation beobachten. In lokalen Kommunikationsprozessen vom Small Talk über Vorstellungs- und Prüfungsgespräche bis zum Familiengespräch am Mittagstisch gibt es feste Routinen, wie und über welche Themen geredet wird (und über welche nicht), und wie die Gesprächsanteile normalerweise verteilt sind. Überlokale Kommunikationsprozesse sind thematisch geordnet (wissenschaftliche, politische, religiöse usw. Diskurse) und bis hin zur erwarteten Wahl von Satztypen, Textsorten und Metaphoriken stilistisch formal bestimmte Systeme von Kommunikationshandlungen. Durch diese als Erwartungs-Erwartungen, also als kollektives Wissen wirksamen Bestimmungen wirken Diskurse hochgradig selektiv in Bezug auf thematisch und formal zulässige und erfolgreiche Beiträge (und Beiträger) zum jeweiligen Diskurs. Mit anderen Worten: Die Beobachtung von Diskursen erweckt den Eindruck, als organisierten sie sich selbst über die Reflexivität sinnorientierten Handelns der Aktanten. ${ }^{8}$

Dass auch mit solchen ordnungsbildenden Strategien kein Kommunikationserfolg erzwungen werden kann, dass Kommunikation also immer riskant und unsicher ist, bedarf keiner weiteren Begründung. Deshalb hat etwa N. Luhmann immer wieder betont, dass Kommunikation auf Vertrauen basiert. Solches Vertrauen hat m. E. verschiedene Aspekte. Es operiert zum einen als Vorschuss-Vertrauen in die Aufrichtigkeit und Glaubwürdigkeit der Kommunikationspartner, die aus bisherigen Kommunikationserfahrungen abgeleitet ist bzw. sich als Hoffnung realisiert. Es operiert zum Anderen auf der operativen Fiktion, dass sich im Verlauf der langen sprachlichen und nichtsprachlichen Sozialisation Vergleichbarkeiten des individuellen Umgangs mit Sprachmaterial herausgebildet haben, die in der Regel hinreichend störungsfreie Kommunikationshandlungen auf der Grundlage eines stabilen Zeichensystems erlauben, dem die Kommunikationspartner vertrauen. Dabei darf nicht übersehen werden, dass Kommunikationsprozesse nur dann entstehen und sinnvoll sein können, wenn es darum geht, Unbestimmtheiten in Bestimmtheiten zu transformieren, also Selektionen aus möglichen Bereichen von Themen, Formen und Zielen, mit anderen Worten also Kontingenz zu bearbeiten. Wo nichts auszuschließen ist, kann kommunizierend auch nichts eingeschlossen werden. Dabei bleibt der Einschluss angesichts des Exkludierten riskant, weil man nicht im Voraus wissen kann, ob der angebotene Einschluss von den Kommunikationspartnern akzeptiert oder goutiert wird.

In der immer wieder aufflammenden Diskussion darüber, wer kommuniziert bzw. ob ein Kommunikationskonzept ohne Aktanten auskommt ${ }^{9}$, möchte ich folgende Überlegung anbieten. In medien-

8 Dialogorientierte Autoren wie Gadamer oder Bakhtin haben bekanntlich vorgeschlagen, Kommunikation insgesamt als eine Frage- und Antwortspiel zu modellieren. - Böhler (1999, S. 55) spricht von einer doppelten Dialogizität der Kommunikation, bestehend aus Reden und Verstehen in Form kompletter Äußerungen und dem sich redend darauf Beziehen.

9 Maturana berichtet von einem Gespräch mit Luhmann: „Er hat mir einmal gesagt, er klammere die Menschen aus seinem Theorieentwurf aus, um universale Aussagen formulieren zu können. Wenn man von Menschen spricht, so sein Argument, ließen sich universale Aussagen nicht mehr machen." (Pörksen 2001, S. 107) 
vermittelten Kommunikationsprozessen (und nur in solchen) kann Kommunikation theoretisch von Handlung abgekoppelt und als ein sich selbst organisierender Prozess modelliert werden, in dem es nur darauf ankommt (heißt: bei dem nur darauf geachtet wird), dass jede Operation Anschlussoperationen erlaubt, damit die Kommunikation nicht abbricht. Dann kann man darauf verweisen, dass Kommunikation zwar psychische Leistungen (Kognitionen) in der Umwelt in Anspruch nimmt, sich aber theoretisch nicht weiter um diese Leistungen kümmern muss. N. Luhmanns (offenbar ausschließlich an medienvermittelter Kommunikation orientierte) irritierende These, dass nur Kommunikation kommuniziert und nicht der Mensch, und dass Kommunikation ein sog. autopoietisches Sinngeschehen bildet, erscheint mir dagegen als kontraproduktiv für eine Modellierung von Kommunikation als soziale Interaktion im Alltag.

Ich denke, man kann aber gerade auch im systemphilosophischen Argumentationsdesign Luhmanns feststellen, dass immer dann, wenn man Kommunikationsprozesse beobachten und beschreiben will, man auch Kognition als konstitutive Umwelt von Kommunikation in Betracht ziehen muss, weil Systeme - so Luhmann - nur in Bezug auf Umwelt und umgekehrt funktionieren und beobachtet werden können.

Ein bezeichnendes Licht auf die Frage nach Kommunikation und Aktant wirft aber nicht nur die Frage auf: Wer kommuniziert?, sondern vor allem auch die Frage: Wozu wird kommuniziert? Eine Frage, die m. E. deutlich darauf verweist, dass Kommunikationshandlungen als motivgeleitete Handlungen in sozialen Settings beschrieben werden sollten, die Aktanten Anlass zu eben diesem bestimmten Handeln liefern. Dass handlungsleitende Motive kulturbestimmt sind, dürfte ohne umständliche Begründung einleuchten.

Ein Faktor, der in der Kommunikation (welchen Typs auch immer) eine wichtige Rolle spielt, ist Zeit. Kommunikation ereignet sich in Form von Kommunikationshandlungen und deren Aggregierung zu Diskursen in der Zeit. Es spielt eben durchaus eine wichtige Rolle, wann etwas gesagt bzw. kommuniziert worden ist. Das ist evident bei allen interaktiven Kommunikationsformen bis hin zum Chatten im Internet. Damit aber bekommen alle Kommunikationsprozesse Geschichtencharakter; und da sie im symbolischen Ordnungsrahmen von Diskursen ablaufen, stellt sich ohne jedes Zutun von Aktanten der Geschichten- und Diskurs-Charakter menschlichen Handels und Kommunizierens ein.

In diesen reflexiven Prozessen erscheinen auch erst die „Kommunikationsgegenstände“, entfalten die Kommunikationspartner ein bestimmtes Thema ebenso wie eine bestimmte Beziehung zu den anderen Partnern. Erst in diesem gemeinsamen Prozess der sprachlichen Entfaltung eines Themas und des Aufbaus einer sozialen Beziehungsstruktur werden Bedeutungen in einer bestimmten Nuance entfaltet, kommentiert, verändert, gedeutet und so weiter. Die Rezeptions- und Nutzungsbedingungen für Medienangebote können zum Gegenstand von Beobachtungen und Beschreibungen gemacht werden, die Partner können sich also aufeinander zubewegen, indem sie in der Kommunikation über ihre kognitiven Prozesse berichten - wie fiktiv auch immer. Aus diesem Blickwinkel 
wird deutlich, warum Kommunikation von vielen Autoren als gemeinsamer Tanz, als Spiel, als Austausch oder Ähnliches beschrieben worden ist.

Ein zweiter wichtiger Faktor von Kommunikation ist Raum. Es ist sicher kein Zufall, dass viele Kommunikationswissenschaftler nur interaktive Kommunikationsprozesse (= face-to-face im selben Wahrnehmungsraum,) für „echte“ Kommunikation halten. Diese Auffassung kollidiert allerdings mit dem Verhältnis von Medien und Kommunikation.

Wie aus der Linguistik bekannt, übernimmt der non-verbale Kanal äußerst wichtige Funktionen. Auf ihm können verbale Aussagen akzeptiert oder zurückgewiesen, kommentiert, konsentiert, hervorgehoben und bewertet werden; auf ihm wird die Einschätzung der Beziehung der Kommunikationspartner zueinander sowie zur Kommunikationssituation ablesbar; und schließlich wird er zur Strukturierung des Prozesses der Kommunikation (etwa bezüglich Sprecherwechsel) eingesetzt. Im Falle einer bemerkten Differenz zwischen den beiden Kanälen genießt in der Regel der non-verbale höhere Glaubwürdigkeit, ist also in seiner kommunikativen wie metakommunikativen Bedeutung gar nicht zu überschätzen.

Verbale wie nonverbale Kommunikationsprozesse sind erfahrungsgemäß unlösbar verbunden mit Performanz, also mit dem Leib. Der Leib wird im Kommunikationsprozess zum Prozess-Träger und damit zu einer Voraussetzung von Kommunikationsprozessen gemacht. Wir sprechen „aus dem Leib" und mit dem Leib. Sprechen darf deshalb nicht auf die Verkettung von Propositionen reduziert werden. Vielmehr kommen über den Leib Emotionen ins Spiel und über die sozialen Einbettungssettings Wahrheitsansprüche bzw. Wahrheitserwartungen, moralische Bewertungen und empraktische, also auf die Lebensrelevanz einer Handlung bezogene Einschätzungen: War ein Kommunikationsangebot nach den Kriterien des jeweiligen Diskurses diskursrelevant, war es gut oder schlecht, achtens- oder ächtenswert, war es emotional befriedigend und in der jeweiligen Situation lebensrelevant?

Die Themen Kommunikation und Verstehen sind unlösbar miteinander verbunden. Wird Kommunikation nicht als Prozess der Übertragung von Informationen und Bedeutungen, sondern als Sinn-orientierte Konstruktion von Bedeutungen in kognitiven Systemen konzipiert, dann wird der Prozesscharakter von Verstehen deutlich. Handlungsverstehen kann dann bestimmt werden als Zuschreiben eines Handlungsmusters zu einer beobachteten Handlung in einem spezifischen Kontext; Äußerungsverstehen kann bestimmt werden als Zuschreiben einer befriedigenden Lesart zu einem Text bzw. zu einer Äußerung. In beiden Fällen transformiert Verstehen kommunikative wie nichtkommunikative Ereignisse in der Umwelt eines kognitiven Systems in eine strikt System-spezifische Semantik unter Verwendung von kollektivem Wissen.

Kognitive wie soziale Verstehensprozesse laufen in der Regel automatisch ab, d. h. sie sind weder bewusstseinsfähig noch bewusstseinspflichtig. Verstehen heißt dann, eine Sprache sprechen können bzw. wissen, was man in einem Geschichten- und Diskurszusammenhang richtigerweise tut. Darum treten Verstehensprobleme erst auf, wenn Routinen versagen und Verantwortlichkeit ein- 
gefordert wird. Verstehensprobleme sind also typische Probleme des Beobachters zweiter Ordnung, die auftreten bei dem Versuch, ablaufende Prozesse und ihre Beobachtung voneinander zu trennen.

\section{Kontingenz}

Der in Abschnitt 2 entwickelte Wirkungszusammenhang von Setzung und Voraussetzung ist unlösbar mit Selektivität verbunden. Selektion und Kontingenz sind komplementär; und da Setzung der Grundmechanismus unseres Handelns ist, ist Kontingenz eine universale Eigenschaft allen menschlichen Handelns. Wie schon oben gesagt: Was immer wir tun, wir tun es in Gestalt einer Setzung: Wir tun dieses und nicht etwas anderes, obwohl wir auch etwas anderes hätten tun können. Kontingent ist also, was weder notwendig noch unmöglich ist.

Auch wenn Menschen immer wieder versuchen, Kontingenz durch Formen von Fundamentalismen (= Kontingenzverschleierung) zu bearbeiten, muss die Vergeblichkeit solcher Versuche betont werden, die immer irgendeinen anfangslosen Beginn postulieren, den es aus logischen und erkenntnistheoretischen Gründen nicht geben kann.

In Medienkulturgesellschaften dienen die verschiedenen verfügbaren Medien gleichsam als Kontingenzagenturen. Sie führen unentwegt vor, dass alles auch anders sein kann, dass andere Gesellschaften andere Problemlösungen praktizieren wie unsere Gesellschaft, und dass andere Individuen andere Wirklichkeitskonstruktionen leben wie wir. Medien als Beobachtungsinstrumente erlauben, ja sie erzwingen Beobachtungen zweiter Ordnung. Das bedeutet aber, dass die Aktionen und Reaktionen unserer Handlungspartner im Prinzip unsicher, unprognostizierbar, riskant und überraschend sind, was gleichermaßen für unsere Handlungspartner in Bezug auf uns gilt. Wir haben es hier also mit doppelter Kontingenz zu tun, die soziale Verhältnisse prinzipiell unvorhersehbar macht. Eben deshalb sind im Verlauf der sozialen Entwicklung Instrumentarien zur Bearbeitung von Kontingenz entstanden, so z. B. Typen kollektiven Wissens wie etwa Schemata, kulturelle operative Fiktionen oder symbolisch generalisierte Kommunikationsmedien. So wie in der Wahrnehmung Kontingenz durch den blinden Fleck invisibilisiert wird, invisibilisiert das Kulturprogramm einer Gesellschaft universale Kontingenz.

Kontingenzerfahrungen stellen erhöhte Anforderungen an die kognitive Flexibilität, die Toleranzfähigkeit und Toleranzbereitschaft der Aktanten. Offensichtlich fällt es den Menschen schwer, mit Pluralismen umzugehen, sie als Ausgangssituation zu akzeptieren und sich auf die Erarbeitung akzeptabler Problemlösungen zu konzentrieren. Das gilt bekanntlich in besonderer Schärfe für Medienkulturgesellschaften unter Globalisierungsbedingungen.

Kontingenz kann unter zwei Gesichtspunkten gesehen werden. Zum einen führt sie dazu, dass unsere scheinbaren Selbstverständlichkeiten ihren scheinbar objektiven Status verlieren, was zu Verunsicherung, Enttäuschung und Angst führen kann. Zum Anderen erhöht die Einsicht in Kontingenz aber unsere Handlungsspielräume, wobei Kreativität und Risiko eng beieinander liegen. Die 
Ernst-von-Glasersfeld-Lectures | Siegfried J. Schmidt

Einsicht des Beobachters zweiter Ordnung in Kontingenz als die Normalverfassung unserer Wirklichkeitskonstruktionen korrespondiert einem Verständnis von Wirklichkeit als einem Phasenraum von Virtualitäten, von denen einige mit Gründen auf Zeit als Wirklichkeiten realisiert werden.

Akzeptiert und praktiziert man den Umgang mit Kontingenz, dann akzeptiert man die Einsicht in die Endgültigkeit der Vorläufigkeit der Endgültigkeit. Das mag unser Können und unseren Stolz blamieren. Auf der anderen Seite entlastet diese Einsicht uns vom philosophischen wie vom wissenschaftlichen Heroismus und gestattet uns, ohne Ressentiment Randfiguren zu sein. Eine Einsicht, die in zwei Zitaten zum Ausdruck kommen soll. So schreibt Elfriede Gerstl: „manche kommen aus dem staunen nicht heraus, manche nie hinein." Und etwas drastischer konstatiert der elegante Essayist Michel de Montaigne: „(...) und selbst auf dem höchsten Thron der Welt sitzen wir nur auf unserem Arsch."

\section{Nachwort: Die Wiederkehr des Realismus (?)}

Autoren wie Paul Boghossian oder Markus Gabriel haben in Veröffentlichungen der letzten Jahre eine Wiederkehr des Realismus und ein Scheitern des Konstruktivismus vorausgesagt. ${ }^{10}$ Boghossians Argument lautet: „Es ist uns nicht gelungen, irgendwelche guten Argumente für konstruktivistische Auffassungen zu finden. Die Schwierigkeit liegt darin, zu verstehen, warum diese Auffassungen so verlockend sind. Warum diese Angst vor der Wahrheit?“ (4. Umschlagseite)

Bemerkenswert an Boghossians Buch ist, dass er „den Konstruktivismus“ kritisiert, aber keinen einzigen konstruktivistischen Autor nennt und analysiert. Stattdessen kritisiert er Vertreter des Relativismus wie Rorty, Goodman, Putnam, Carnap oder Wittgenstein, die er ohne weitere Begründung als Konstruktivisten bezeichnet. Ihnen unterstellt er eine ganze Liste von s. E. falschen Argumenten, so z. B.

- die These der Gleichwertigkeit aller Arten von Weltverständnis

- die These der sozialen Konstruktion alles Wissens

- Antiobjektivismus, demzufolge alle Konstruktionen lediglich unsere Bedürfnisse und Interessen widerspiegeln

- Postmodernismus

- globalen Relativismus und Pluralismus.

Stattdessen empfiehlt er, sich auf den "gesunden Menschenverstand“ zu verlassen, wonach die Welt ist, wie sie ist, unabhängig von unseren Meinungen über sie.

I. S. der Argumentationen H. von Foersters, E. von Glasersfelds oder H. R. Maturanas kann man auf diese Unterstellungen kurz wie folgt antworten:

10 Vgl. Boghossian 2013 mit einem Nachwort von Gabriel, in dem er seine eigenen Thesen zusammenfasst. 
- Bei den unterschiedlichen Arten von Weltverständnis geht es nicht um eine Gleichwertigkeitsbehauptung, sondern um den Hinweis auf eine Konkurrenz verschiedener Arten von Wissensproduktion nach unterschiedlichen Standards und Kriterien.

- Statt Existenzbehauptungen oder -leugnungen „der Wirklichkeit/Welt“ geht es um die Einsicht in die Beobachtergebundenheit allen Wissens.

- Tatsachen in Geschichten und Diskursen sind Tatsachen für Beobachter und ihre Unterscheidungs- und Beschreibungspraxis; sonst ist von Tatsachen nicht die Rede.

- Die angebliche Angst vor Wahrheit und Wissen ${ }^{11}$ ist eine Unterstellung. Konstruktivisten wenden sich lediglich gegen absolutistische Wahrheitsansprüche, die den Beobachter ausschließen. Und dass diese Zurückweisung absolutistischer Wahrheitsansprüche philosophische wie gesellschaftliche und politische gute Gründe hat, kann man nicht zuletzt bei Maturana und seinen Erfahrungen mit der chilenischen Diktatur nachlesen.

P. Boghossian und M. Gabriel (2013) mögen gegen Relativismus und Postmodernismus eine Wiederkehr des Realismus im erkenntnistheoretisch dualistischen Gewand propagieren. Vom Diskurs des Radikalen Konstruktivismus (Schmidt 1987) haben sie leider noch nicht Notiz genommen.

Auch die Kritik der Neuen Realisten an „dem Konstruktivismus“ bezieht ihre Motivation nicht zuletzt aus der Irritation, die das Adjektiv „radikal“ in der Bezeichnung „Radikaler Konstruktivismus“ auslöst. Hinzu kommt, dass Konstruktion als willkürliche Setzung missverstanden wird, die das Gegenargument produziert: Die Welt existiert auch ohne uns!

Vielleicht kann man die Konfliktsituation dadurch entspannen, dass man statt von Wirklichkeitskonstruktion von Herstellung von Wissen in konkreten Situationen im Rahmen soziokultureller Kontexte spricht. Dann könnte die in diesem Beitrag vorgeschlagene Prozess-Orientierung des philosophischen Argumentierens vielleicht eine Auflösung des ontologischen Diskursdilemmas dualistischen Zuschnitts in Gang setzen.

\section{Literatur}

Böhler, Dietrich (1999): Warum moralisch sein? Hannah Arendt, Eichmann, Sokrates und die Verbindlichkeit des Dialogprinzips. Handlung, Kultur, Interpretation, 8 (1), S. 43-63.

Boghossian, Paul (2013): Angst vor der Wahrheit. Ein Plädoyer gegen Relativismus und Konstruktivismus. Frankfurt/M.: Suhrkamp. (Fear of Knowledge. Against Relativism and Constructivism, 2006; aus dem Amerikanischen von J. Rometsch)

11 Ernst von Glasersfeld hat sein Leben lang über Wissen und Wahrheit reflektiert. Vgl. etwa von Glasersfeld 1997 und 1998 oder die Beiträge in Rusch (Hg.) 1999. 
Ernst-von-Glasersfeld-Lectures | Siegfried J. Schmidt

Bourdieu, Pierre (1982): Was heißt sprechen? Die Ökonomie des sprachlichen Tauschs. Wien: Braunmüller.

Feilke, Helmut (1996): Sprache als soziale Gestalt. Ausdruck, Prägung und die Ordnung der sprachlichen Typik. Frankfurt/M.: Suhrkamp.

Finke, Peter (2005): Die Ökologie des Wissens. Exkursionen in eine gefährdete Landschaft. Freiburg München: Karl Alber.

Gabriel, Markus (2013): Warum es die Welt nicht gibt. Berlin: Ullstein, 8. Auflg.

Janich, Peter (2001): Logisch-pragmatische Propädeutik. Ein Grundkurs im philosophischen Reflektieren. Weilerswist: Velbrück Wissenschaft.

Janich, Peter (2009): Kein neues Menschenbild. Zur Sprache der Hirnforschung. Frankfurt/M.: Suhrkamp.

Maturana, Humberto R: (1982): Erkennen: Die Organisation und Verkörperung von Wirklichkeit. Braunschweig-Wiesbaden: Vieweg.

Merten, Klaus (1977): Kommunikation. Eine Begriffs- und Prozeßanalyse. Opladen: Westdeutscher Verlag.

Merten, Klaus (1999): Einführung in die Kommunikationswissenschaft. Bd. I: Grundlagen der Kommunikationswissenschaft. Münster: LIT.

Mitterer, Josef (1992): Das Jenseits der Philosophie. Wider das dualistische Erkenntnisprinzip. Wien: Passagen Verlag.

Mitterer, Josef (2001): Die Flucht aus der Beliebigkeit. Frankfurt/M.: Fischer Taschenbuchverlag.

Pörksen, Bernhard (2001): Gewissheit der Ungewissheit. Gespräche zum Konstruktivismus. Heidelberg: Carl-Auer-Systeme Verlag.

Roth, Gerhard (2001): Fühlen, Denken, Handeln. Wie das Gehirn unser Verhalten steuert. Frankfurt/M.: Suhrkamp.

Rusch, Gebhard (Hg.) (1999): Wissen und Wirklichkeit. Beiträge zum Konstruktivismus. Eine Hommage an Ernst von Glasersfeld. Heidelberg: Carl-Auer-Systeme Verlag.

Schmidt, Siegfried J. (1973): Texttheoretische Aspekte der Negation. Zeitschrift für Germanistische Linguistik, H. 2, S. 178-208.

Schmidt, Siegfried J. (Hg.) (1987): Der Diskurs des Radikalen Konstruktivismus. Frankfurt/M.: Suhrkamp.

Schmidt, Siegfried J. (Hg.) (1991): Gedächtnis. Probleme und Perspektiven der interdisziplinären Gedächtnisforschung. Frankfurt/M.: Suhrkamp.

Schmidt, Siegfried J. (2003): Geschichten \& Diskurse. Abschied vom Konstruktivismus. Reinbek bei Hamburg: Rowohlts Taschenbuch Verlag.

Schmidt, Siegfried J. (2010): Die Endgültigkeit der Vorläufigkeit. Prozessualität als Argumentationsstrategie. Weilerswist: Velbrück Wissenschaft.

von Glasersfeld, Ernst (1997): Wege des Wissens. Konstruktivistische Erkundungen durch unser Denken. Heidelberg: Carl-Auer-Systeme Verlag. 
von Glasersfeld, Ernst (1998): Die Radikal-Konstruktivistische Wissenstheorie. Ethik und Sozialwissenschaften, 9 (4), S. 503-511.

von Weizsäcker, Carl Friedrich (1980): Der Garten des Menschlichen. Beiträge zur geschichtlichen Anthropologie. München: Hanser.

Watzlawick, Paul; Bevin, Janet H. \& Donald D. Jackson (1967): Pragmatics of Human Communication. New York: Norton.

\section{Autor}

Siegfried J. Schmidt. Geboren 1940. Studium der Philosophie, Germanistik, Linguistik, Geschichte und Kunstgeschichte. Von 1971 bis 2006 Universitätsprofessor an den Universitäten Bielefeld, Siegen und Münster. 



\section{Sicherheit und Freiheit}

\section{Gebhard Rusch}

\section{Zusammenfassung}

Hier und heute bezeichnen die Worte Freiheit und Sicherheit vor allem jene politischen Begriffe, die den rhetorischen Referenzrahmen im sicherheitspolitischen Koordinatensystem unserer westlichen Demokratien nach Innen und Außen abstecken. Legitimatorische und agitatorische Diskurse, Wahlkampfrhetorik und Parlamentsdebatten, Zivilgesellschaft und politische Administration bemühen regelmäßig und formelhaft Begriffe von Freiheit und Sicherheit für ihre jeweiligen Zwecke. Dabei werden die Begriffe oft in ein oppositionelles Verhältnis zueinander gesetzt: Mehr (z.B. innenpolitische) Sicherheit bedeutet dann weniger (z.B. persönliche) Freiheit, und umgekehrt. Oder Sicherheit wird zur Voraussetzung und Bedingung von Freiheit (z.B. in der „wehrhaften Demokratie“).

Die operationalen Wurzeln dieser Begrifflichkeit in der Wahrnehmung, im Verhalten und Handeln gelangen dabei jedoch weit aus dem Blick. Welche initialen und konsolidierten Eindrücke, Einsichten und Erfahrungen sind es, auf die wir uns affektiv und rational mit diesen Begriffen beziehen? Wie fühlt sich Sicherheit an? Wie sieht Verhalten oder Handeln als Ausdruck von Freiheit aus? Kann man Freiheit spüren? Zu welcher Freiheit ist man überhaupt fähig? Wieviel Sicherheit ist für das Leben nötig? Welche operationalen Evidenzen bieten Wahrnehmung und Verhalten für die Begriffe der Sicherheit und Freiheit vor all ihren ideologischen Aufladungen, historischen Interpretationen und philosophischen Explikationen?

\section{Einleitung}

"Jeder Mensch hat das Recht auf Freiheit und Sicherheit." So heißt es in Artikel 6 der Charta der Grundrechte der Europäischen Union. Auch das deutsche Grundgesetz kennt eine Reihe von Freiheits- und Schutzrechten, allerdings nicht in dieser Konjunktion.

Neben diesen Rechtsgütern bezeichnen die Worte Freiheit und Sicherheit aber vor allem politische Begriffe. Legitimatorische und agitatorische Diskurse, Wahlkampfrhetorik und Parlamentsdebatten, Zivilgesellschaft und politische Administration bemühen regelmäßig und formelhaft Begriffe von Freiheit und Sicherheit für ihre jeweiligen Zwecke. Dabei werden die Begriffe oft in ein oppositionelles Verhältnis zueinander gesetzt: Mehr (z.B. innenpolitische) Sicherheit verlangt dann Einschränkungen der (z.B. persönlichen) Freiheit, und umgekehrt. Oder Sicherheit wird zur Voraussetzung und Bedingung von Freiheit (z.B. in der „wehrhaften Demokratie“). Dann soll etwa 
Ernst-von-Glasersfeld-Lectures | Gebhard Rusch

die Durchlöcherung und Einschränkung z.B. des Brief- und Fernmeldegeheimnisses durch geheimdienstliche Überwachung und Kontrolle die Sicherheitslage verbessern. Oder die Meinungsfreiheit soll durch Vorratsdatenspeicherung geschützt werden. Also, ich verstehe das nicht. ${ }^{1}$ Deshalb möchte ich die Frage stellen, ob das Verhältnis von Sicherheit und Freiheit nicht ganz anders begriffen werden könnte - begriffen werden müsste?

Dazu werde ich Ernst von Glasersfelds Vorbild folgen und zunächst nach operationalen Wurzeln dieser Begrifflichkeiten in Denken und Wahrnehmung, Verhalten und Handeln, Gesellschaft und Kultur suchen. Genauer gesagt geht es hier um Prozesse der kognitiven und sozialen Konstruktion von Sicherheit und Freiheit. Auf dieser Basis möchte ich wesentliche Merkmale dieser operationalen Begriffe von Sicherheit und Freiheit identifizieren und ihren Zusammenhang klären. Damit möchte ich dafür plädieren, neben der Sicherheitspolitik (nach Innen und Außen) eine explizite Freiheitspolitik im Interesse der Bürgerinnen und Bürger, der Organisationen und der Gesellschaft - wie immer multikulturell oder multiethnisch sie zusammengesetzt sein mag - zu betreiben.

\section{Zur kognitiven und sozialen Konstruktion von Sicherheit und Freiheit}

Welche initialen und konsolidierten Eindrücke, Einsichten und Erfahrungen sind es, auf die wir uns affektiv und rational mit Begriffen der Sicherheit und Freiheit beziehen? Wie fühlt sich Sicherheit an? Wie sieht Verhalten oder Handeln als Ausdruck von Freiheit aus? Kann man Freiheit spüren? $\mathrm{Zu}$ welcher Freiheit ist man überhaupt fähig? Inwieweit ist Sicherheit für das Leben nötig? Welche operationalen Evidenzen bieten Wahrnehmung und Verhalten für Begriffe der Sicherheit und Freiheit vor all ihren ideologischen Aufladungen, historischen Interpretationen und philosophischen Explikationen? Fragen über Fragen - wir werden sie nicht alle hier und heute beantworten können.

\section{Sicherheit}

Beginnen wir mit der Semantik und Etymologie unserer Begrifflichkeiten. „Sicher“, „Sicherheit “, „schützen“, „Schutz“ etc. geht zurück auf das lat. „securitas“ - Sorglosigkeit (Gemütsruhe, Unerschrockenheit, Sicherheit/Sicherung) und das lat. protegere - decken, schützen.

Entlang der Grenze zwischen „sicher sein, dass ...", also der Gewissheit (i.S.v. Logik, Mathematik, aber auch Glaube), des Wissens, der Erfahrung, des Könnens (i.e. Techniksicherheit, i.S.v. Safety, Reliabilty) und „sicher sein vor ...“, also z.B. vor Gefahren, Verlusten, Ungewissheit, Unwägbarkeit

1 Offenbar hat das auch der Europäische Gerichtshof nicht verstanden und mit seinen Urteilen (Rs. C-293/12 und C-594/12) aus dem Jahr 2014 die EU-Richtlinie zur Vorratsdatenspeicherung mit Bezug auf jenen Artikel 6 kassiert, allerdings nicht ohne auch explizit auf das Recht auf Sicherheit zu verweisen, und damit möglicherweise spätere Einschränkungen vorzubereiten. (vgl. dazu Leuschner 2014) 
konstituieren sich die persönlichen, sozialen und kulturellen „Lösungen“ des Sicherheitsproblems als Modalitäten des (Rest-) Risikomanagements zwischen Rationalität und Affektivität (i.e. Ordnung, Vorsorge/Absicherung, Garantien/Versprechen, Gefühl von Sicherheit/Unsicherheit unter dem Aspekt von Security).

Das bis heute vorherrschende Begriffsverständnis hat Arnold Wolfers bereits 1962 so formuliert: "Security after all is nothing but the absence of the evil of insecurity" (Wolfers 1962, S. 153) bzw. "the absence of threats to acquired values" (ebd., S. 150).

Diese Sicht teilt in den 1970-er Jahren auch Franz Xaver Kaufmann, wenn er feststellt, dass „Sicherheit überhaupt nur als Nicht-Unsicherheit positiv bestimmt werden kann." (Kaufmann 1973, S. 158) Und auch im Jahr 2008 gelangt Werner Schirmer, inspiriert durch die Luhmannsche Systemtheorie, zu der Auffassung, dass "Sicherheit <...> Bedrohungen als unmarkierte Seite <braucht>, um selbst als Sicherheit sichtbar sein zu können, doch durch die Visibilisierung von Bedrohungen wird Sicherheit zum nie erreichten Horizont" (Schirmer 2008, S. 153f.).

Auch das jüngste Konzept eines auf mehrere Dimensionen (außenpolitisch, innenpolitisch bzw. polizeilich, ökonomisch, ökologisch, sozial, personal etc.) erweiterten Sicherheitsbegriffs (vgl. Heinrich/Lange 2009; Daase 2011) setzt nicht prinzipiell anders an, sondern multipliziert lediglich die negative Bestimmung des Sicherheitsbegriffes in seiner jeweiligen Dimensionierung. So wird schließlich das Konzept der Unsicherheit zum Genus Proximum der Definition des Sicherheitsbegriffs (vgl. Giebel 2012, S. 44).

„In den letzten fünfzig Jahren hat der Sicherheitsbegriff seine Bedeutung so stark gewandelt, dass es gerechtfertigt erscheint, von einem "post-modernen“ Sicherheitsverständnis zu sprechen. Die Erweiterung des Sicherheitsbegriffs geht dabei mit einer Individualisierung, einer Entdifferenzierung, einer Entgrenzung und einer Proaktivierung des Sicherheitsverständnisses einher. Individualisierung heißt, dass nicht länger der Staat mit seinen nationalen Sicherheitsinteressen im Zentrum steht, sondern das menschliche Individuum mit seinen elementaren Sicherheitsbedürfnissen nach Freiheit von Angst und Not, freedom from fear and want. Entdifferenzierung bedeutet, dass immer mehr Politikbereiche als sicherheitsrelevant angesehen werden und die vormals getrennten Sphären äußerer, innerer und sozialer Sicherheit zunehmend ineinander übergehen. Entgrenzung beschreibt den Prozess der geographischen Ausweitung sicherheitspolitischer Ansprüche und Praktiken, die ehemals auf das nationale Territorium fokussierten und über regionale und internationale Beziehungen sich heute auf globale Zusammenhänge beziehen. Proaktivierung beschreibt schließlich den Paradigmenwechsel von der Abwehr akuter Bedrohungen zur Reduzierung von Risiken und damit einen verstärkten Interventionismus in der Sicherheitspolitik." (vgl. Daase/ Deitelhoff 2013)

Während sich diese Ausdifferenzierung des Sicherheitsbegriffs vor der Folie historischer Veränderungen der dominanten Framings jeweils aktueller Bedrohungsdiskurse vollzieht, wie sie z.B. durch Schlüsselbegriffe wie „Kalter Krieg“, „RAF-Terror“, „Mauerfall“, „Internationaler Terrorismus“, und jüngst „Armuts- und Kriegsmigration“ gekennzeichnet werden können, markiert sie zugleich 
Ernst-von-Glasersfeld-Lectures | Gebhard Rusch

auch den Wandel politischer Sicherheitsdoktrin, legislativer und exekutiver Sicherheitsregimes, den Wandel gesellschaftlicher Sicherheits- und Sicherungskulturen (vgl. Lindner 2010). In nur zwanzig Jahren wandelten sich demgemäß sozialwissenschaftliche Gesellschaftsdiagnosen von Ulrich Becks Risikogesellschaft (Beck 1986) hin zum Konzept einer Sicherheitsgesellschaft, deren Konzepte und Verfahren sozialer Kontrolle kritisch reflektiert (Singelnstein \& Stolle 2006) oder als Ausdruck von Transformationen der Konstruktion und Regulation innerer oder makrosozialer Unsicherheit (Gronemeyer 2010, vgl. dazu auch Gerhold 2009) analysiert werden.

Was mit dem Begriff der Sicherheitsgesellschaft als ausgreifende Versicherheitlichung in der Gesellschaft diagnostizierbar wird, ist mit Blick auf die bereits angesprochenen Bedrohungsdiskurse dann stets und unvermeidbar ein Resultat der von Ole Waever und Barry Bozan beschriebenen Kommunikationsstrategie der Securitization (vgl. Waever 1995), der Thematisierung („securitizing move“) eines Sachverhaltes unter Aspekten von Risiko, Bedrohung oder Sicherheit (Buzan et al. 1998). Der Securitization-Ansatz nimmt damit Bezug auf die Sprechakttheorie John Austins und John Searles. So wie Sprechakte Sachverhalte konstituieren (z.B. ein Versprechen), konstruiert die Thematisierung einer Angelegenheit unter dem Blickwinkel von Risiko oder Bedrohung ein Sicherheitsproblem. Darin orientiert sich der Ansatz auch an sozialkonstruktivistischen Konzepten.

Diese Veränderungen des Sicherheitsverständnisses, allen voran die Individualisierung, haben die Voraussetzungen dafür geschaffen, dass wir jetzt sogar nach den kognitiven Voraussetzungen und Bedingungen der Konstruktion von Sicherheit (und Freiheit) fragen können.

Leider hat Ernst von Glasersfeld den Sicherheitsbegriff in seinen Schriften nicht expliziert. Er hat jedoch immer wieder die fundamentale Bedeutung der Konstruktion kognitiver Invarianten, z.B. der Objektkonstanz, und die operationale Relevanz viabler Denk- und Handlungsmuster hingewiesen. In genau diesem Sinne interpretiert auch Siegfried J. Schmidt in seinem Vortrag die Viabilität von Denk- und Handlungsmustern als Quelle von „Wirklichkeitssicherheit“2.

\section{Freiheit}

Der Freiheitsbegriff (aus dem lat. libertas) ist ebenfalls in Form zweier Prädikate zu explizieren, nämlich als „frei sein von ... “ (z.B. Forderungen, Beschränkungen, Zwängen, Ängsten) und als „frei sein für ..." (z.B. Entscheidungen, neue soziale Kontakte). Im engeren Sinne meint libertas zunächst den Stand des (aus Gefangenschaft, Leibeigenschaft oder Sklaverei) Freigelassenen, dann den Stand des Freien (z.B. des Bürgers), der durch Unabhängigkeit, Ungebundenheit oder Selbstständigkeit gekennzeichnet ist, wozu auch die Freiheit bzw. Befreiung oder Lossprechung (liberatio) von Schulden, Gelübden, Vorwürfen oder Verpflichtungen gehören kann.

2 S. J. Schmidt in diesem Band 
Als politischer Kampfbegriff und als soziale Errungenschaft steht „Freiheit“ in dieser Bedeutungstradition für ein selbstbestimmtes, unabhängiges, ungestörtes und unversehrtes Leben des einzelnen Menschen, sozialer Gruppen und ganzer Gesellschaften. Gemeint sind hier die Freiheiten, die in der Menschheitsgeschichte oft blutig, jedoch nicht nur in den großen Revolutionen und politischen Umbrüchen erkämpft, sondern auch durch Literalisierung und Bildung, Handel, religiöse, philosophische, politische und juristische Reflexion kulturell entwickelt wurden, nicht zuletzt durch das allägliche Bemühen so vieler Generationen um konfliktarme Lösungen für den Ausgleich, besser: die Balance von Interessen, Ansprüchen, Bedürfnissen und Leistungen.

Der „vorläufig endgültige“"3 Stand dieser Entwicklung wird z.B. durch die schon eingangs zitierten Grundrechte markiert, die für ihren Geltungsbereich im wesentlichen Statusfragen und Handlungsmöglichkeiten für die zwischenmenschliche Interaktion und das Verhältnis von Bürger und Staat klären. Schon ein kurzer Blick auf die Grundrechtsartikel zeigt, dass und in welcher Weise diese Freiheits- und Schutzrechte regulierend in das Handeln der Bürger und die Maßnahmen des Staates gegenüber seinen Bürgern eingreifen.

Artikel 1 - Schutz der Menschenwürde, Menschenrechte

Artikel 2 - Freie Entfaltung der Persönlichkeit, Recht auf Leben, körperliche Unversehrtheit, Freiheit der Person

Artikel 3 - Gleichheit vor dem Gesetz

Artikel 4 - Glaubens-, Gewissens- und Bekenntnisfreiheit

Artikel 5 - Recht der freien Meinungsäußerung, Medienfreiheit, Kunst- und Wissenschaftsfreiheit

Artikel 6 - Ehe und Familie

Artikel 7 - Schulwesen

Artikel 8 - Versammlungsfreiheit

Artikel 9 - Vereinigungsfreiheit

Artikel 10 - Brief-, Post- und Fernmeldegeheimnis

Artikel 11 - Freizügigkeit

Artikel 12 - Berufsfreiheit

Artikel 13 - Unverletzlichkeit der Wohnung

Artikel 14 - Eigentum, Erbrecht und Enteignung

Artikel 15 - Sozialisierung, Überführung in Gemeineigentum

Artikel 16 - Ausbürgerung, Auslieferung

Artikel 16a - Asylrecht

Artikel 17 - Petitionsrecht

Artikel 18 - Verwirkung von Grundrechten

Artikel 19 - Einschränkung von Grundrechten

3 Vgl. dazu den Beitrag von S. J. Schmidt in diesem Band. 
Ernst-von-Glasersfeld-Lectures | Gebhard Rusch

Die Grundrechte betreffen, wie unschwer auszumachen ist, einerseits Freiheit(en) i.S. des engl. Begriffs Liberty, also etwa die Freiheit von Zwang, Repression und Willkür, andererseits Freiheit(en) i.S. von Freedom, also z.B. die Freiheit zu/für Selbstbestimmung und Selbstverwirklichung in Privatleben, Beruf und Öffentlichkeit.

\section{Sicherheitskultur}

Kultur wird hier nicht als eine Entität angesehen, sondern als Modalität, und zwar als die Modalität der Verwirklichung von Gesellschaft, als die Art und Weise, wie Gemeinschaft „gelebt“ wird. Kultur zeigt sich dann in allem, worin sich Gesellschaften oder Organisationen oder soziale Gruppen voneinander unterscheiden (können). In diesem Sinne subsumiert dieser differentielle Kulturbegriff potentiell alle anderen Begriffe von Kultur (von Tylor 1871 bis zu Hansen 2003).

Fasst man Kultur als Modalität des Vollzuges (Prozessierens) sozialer Gemeinschaft, so eröffnen sich Fragen der Beschreibung der spezifischen Art und Weise, in der sich Gruppen, Organisationen oder ganze Gesellschaften (im Unterschied zu und in Auseinandersetzung mit anderen) verwirklichen, Fragen nach Ursachen und Gründen solcher Formen sozialer Selbstverwirklichung und nach den spezifischen „Mechanismen“ der soziokulturellen Evolution (i.e. Reproduktion und Modifikation von Lebensstilen, Gepflogenheiten, Konventionen, Normen, Artefakten).

Ein Begriff der Sicherheitskultur kann dann die Art und Weise bezeichnen, in der in Gemeinschaften und Gesellschaften Begriffe von Sicherheit, Schutz, Gefahr und Risiko bestimmt werden (Konzeptualisierung), Sicherheits- und Schutzziele definiert (Zielfindung), Gefahren und Risiken wahrgenommen und identifiziert werden (Erkennung), wahrgenommene Gefahren und Risiken präventiv und reaktiv bearbeitet werden (Entwicklung von Strategien und Maßnahmen). D.h.: es ist auch Ausdruck von Sicherheitskulturen, wie Sicherheit (als Safety oder als Security) herzustellen versucht wird, welche Sicherheitslösungen überhaupt entwickelt werden, wie Sicherheitslösungen geprüft und bewertet werden (Evaluation), wie erfolgreiche und als relevant oder unverzichtbar erachtete Sicherheitslösungen gepflegt werden (Tradierung), wie Sicherheitsparadigmen historisch und sozial ausgeprägt, tradiert, erschüttert, innoviert oder revolutioniert werden (Wandel), wie schließlich Sicherheitsparadigmen endogen (durch Politik, Wissenschaft, Technik, Ökonomie und kulturelle Faktoren), vor allem aber durch exogene Trigger (z.B. Umwelt) beeinflusst werden (Interaktionen). Sicherheitskulturen sind kontingent, teils emergieren sie in der Wechselwirkung politischer, ökonomischer, sozialer und kognitiver Prozesse, teils werden sie aktiv und intendiert kreiert, entwickelt oder verändert, wie es z.B. die militärische und in jüngerer Zeit auch die zivile Sicherheitsforschung tut.

Die Wandlungsprozesse, mit denen man es dabei zu tun hat, sind Prozesse der kulturellen Evolution. Der Wandel von Sicherheitskulturen vollzieht sich deshalb auch in vielerlei Gestalten: als Wandel von Konzepten und Zielen, als Wandel des Risikobewusstseins und der Gefahrenwahrnehmung, als Wandel einzelner Sicherheitslösungen durch technische Innovationen, als Wandel von Sicherheits- 
Konventionen, Werten, Normen und Gesetzen (z.B. der o.g. Grundrechte), als Wandel von Sicherheitsdoktin und -paradigmen und nicht zuletzt als Wandel sozialer Sub-Systeme, Institutionen und Organisationen, ja sogar als Wandel ganzer Gesellschaften, ihrer Kulturen und Ökonomien.

Im gegenwärtigen Diskurs der Sicherheitsforschung in Deutschland ist Sicherheitskultur von Christopher Daase in einem praxistheoretischen Verständnis bestimmt worden, als „diejenigen Werte, Diskurse und Praktiken ..., die dem auf Erzeugung von Sicherheit und Reduzierung von Unsicherheit gerichteten sozialen Handeln individueller und kollektiver Akteure Sinn und Bedeutung geben“" (Daase 2011, S. 63). Und er meint damit „keine identifizierbare Variable [...], sondern ein Arrangement ineinandergreifender Faktoren, das je nach kulturtheoretischer Perspektive und sicherheitspolitischer Fragestellung unterschiedlich analysiert werden kann" (ebd.). Mit der diskurs- und praxistheoretischen Ausrichtung steht dieser Ansatz einem differentiellen Verständnis von Kultur sehr nahe. Doch obwohl Daase mit guten Argumenten die bekannten Reifizierungen und Homogenisierungen des Kulturbegriffes kritisiert hat, ist doch auch der vorgeschlagene Ansatz in der Gefahr, genau diesen Verführungen - wenn auch auf einem deutlich höheren Komplexitätsniveau (hier: Diskurse, Praktiken) - erneut zu erliegen.

Die Analyse der Kultur einer Gesellschaft ist eben faktisch nichts anderes als die Analyse dieser Gesellschaft im Hinblick auf die spezifische Art und Weise ihrer (Selbst-) Verwirklichung (in Begrifflichkeiten, Praktiken, Artefakten, etc.), wie diese im Vergleich erkennbar wird. Die dabei beobachtbare Varianz in der Vielfalt und Unterschiedlichkeit der Kulturen ist unmittelbarer Ausdruck kognitiver und sozialer Plastizität und Kontingenz. Und genau dies ist es, was die Kultürlichkeit der Verhältnisse ausmacht mit der Folge, dass sie grundsätzlich immer und überall und letztlich veränderbar sind.

Gemeinschaft und Gesellschaft, und mit diesen die Kultur als viabler Modus des kognitiv-sozialen Zusammenwirkens von Menschen erweisen sich daher selbst als wesentliche Quellen für Sicherheit. Der Einzelne gewinnt Sicherheit im Handeln und Denken durch Intentionalität und Anschlussfähigkeit (in Interaktion, Kommunikation, Kooperation). Die Gemeinschaft als Ganze gewinnt Sicherheit aus der Bindung der Einzelnen aneinander, aus der durch Konventionen beschleunigten Interaktion und aus einem gewissen Konservatismus, der sich aus dem Interesse der Einzelnen an kalkulierbaren Verhältnissen und Sicherheit im Handeln erklären lässt.

\section{Verhalten, Handeln und Selbstwirksamkeit}

Die Begriffe von Freiheit und Sicherheit werden hier als Konstrukte betrachtet, d.h. als Hervorbringungen im Prozess kognitiver-sozialer Wirklichkeitskonstruktion. Die kognitiven und sozialen Anteile an der Wirklichkeitskonstruktion können wegen ihrer engen und vielfältigen Wechselwirkungen nur analytisch unterschieden werden. Es wird entsprechend zu zeigen sein, wie und welche sozialen Regulationen unter den Bedingungen kognitiver Autonomie entstehen. 
Ernst-von-Glasersfeld-Lectures | Gebhard Rusch

\section{Zur kognitiven Konstruktion von Sicherheit}

Betrachten wir zunächst die kognitive Konstruktion von Sicherheit etwas genauer. Nach dem Vorbild Jean Piagets, der die ontogenetische Konstruktion physikalischer Grundbegriffe nachzeichnete, soll hier im Ansatz versucht werden, Begriffe von Freiheit und Sicherheit im affektiven und reflexiven Erleben eigenen Verhaltens zu analysieren. Aus der Entwicklungspsychologie Piagets (vgl. Piaget 1975 und 1976) kann man lernen, dass die ontogenetische kognitive Entwicklung ein Prozess der Bildung und Verknüpfung sensu-motorischer Schemata, der Koordination solcher Verknüpfungen und der Interiorisierung von motorischem Verhalten ist. Durch rekursive Kopplungen dieser Schemata entsteht schließlich in der Ontogenese das Konzept des Selbst (und der Umwelt) aus Selbstbeobachtung und Erfahrung von Selbstwirksamkeit. Die neuere Kognitionsforschung hat an die Schematheorie angeschlossen (vgl. exemplarisch Johnson-Laird 1983, Lakoff 2004, Mandl \& Spada 1988, Ciompi 1997) und mit den Begriffen der kognitiven Konzepte, Mental Models, kognitiven Scripts, Frames und Plans (um nur die wichtigsten zu nennen) Instrumente zur Verfügung gestellt, jene internen Repräsentationen und Relationen zwischen sinnlichen Anmutungen, verbalen Bezeichnungen, Vorstellungen und verknüpften motorischen Aktivitäten zu modellieren. Dabei ist menschliches Tun kognitiv repräsentiert durch Schemata, Scripts und Plans, die als prozedurales, oder besser: operationales Wissen einerseits das Handeln (als intentionales Verhalten) leiten, indem sie dem Handeln eine Ausführungsreihenfolge, einen kontextuellen Rahmen (i.e. Sinn) sowie die Richtung weisen, andererseits und zugleich der (Selbst-)Beobachtung als Assimilationsschema zur Verfügung stehen, um die Wahrnehmung (als Identifikation sinnlich-affektiver Zustände) aisthetisch, begrifflich und sprachlich zu gestalten (vgl. Gestaltbegriff bei Wertheimer, Metzger). Kognitive Konzepte, Schemata, Frames usw. ermöglichen so die Assimilation von immer wieder mehr oder weniger unterschiedlichen sensorischen Zuständen an ein endliches Repertoire von Begriffen und Schemata. Dadurch ist so etwas wie die Wiedererkennung und Erkennung von Bekanntem im Neuen und Fremden möglich. Es entsteht eine in Gestalten, Farben, Formen, Anmutungen, Affekten und Begriffen möblierte Wirklichkeit, die als relativ stabiles Raum-Zeit-Kontinuum erlebt und konzeptualisiert werden kann. Und weil kognitive Systeme nicht in ihren Wirklichkeiten (wie in Umwelten), sondern vermittels ihrer Wirklichkeitskonstruktion (als kognitiver Leistung, Funktion oder Betriebsmodalität) überleben oder scheitern, sind viable und stabile kognitive Verhältnisse eine wesentliche Voraussetzung und eine potentielle Quelle von Sicherheit in der Wahrnehmung, in der Verhaltenssynthese, im reflektierenden und schlussfolgernden Denken.

Entscheidend ist hier, dass Wissen generell als Knowhow anfällt, also als operationales Wissen davon, was wie getan, gesehen, gedacht, gefühlt oder vorgestellt werden kann. Die z.T. mühsam erlernte Erreichung von Zielen durch die Ausführung bestimmter Tätigkeiten verdichtet sich in Handlungsrepertoires zu Vollzügen des Könnens, zu Fähigkeiten und Fertigkeiten, allgemein zu Kompetenzen. Es entsteht für das Subjekt eine eigene Handlungsmächtigkeit, und zwar als das Vermögen, eigene Zustände zielgerichtet, intentional verändern zu können. Und aus dieser Quelle sehen wir 
auch so etwas wie Selbst-Bewusstsein, Selbst-Gewissheit, Selbst-Wirksamkeit und Selbst-Beherrschung hervorgehen.

Die Intensität und Beharrlichkeit, mit der Kompetenzen vom Kindes- bis ins Erwachsenenalter ausgebildet und entwickelt werden, wäre kaum erklärbar, wenn nicht damit auch Vergnügen, Befriedigung oder Lust verbunden wäre. Entsprechend hat Piaget das Konzept der Funktionslust als frühkindliche Wirksamkeitsmotivation expliziert, als Antrieb zum Üben durch Wiederholung immer gleicher Abläufe, als Spaß an körperlicher oder geistiger Betätigung, und ebenfalls als Reiz des Spiels. Dazu kommen weitere Arten von Belohnungen (z.B. soziale Nähe, Zuwendung, Bestätigung, Incentives und Gratifikationen) und Sanktionen (z.B. soziale Distanzierung, Zurückweisung, Ablehnung, Bestrafung), die bestimmtes Verhalten, bestimmte Tätigkeiten und Handlungen so bestätigen und verstärken, dass sie zu wiederkehrenden Handlungsmustern und HandlungsRepertoires, zu Gewohnheiten, Routinen und Ritualen verfestigt werden.

Die Erfahrung kompetenten Handelns, d.h. die Erfahrung, über ein komplexes Handlungswissen zur Erreichung bestimmter Ziele zu verfügen, dessen Ausführung in der Aufeinanderfolge einzelner Handlungsschritte (Kontinuität) tatsächlich diese Ziele und nicht etwas anderes erreichen lässt (Validität), die Erfahrung, das diese Ziele mit hoher Zuverlässigkeit und im Prinzip an allen Orten und zu allen Zeiten durch die Ausführung des entsprechenden Verhaltens zu erreichen sind (Reliabilität) und die Erfahrung, dass man dieses Verhalten flüssig, ohne Stocken, vielleicht sogar mit einer gewissen Eleganz oder Perfektion beherrscht (Fluidität), diese Erfahrung kondensiert in dem Gefühl der Sicherheit, das als affektive oder emotionale Tönung das kompetente Handeln auszeichnet und begleitet. Und es ist dieselbe Erfahrung, die als valides Wissen und Können (in Gestalt von Fähigkeiten und Fertigkeiten) rationalisiert wird und auf die sich Zutrauen und Mut im Handeln gründen. - Sicher in einer Fremdsprache sein, sicher ein Stück auf dem Klavier spielen, sicher eine Halse mit dem Segelboot fahren.

Sicherheit bezeichnet hier zugleich eine Qualität, nämlich die Güte (Fluidität und Kontinuität) der Handlungsausführung (i.S.v. Security) und die erfahrungsgesättigte Erwartung der damit verbundenen Zielerreichung (i.S.v. Safety). Sicher wissen, was wie getan werden kann. Und sicher erwarten können, dass Handlungsziele auf bekannte Arten und Weisen erreicht werden können. Jede Vollendung einer Handlung erzeugt für den Akteur so immer neue Evidenz für deren Gültigkeit, Brauchbarkeit und Sinnhaftigkeit.

\section{Zur sozialen Konstruktion von Sicherheit}

Kommen wir nun zu einigen Aspekten der sozialen Konstruktion von Sicherheit. (Sozialisations-) Gemeinschaft in Familie, Clan oder Stamm, in Gruppen oder Völkern, schließlich in Gesellschaft, Nation oder Staat bietet Sicherheiten in zahlreichen unterschiedlichen Hinsichten.

So können z.B. Nähe und Vertrautheit, intime Kenntnis und emotionale Bindung, gegenseitige 
Unterstützung und Hilfe, gemeinsame Sprache, Sitten und Gebräuche in Familie und Clan ein Gefühl von Sicherheit durch eine Atmosphäre der Zusammengehörigkeit, Geborgenheit und des Geschütztsein erzeugen, die mit zunehmender Größe des sozialen Gebildes, d.h. mit dem Schwinden direkter und dauerhafter Sozialkontakte von jedem mit jedem, zwar schwächer wird, historisch jedoch in den größeren und großen Sozialsystemen stabilisiert wurde durch Ausweitung von Sprachgemeinschaft (z.B. Nationalsprachen), durch die Kanonisierung von Bildungsinhalten, die Homogenisierung von Lebensstilen (z.B. durch Ständeordnung, Bürgergesellschaft), durch intensive Handelsbeziehungen, die Angleichung von Rechtssystemen und Zahlungsmitteln und die Stiftung neuer Gemeinsamkeiten (etwa der Staatszugehörigkeit und staatlicher Symbole).

Klarerweise bedeutet Gemeinschaft auch physische und ökonomische Stärke, etwa gemessen an der Anzahl von Kriegern oder Kanonen, an der Wirtschaftskraft oder der Größe des beherrschten Territoriums. In diesem Sinne verbessern Gemeinschaft, Gesellschaft und Staat als Versorgungsund Verteidigungsgemeinschaften über die Befriedigung existentieller Grundbedürfnisse hinaus ganz entschieden die Überlebens- und Reproduktionschancen und verbessern - gewissermaßen als Mehrwert - überdies die Aussichten auf Wohlfahrt, Komfort, Bildung, Unterhaltung und einen gewissen Luxus. Dies spiegeln auch die Siedlungsformen vom Dorf und der Ansiedlung an Herrschersitzen (wie Gütern, Burgen, Schlössern) bis hin zur Stadt, die als erweiterte Burganlage befestigt und von Mauern umgeben zum Inbegriff des sicheren Ortes wurde.

Jenseits der z.T. sehr scharf konturierten Ränder oder Außengrenzen solcher Sozialsysteme beginnen fremde, ungeschützte und deshalb gefährliche Gefilde, die konnotiert sind mit Unsicherheit, Angst, aus denen schließlich Feindschaft gegenüber rivalisierenden oder konkurrierenden Gemeinschaften oder Gesellschaften entsteht. Als wie bedeutend der Schutz durch die Gemeinschaft bzw. die Sicherheit in der Gemeinschaft einzuschätzen ist, lässt sich erahnen, wenn man an Strafen wie die Verbannung oder den Ausschluss aus der Community denkt.

Das vielleicht wichtigste kognitiv-soziale Bindemittel stellen aber Konventionen dar. Sie wirken genau an der Schnittstelle von Kognition und Sozialsystem. Die Relevanz von Konventionen für die Regulation und Koordination des Handelns kognitiv autonomer Systeme kann schwerlich überschätzt werden. Konventionen sind neben affektiven Bindungen durch Abstammung, Verwandtschaft oder Freundschaft gewissermaßen der Kit, der größere soziale Gebilde zusammenhält. Der sozial-kognitive Konventionenbegriff von David Lewis schlägt mit dem Konzept der ErwartungsErwartungen eine Brücke zwischen kognitiver Autonomie und sozialer Regulation.

„Wir (als Interaktionspartner in einer bestimmten sozialen Gruppe bzw. als deren Beobachter, GR) erwerben schließlich eine allgemeine, zeitlich unbeschränkte Überzeugung, dass Mitglieder einer bestimmten Gruppe bei einer bestimmten Art wiederkehrender Koordinationsprobleme zum Zweck der Koordination einer gewissen Regularität folgen. Jede neue in Übereinstimmung mit der Regularität erfolgte Handlung verstärkt unsere Erfahrung von der allgemeinen Befolgung dieser Regu- 
larität. ... Ist der Prozess einmal in Gang gekommen, so haben wir ein metastabiles, sich selbst perpetuierendes System von Präferenzen, Erwartungen und Handlungen, das in der Lage ist, unbegrenzt lange fortzubestehen. Solange allgemeine Befolgung zu einem koordinativen Gleichgewicht führt, so dass jeder sie üben will, sofern die anderen das Gleiche tun, bewirken regularitätskonforme Handlungen Erwartungen konformer Handlungen, und Erwartungen konformer Handlungen regularitätskonforme Handlungen. Dies ist das Phänomen, das ich Konvention nenne." (Lewis 1975, S. 42 f; Hervorhebung GR)

Dieses Prinzip lässt uns verstehen, wie soziale Regulation unter Bedingungen kognitiver Autonomie überhaupt möglich ist. Wir sehen darin, wie Bedingungen und Möglichkeiten sozialer Interaktionen gewissermaßen „unter die Haut gehen“ und wie sich umgekehrt das Denken in der Handlungsplanung und -ausführung der beteiligten Akteure (in Gestalt eben solcher Erwartungs-Erwartungen) in der sozialen Interaktion ausdrückt und wiederkehrende Interaktionsmuster als soziale Strukturen entstehen lässt. Gesellschaft, Staat und Verfassung werden sozusagen tagtäglich aufgrund der Bereitschaft der Gesellschaftsmitglieder reproduziert, sich erwartungskonform zu verhalten und Erwartungskonformität von anderen zu erwarten. Wird diese Bereitschaft nicht mehr aufgebracht, zerfällt die politische Ordnung und gesellschaftliche Organisation. ${ }^{4}$

Was bedeuten Konventionen nun aus sicherheitstheoretischer Perspektive? Zunächst ist hier zu nennen die höhere Geschwindigkeit und Zuverlässigkeit, mit der bekannte Koordinations- und Orientierungsaufgaben bzw. Probleme bewältigt werden können. Sodann, und darauf war bereits verwiesen worden, spielt die Bindung durch Gleichartigkeit, Konsens und vor allem durch Vertrauen eine

4 Darin erweist sich dieser Ansatz zudem als kompatibel mit dem Konzept der sozialen Figurationen (vgl. Elias 1977), die die vielen Einzel-Akteure in ihrem Zusammenwirken gemeinsam (teils intentional, teils als unbeabsichtigte Konsequenz ihres Handelns) im Sinne sozialer Strukturationen (vgl. Giddens 1988) erzeugen, und die dann durch die Fortsetzung konformen Handelns als soziale Systeme stabilisiert, weiter entwickelt und ausdifferenziert werden können. Im Gegensatz zu biologischen, lebenden Systemen (also Organismen) sind soziale Systeme unter diesen Voraussetzungen operational prinzipiell offen und sogar organisationell plastisch, da ihre Komponenten, nämlich kognitiv autonome Systeme, nur relativ lose miteinander gekoppelt sind. Deshalb bietet, was für biologische Systeme so gar nicht möglich ist, die strukturelle und organisationelle Flexibilität sozialer Systeme nicht nur erweiterte Spielräume für die Selbstorganisation, sondern eröffnet überhaupt erst die Möglichkeit der Organisationsgestaltung, der Re-Organisation bzw. des Organisationsmanagements. Auf gesellschaftlicher Ebene eröffnet sich damit die Möglichkeit der politischen Gestaltung und der Veränderung von sozialen Strukturen, Funktionen und Verhältnissen. Der Gedanke der aufgetauten, chronisch flüssigen bzw. fluiden Organisation setzt diese Eigenschaft sozialer und sozio-technischer Systeme und ihren fundamentalen Unterschied zu biologischen Systemen grundsätzlich voraus. Auch aus diesem Grund scheitert Luhmanns Theorie sozialer Systeme. (vgl. Hayek 1994; Weick 1977; Weber 1996; Rüegg-Stürm 2003) 
Ernst-von-Glasersfeld-Lectures | Gebhard Rusch

wichtige Rolle. Vertrauen, wie es durch wechselseitige Kalkulierbarkeit, und diese wiederum durch Verlässlichkeit im Handeln entsteht. Schließlich ist auch die Transparenz der sozialen Verhältnisse (Beziehungen, Strukturen, Funktionen) hervorzuheben, die sich für alle Beteiligten aus der Strukturationsleistung konventionalen gelingenden Handelns ergibt.

Fassen wir zusammen: Sicherheit wird sozial durch/als Kulturalisierung der Lebensbedingungen und Lebensverhältnisse (also durch Konventionalisierung, Institutionalisierung und Regulierung (z.B. durch Recht, Normen) im buchstäblichen Sinne gesellschaftlich produziert. Sicherheit ist deshalb stets etwas Gemachtes, mit dem Menschen auf anthropologische und soziobiologische Bedürfnisse und Bedarfslagen reagieren. Auch muss Sicherheit unter diesen kognitiven und sozialen Bedingungen immer wieder hergestellt und reproduziert werden. In dieser Eigenschaft ist Sicherheit stets relativ zu „erkannten“, „wahrgenommenen“ und „für relevant erachteten“ Bedrohungen, Gefahren, Unwägbarkeiten oder Risiken. Die kognitive und soziale Konstruktion solcher „Sicherheitsprobleme" erfolgt auf der Basis jeweils historischer Mindsets und im Hinblick auf Ziele, die über den Rahmen der unmittelbaren Problemlösung weit hinausreichen können, z.B. auf eventuelle Risiken von morgen, weitergehende politische oder ökonomische Ziele, Prävention und Preparedness. Sicherheit wird im Handeln und in den Interaktionen der vielen Einzelnen und durch soziale Strukturation (z.B. Vergemeinschaftung, Vergesellschaftung) dem Schicksalhaften, den Widerfahrnissen (als spontan und unerwartet eintretenden Ereignissen), dem Fremden (Unbekannten) und Unkalkulierbaren (weil nicht selbst Gemachten) entgegengestellt.

\section{Organisationale Sicherheit und Freiheit}

Auf organisationaler Ebene, d.h. auf der Meso-Ebene sozialer und soziotechnischer Systeme zeigt sich die Güte des organisationalen Prozessierens vor allem in seiner Effektivität, also der Ziel- bzw. Zwecktreue (Validität) und Prozesstreue (Reliabilität) sowie der Effzzienz, z.B. der Flüssigkeit (Fluidität) und Fortsetzbarkeit (Kontinuität), der Reibungslosigkeit der Abläufe, dem günstigen Verhältnis von Aufwand und Kosten usw.

Wieder entsteht Sicherheit (hier im Sinne von Security und Safety) für die betrieblichen EreignisSysteme (i.S.v. Ruegg-Stürm) und Prozessketten (z.B. in der Just-in-Time-Logistik) aus der dynamischen Stabilität und der Zuverlässigkeit, mit der die einzelnen Prozesse bestimmten Output generieren und das Gesamtsystem aus dem Zusammenspiel der Teilprozesse seine Leistung erbringt. Diese Leistung beschreibt sozusagen die System- oder Prozess-Mächtigkeit der Organisation, in der sich auch so etwas wie die Prozess-Beherrschung und schließlich so etwas wie Organisations-Gewissheit artikulieren, alles Ausdruck der System- oder Organisationsgüte, Ausdruck einer organisationalen Kompetenz, also eines organisationalen und systemischen Knowhows, das im Handeln des Managements und der Mitarbeiter verkörpert wird. Fluidität und Prozess-Kontinuität (i.e. Business Continuity) sind deshalb Ausdruck organisationaler Sicherheit. Deshalb stellt sie auch einen wesentlichen 
Faktor im Qualitätsmanagement und eine wesentliche Bedingung für Vertragsfähigkeit und Vertragstreue dar.

Dass Prozess-Sicherheit (Safety) - wie im sozialen Feld durch Konventionalisierung - im technologischen Bereich durch Standardisierung, Normung oder Definition von Service Levels gefördert wird, liefert eine zusätzliche Bestätigung dafür.

Halten wir fest: Sicherheit ist etwas kognitiv und organisational Gemachtes, aktiv Produziertes, das prinzipiell immer wieder hergestellt, immer wieder (tagtäglich) reproduziert werden kann und muss. Sicherheit ist relativ zu wahrgenommenen, erkannten, als relevant erachteten Irritationen von Handlungsmächtigkeit oder Handlungsgüte, organisationaler oder prozessualer Kontinuität. Entsprechend relativ sind Sicherheitsprobleme sowie Schutz- und Vorsorge-Ziele. Auch auf organisationaler gesellschaftlicher Ebene besteht der gleiche systemische Zusammenhang zwischen Sicherheit und Freiheit. Genau deshalb besteht das Geschäft kluger Politik in der Balance von Beschränkung (Verbote) und Erringung/Gewährung von Freiheiten (Rechten) mit spezifischer temporaler, spatialer, personaler, organisationaler oder operationaler Geltungssteuerung. Mehr noch: die durch Verbote wirksamen Einschränkungen von Freiheiten werden zugleich als Schutzrechte (i.e. Schutz vor dem Verbotenen) reklamierbar. Auf diese Weise können Verbote für viele Bürger (z.B. für die Mehrheit) operational irrelevant sein, nur für eine tolerierbare kurze Dauer (z.B. Ausnahmezustand) gelten, nur in einer dem Alltagsleben fernen Zone (z.B. Sondergebieten) wirksam sein, nur für bestimmte Einzelpersonen (z.B. im Aufenthaltsrecht) oder Personengruppen (z.B. bei kriminellen Vereinigungen) Geltung haben. Freiheit und Sicherheit sind unter den einzelnen Akteuren, selbst wenn sie vor dem Gesetz gleich sind, in den Gesellschaften grundsätzlich nicht gleichverteilt. Auch deshalb ist die eine und gleiche Sicherheit für alle genauso eine Fiktion wie die eine und gleiche Freiheit für alle.

Quelle und Basis von Sicherheit für die Subjekte als Mitglieder von Gesellschaft sind stets deren jeweiliges freies Denken und Handeln. Deshalb ist auch die Sicherheit von Gesellschaft als Ganzer letztlich nur als die Sicherheit des freien Denkens und Handelns ihrer Mitglieder vorstellbar. Und aus diesem Grund sind die Mittel der Sicherheitsproduktion auch auf gesellschaftlicher Ebene niemals nur die Mittel des staatlichen oder organisationalen Risikomanagements, also etwa der zivilen oder militärischen Gefahrenabwehr, des Bevölkerungsschutzes oder der Katastrophenvorsorge, sondern vor allem die Mittel der Politik, also der Gesetzgebung und der politischen Ordnung. Das hat auch die auf alle gesellschaftlichen Bereiche durchschlagende Konsequenz, dass alle sozial-, wirtschafts- oder kulturpolitischen Entscheidungen für Gesellschaften immer sicherheitsrelevant sind, da sie stets die Lebensbedingungen, mithin die Denk- und Handlungsmöglichkeiten der Bürger betreffen. Fassen wir zusammen: Angesichts der grundlegenden Bedeutung, die Handlungsmächtigkeit und Handlungssouveränität in unserer Argumentation zukommt, ist es selbstverständlich auch kein Zufall, dass die Bewältigung des Alltags am besten in Routinen, Ritualen und Praktiken gelingt, und dass es solche Regularitäten, Stereotypen und Wiederholungen (i.e. Gewohnheiten) sind, die den Alltag als solchen geradezu verkörpern und zugleich für seine tagtägliche Reinstan- 
tiierung sorgen, was ihn als Ort der Stabilität und Sicherheit auszeichnet. Auf sozialer Ebene sind es z.B. Konventionen und Institutionen, die in Interaktion und Kommunikation für Stabilisierung, Kalkulierbarkeit und Wiedererkennbarkeit der Verhältnisse sorgen und dadurch wiederum die Anschlussfähigkeit eigenen Handels sichern. In beiden Fällen, für das Individuum und für die Gesellschaft, bieten solche Sicherheiten als die Geschäftsgrundlagen des Lebens zugleich jene Freiheiten, aus denen heraus und auf deren Grundlage jeweils Neues und Anderes entstehen kann.

Mit der Flüssigkeit und Fortsetzbarkeit des Operierens von Systemen sind somit zwei systemische Kriterien gewonnen, mit und an denen sich Begriffe der Sicherheit und Freiheit operational (d.h. systemintern) bestimmen und sogar quantifizieren, also nach ihrer Intensität im Selbst-Erleben und ihrer Reichweite im operationalen Raum bemessen lassen. Geht man diesen Weg weiter, so steht eine Theorie von Sicherheit und Freiheit in Aussicht, die nicht das eine gegen das andere ausspielt, sondern deutlich werden lässt, dass jede Einschränkung von Freiheit stets Unsicherheit erzeugt, und dass mehr Sicherheit letztlich nur durch mehr Freiheit erreicht werden kann.

\section{Unsicherheit und Unfreiheit}

Setzen wir nun den positiven Sicherheitsbegriff unseres operational-systemischen Ansatzes voraus, der Sicherheit nicht nur als pragmatisch möglich, sondern sogar als Symptom entwickelter Kognition und Handlungsfähigkeit und als Prozessmodus vitaler Organisationen ansieht, entsteht Unsicherheit entsprechend aus der Irritation von Handlungsmächtigkeit, Handlungsgüte oder organisationalem Prozessieren.

Was kann Irritationen im Ablauf von Handlungen heißen? Die folgende Liste ist sicher nicht vollständig, gibt aber einen Eindruck davon, welche Formen von Störungen des Operierens (z.B. von Handlungsvollzügen oder auch organisationalen Prozessen) als Quellen von Unsicherheit zu bedenken sind. Unter den möglichen Ursachen solcher Störungen ist stets auch ein Mangelan Ressourcen für die Initiierung und Fortsetzung von Handlungen oder die Aufrechterhaltung von Prozessen anzusetzen.

Als Erstes wären als solche Irritationen hier wohl Behinderungen in der Erreichung von Zielen zu nennen, die Verzögerungen oder die Erhöhung von Aufwand bedeuten. Die Handlungsausführung wird in solchem Fall ohne Unterbrechung fortgesetzt, jedoch erhöhen sich Dauer, Wegstrecken, Energieaufwände, etc. Dies ist z.B. der Fall bei Umleitungen im Straßenverkehr oder bei der Reduzierung von Fahrgeschwindigkeiten durch hohes Verkehrsaufkommen, aber auch bei Ablenkungen von einer Aufgabe, bei Erschwernissen der Handlungsausführung etwa durch Konzentrationsschwächen oder Widerstände (wie z.B. Gegenwind bei Radfahren).

Sodann kann an man das Stocken von Operationen, Handlungsausführungen oder Prozessen denken, z.B. durch den vorübergehenden Ausfall von Teilprozessen, also an Unterbrechungen oder Pausen, nach denen es zur Wiederaufnahme bzw. Fortsetzung eines begonnenen Vorganges kommt. 
Der Vortrag eines auswendig gelernten Gedichtes stockt, wenn der Rezitator sich z.B. verspricht (und daraufhin korrigiert) oder ihm der nächste Vers nicht gleich einfällt und so eine ,Kunstpause“ entsteht. Die Montage eines Produktes stockt, wenn ein benötigtes Werkzeug verlegt oder nach Montagematerial erst noch gesucht werden muss. Der Straßenverkehr stockt, wenn die Verkehrsdichte zu hoch ist, sich ein Unfall ereignet oder wenn es aus anderen Gründen, z.B. wegen Verkehrskontrollen zu Stopp \& Go oder zum Stau kommt.

Schließlich kann es auch zum Versagen von Kompetenzen oder Leistungen, d.h. zum Aus- bzw. Unterbleiben von Leistungen kommen oder zum vollständigen Abbruch eines Vorgangs. Bleiben Leistungen vollständig (und nicht nur kurzzeitig oder vorübergehend) aus, die zuvor bereits schon erbracht wurden bzw. im Prinzip erbracht werden können, so spricht man von Versagen, bei Material-Leistungen von Bruch (z.B. beim Defekt eines Wellenlagers). Verlässt den Rezitator komplett die Erinnerung an die nächsten Zeilen des gelernten Gedichts, bricht der Vortrag an der Stelle ab. Gelangen Montageteile in einer Just-in-Time-Produktion nicht an den Ort, an dem sie benötigt werden, kommt die ganze Produktionskette zum Stillstand. Kommt es in ökonomischen Systemen zu einer kritischen Asymmetrie in der Verteilung von Ressourcen (z.B. am Kapitalmarkt durch die Bildung sog. Investitionsblasen), bedeutet dies ein komplettes Marktversagen, das nur durch Interventionen von Außen (z.B. durch politische Maßnahmen) korrigiert werden kann.

Häufig entstehen Irritationen der Systemdynamik auch durch Fehler, also durch situativ, zeitlich oder operativ unpassende falsche Leistung oder Fehlleistung. Wird in einem situativen bzw. prozessualen Kontext eine Leistung z.B. nur unvollständig (d.h. es fehlt mindestens irgendein Prozesselement) erbracht oder werden von den in diesem Zusammenhang bekanntermaßen erfolgreichen und üblichen Leistungen abweichende Leistungen erbracht, so bleibt der Erfolg stets aus, wenn die Leistungsäquivalenz der Handlungen oder Prozesse nicht gegeben ist. In diesen Fällen spricht man von Fehlern. Ein Fehler ist also eine (1) im jeweiligen Kontext (2) mit Blick auf das erwartete Ergebnis/Resultat und (3) im Vergleich mit erfolgreichen Lösungen nicht äquivalente Leistung. Eine Leistung stellen Fehler allerdings schon deshalb dar, weil sie schließlich aktiv gemacht werden. Erheblich schwerwiegender als alle bislang genannten Irritationen ist die Verminderung von (Handlungs-)Möglichkeiten, wie sie als Blockade einzelner Operationen, als Zwang zum Ausweichen oder Zwang zu Alternativoperationen spürbar werden kann. Der Verringerung von Handlungsoptionen (i.S. zielführender Alternativen zu den gewöhnlichen oder präferierten Lösungen) tritt in krisenhaften oder katastrophisch eskalierenden Lagen als Erfahrung zunehmender Ausweglosigkeit, auch des in der Situation Gefangen-Seins in Erscheinung. Analog kann dies auch als Verknappung von Ressourcen (Zeit, Fluchtwege, Wissen über Gegenmaßnahmen etc.) bzw. als fortschreitende Verminderung der Ressourcenverfügbarkeit diskutiert werden.

Schließlich stellt die Verunmöglichung jedes weiteren Operierens, also die Blockade jeder physischen Operation, die zeitliche, räumliche, situative und operative nahezu maximale Beschränkung 5 , Ohn-

5 Die maximale Beschränkung entspricht dann der letalen System-Dissoziation. 
Ernst-von-Glasersfeld-Lectures | Gebhard Rusch

macht i.S.d. Verlustes jeglicher Handlungsmacht, die völlige Alternativlosigkeit oder der Zwang zur Schicksalsergebenheit die stärkste Form von Irritation dar. Eine solche Zwangslage kann veranschaulicht werden am Beispiel von Verschütteten, deren Lage keine Körperbewegung mehr zulässt, oder mit Blick auf die Situation von Erdbeben-Opfern, deren ganze Welt in einem Moment in Schutt und Asche fällt, oder auch am Beispiel von Tsunami-Opfern, die angesichts der auf sie zurollenden Flutwelle ihre verzweifelte Lage realisieren. Auf organisationaler Ebene, etwa am Beispiel von Unternehmen, entspricht eine solche Lage z.B. der Insolvenz, also letztlich einem Totalverlust der für die Aufrechterhaltung des Systems nötigen Ressourcen.

\section{Fazit}

\section{Erste Schlussfolgerung: Positiver Sicherheitsbegriff}

Die bisherigen Überlegungen zeigen, dass der Begriff der (operationalen) Sicherheit positiv bestimmt werden kann als Eigenschaft eines Tuns, in dem sich die Handlungssouveränität des Akteurs sowohl als Fertigkeit (in der Qualität der Ausführung der Handlung) wie auch als Fähigkeit (in der situativ gebundenen Entscheidung für die Ausführung, und sodann in der Fortsetzung und Vollendung der Handlung) artikuliert. Deshalb trifft es nicht zu, dass der Begriff der Sicherheit nur ex negativo bestimmt werden könne über einen Begriff von Unsicherheit oder aus der Betrachtung all dessen, was Sicherheit vermindere oder bedrohe. Man muss also die Dialektik von Sicherheit und Unsicherheit nicht bedienen, weil Sicherheit positiv durch das Vorhandensein spezifischer Bedingungen für das Operieren von Systemen, und nicht nur negativ durch das Fehlen oder die Abwesenheit von Bedrohungen oder Gefahren zu charakterisieren ist.

\section{Zweite Schlussfolgerung: Positive Korrelation von Sicherheit und Freiheit}

In der operationalen Selbstbestimmung im Handeln (Intentionalität), in der flüssigen Handlungsausführung (Fluidität) und in der Zielerreichung durch die Fortführung und Vollendung des Handelns (Kontinuität) fällt die größtmögliche Sicherheit mit der größtmöglichen Freiheit (Freedom und Liberty) zusammen. Im Handeln sind operationale Freiheit und Sicherheit äquivalent. Die im kompetenten Handeln erfahrene Sicherheit in den Anmutungen und Begriffen flüssiger und erfolgreicher Handlungsausführung ist zugleich Ausdruck höchster (Handlungs-)Freiheit, Ausdruck maximaler operationaler Freiheit. Sicherheit (als Operational Security) und Freiheit (als Operational Freedom) erweisen sich so als Seiten derselben Medaille: des guten Gelingens von Handlungen. Sicherheit und Freiheit erweisen sich darin aber auch als spezifische Handlungseigenschaften, und zwar als Affekt des Zutrauens bzw. Vertrauens in eigene Kompetenz (i.e. Security), als Erwartungsgewissheit 
mit Blick auf das Gelingen der Handlungsausführung und die Erreichung der Handlungsziele (i.e. Safety), als Erfahrung von Flüssigkeit und Kontinuität in der Handlungsausführung (i.e. Freedom) sowie als Erfahrung und Wissen von Selbstbestimmtheit und Selbstwirksamkeit (i.e. Liberty).

\section{Dritte Schlussfolgerung: Operationale Relativität}

Freiheit und Sicherheit gibt es nur im Plural; die Bindung der Attribute Sicherheit und Freiheit an (wie immer komplexe) Handlungen führt zu einer entsprechenden operationalen Relativierung; so viele Sicherheiten wie gelingende Handlungen, so viele Freiheiten wie fluide und kontinuierliche Handlungsvollzüge, so viele Unsicherheiten wie Irritationen im Handeln, so viele Unfreiheiten wie Handlungsbeschränkungen. Deshalb können Sicherheiten und Freiheiten nur über das tatsächliche Handeln und Wollen von Akteuren, nur mit Blick auf deren Handlungsziele und die konkreten Modalitäten der Zielerreichung und nur durch die Betrachtung der tatsächlichen Leistungen und Ziele von Organisationen bilanziert und kalkuliert werden.

Dies hat die fatale Konsequenz, dass die Unsicherheit mit dem Streben nach Perfektion und die Unfreiheit mit dem Wissen von potentiellen Handlungs- oder Operationsmöglichkeiten zunimmt. Man realisiert eben letztlich nur die Freiheiten, die man sich nimmt - und die Unfreiheiten, die man sich dadurch zumutet. Deshalb ist davon auszugehen, dass jeder seine eigenen (Un-)Sicherheiten und (Un-)Freiheiten in und mit seinem Handeln kreiert.

\section{Vierte Schlussfolgerung: Skalierbarkeit und Verteilung}

Sicherheit und Freiheit sind nicht absolut oder total, sondern partiell und graduell. Für jeden Einzelnen gibt es im Handeln und für jede Organisation im Prozessieren fallweise mehr oder weniger Sicherheiten und Freiheiten. Schon in den unterschiedlichen Lebensphasen vom Kindes- bis ins Seniorenalter und in den unterschiedlichen Lebensbereichen des Menschen (z.B. im Privat- und im Berufsleben) ist dieses Mehr oder Weniger von Freiheiten und Sicherheiten unmittelbar zu erfahren. Erst recht zeigen Zwangslagen im Vergleich mit Perioden des Easy Going, wie groß die Bandbreite im Erleben von Unfreiheiten oder Sicherheiten sein kann - und wie klein manchmal die Differenz im Handeln oder im Prozess.

Auch das Erleben von Freiheiten in Diktaturen oder Sicherheiten in Katastrophen kann deshalb keine Überraschung sein. Es sind wohl nicht nur politische Ignoranz oder innere Emigration, sondern ganz pragmatische kognitive und soziale Faktoren, die das „kleine Glück“ auch noch unter den widrigsten Umständen zulassen. Wenn das so ist, dann sind Sicherheiten und Freiheiten (ebenso wie Unsicherheiten und Unfreiheiten) also nicht nur im persönlichen Leben jedes Einzelnen, sondern auch unter den Gesellschaftsmitgliedern mit ihren Kompetenzen und ihrem Streben ungleich verteilt. 
Ernst-von-Glasersfeld-Lectures | Gebhard Rusch

\section{Fünfte Schlussfolgerung: Balance von (Un-)Sicherheit und (Un-)Freiheit}

Die kontinuierliche Balance von (Un-)Sicherheit und (Un-)Freiheit gehört genauso zum Management persönlicher und organisationaler Identität, wie die permanente Konfrontation des eigenen Selbstbildes mit fremden Identitätszuschreibungen. Vielleicht bringt das Konzept der Selbstverwirklichung diese beiden Aspekte in der Konstruktion des Selbst sogar am besten auf den Begriff. Die Sicherheiten und Freiheiten, die jemand für sich in seinen sozialen Umfeldern gewinnen, erhalten und entwickeln kann, sind nicht nur Ausdruck seiner Handlungsmächtigkeit, sondern prägen und charakterisieren wesentlich seine Persönlichkeit.

Dazu gehört dann aber mit konkreter werdenden Selbstkonzepten auch die Fähigkeit, auf manche Sicherheiten und Freiheiten (letztlich) bewusst und freiwillig zu verzichten, d.h. zugleich manche Unsicherheiten und Unfreiheiten zu tolerieren oder zu akzeptieren, z.B. Risiken einzugehen, nach Recht und Gesetz zu handeln, Affekte zu kontrollieren. Nicht erst an dieser Stelle zeigt die Untersuchung des Sicherheits- und Freiheitsmanagements seine ethische Dimension. Zwar kann der Verzicht auf manche Freiheit (schon mit Blick auf das entsprechende unterlassene Handeln) nicht mehr Sicherheit schaffen, eröffnet aber neue Sicherheits- und Freiheitschancen in anderem Handeln. Nur so kann das ethische Kalkül z.B. des kategorischen Imperativs (I. Kant), aber ebenso das Recht überhaupt produktiv werden.

\section{Letzte Schlussfolgerung: Sicherheits- und Freiheitspolitik}

Es entspricht unseren Wirklichkeitsmodellen, Sicherheitsfragen vordergründig unter Gefahrenoder Bedrohungsaspekten zu diskutieren, also etwa mit Blick auf Äußere und Innere Sicherheit oder den Katastrophenschutz. Indem wir also Irritationsquellen für unser Handeln als (uns äußerliche) Gefahren oder Bedrohungen identifizieren (i.e. konstruieren), richten wir die Coping- bzw. Bewältigungsstrategien wiederum vordergründig auf Schutz vor und Abwehr von solchen Bedrohungen aus. Weil aber Schutz- und Abwehrmaßnahmen (wie immer sie technisch ausgestattet und beschaffen sein mögen) zuerst und zuletzt Veränderungen des Handelns sind (also entweder Modifikationen von Handlungen oder neue und zusätzliche Handlungsaufwände), ist die Bilanzierung von Sicherheits- und Freiheitsgewinnen fragwürdig.

Wenn das, was faktisch geschützt werden soll, wesentlich die Fortsetzung bisheriger Praktiken ist, und das, was abgewehrt werden soll, faktisch deren Irritationen (in Gestalt von Krankheiten, Feinden, Naturereignissen usw.) sind, dann wäre doch auch die Viabilität der schutzbedürftigen oder irritationsanfälligen Praktiken zu diskutieren. Die Besinnung auf die operationalen Bedingungen von Sicherheit richtet von vornherein die Aufmerksamkeit auch auf die Vermeidung problematischen Handelns und auf die Suche nach (weniger kritischen) Substitutionshandlungen als Copingstrategien und lässt fragen, wie es mit der Sicherheit der Schutz- und Abwehrmaßnahmen selbst steht, 
von wem sie auf welche Weise geleistet werden können oder sollen, und wie nachhaltig sie sind. Zu fragen ist immer auch, wer oder was und welche Praktiken geschützt werden sollen und warum. All dies sind hochpolitische Fragen, die auch in demokratischen Gesellschaften und durch bürgerliches Recht nur teilweise ordnungspolitisch vorstrukturiert oder geregelt sind. Jenseits solcher verfassungsmäßigen und rechtlichen Orientierungen sind wieder alle Fragen offen.

Das zeigen drei aktuelle Fragen aus dem laufenden gesellschaftlichen Sicherheitsdiskurs, eine zur äußeren und eine zur inneren Sicherheit, die dritte zu einem aktuellen Problem konfligierender Freiheitsrechte:

1. Werden Sicherheit und Freiheit von EU-Bürgern tatsächlich durch Mauern und Stacheldraht an den südlichen Außengrenzen erhöht?

2. Wie steht es eigentlich um die sicherheitspolitische Bedeutung des Mindestlohns?

3. Wie können im Zusammenleben der Menschen Konflikte zwischen verfassungsmäßig garantierten Freiheitsrechten, z.B. der Freiheit der Kunst im Verhältnis zur Freiheit des Glaubens und der Religionsausübung vermieden oder gelöst werden?

\section{Literatur}

Ulrich Beck (1986): Risikogesellschaft. Auf dem Weg in eine andere Moderne. Frankfurt a.M.: Suhrkamp.

Buzan, Barry; Wæver, Ole; Wilde, Jaap de (1998): Security. A new framework for analysis. Boulder: Lynne Rienner.

Ciompi, Luc (1997): Die emotionalen Grundlagen des Denkens. Entwurf einer fraktalen Affektlogik. Göttingen: Vandenhoeck \& Ruprecht.

Daase, Christopher (2011): Der Wandel der Sicherheitskultur - Ursachen und Folgen des erweiterten Sicherheitsbegriffs. In: Zoche, Peter; Kaufmann, Stefan; Haverkamp, Rita (Hrsg.): Zivile Sicherheit. Bielefeld: transcript, S. 139-158.

Daase, Christopher; Deitelhoff, Nicole (2013): Privatisierung von Sicherheit. In: Schiller, Jochen; Gerhold, Lars; Steiger, Saskia; Jäckel, Helga (Hrsg.): Forschungsforum Öffentliche Sicherheit. Schriftenreihe Sicherheit Nr. 11. Berlin.

Elias, Norbert (1977): Über den Prozeß der Zivilisation. Bd. 1. Frankfurt/M: Suhrkamp.

Gerhold, Lars (2009): Umgang mit makrosozialer Unsicherheit. Zur individuellen Wahrnehmung und Bewältigung gesellschaftlich-politischer Phänomene. Lengerich: Pabst Science Publishers.

Giddens, Anthony (1988): Die Konstitution der Gesellschaft. Frankfurt/M., New York: Campus.

Giebel, Daniela (2012): Integrierte Sicherheitskommunikation. Zur Herausbildung von Unsicherheitsbewältigungskompetenzen durch und in Sicherheitskommunikation. Münster: LIT.

Gronemeyer, Axel (2010): Wege der Sicherheitsgesellschaft. Gesellschaftliche Transformationen der Konstruktion und Regulierung innerer Unsicherheit. Wiesbaden: VS. 
Ernst-von-Glasersfeld-Lectures | Gebhard Rusch

Hansen, Klaus P. (2003): Kultur und Kulturwissenschaft. Tübingen: A. Francke. (3. Auflage).

Hayek, Friedrich A. von (1994): Freiburger Studien. Gesammelte Aufsätze. Tübingen: Mohr-Siebeck. 2. Auflage.

Heinrich, Stephan; Lange Hans-Jürgen (2009): Erweiterung des Sicherheitsbegriffs. In: Lange, Hans-Jürgen; Ohly, H. Peter; Reichertz, Jo (Hrsg.): Auf der Suche nach neuer Sicherheit. Fakten, Theorien und Folgen. Wiesbaden: VS Verlag für Sozialwissenschaften, S. 253-268.

Johnson-Laird, Philip N. (1983): Mental Models: Toward a Cognitive Science of Language, Inference and Consciousness. Boston: Harvard University Press.

Kaufmann, Franz X.: (1973): Sicherheit als soziologisches und sozialpolitisches Problem. Stuttgart: Enke. 2. Auflage.

George Lakoff (2004): Don't Think of an Elephant: Know Your Values and Frame the Debate. White River Junction: Chelsea Green Publishing.

Leuschner, Sebastian (2014): EuGH und Vorratsdatenspeicherung: Emergenz eines Grundrechts auf Sicherheit?, VerfBlog, 2014/4/09, Abgerufen unter: http://www.verfassungsblog.de/ eugh-und-vorratsdatenspeicherung-emergenz-eines-grundrechts-auf-sicherheit/

Lindner, Joachim (2010): Sicherungskultur und Schutzkonzepte. Stuttgart: Steinbeis Edition

Lewis, David K. (1975): Konventionen. Eine sprachphilosophische Abhandlung. Berlin/New York: de Gruyter.

Mandl, Heinz \& Hans Spada (Hrsg.) (1988): Wissenspsychologie. München, Weinheim: PVU

Piaget, Jean (1975): Der Aufbau der Wirklichkeit beim Kinde. Gesammelte Werke Bd. 2. Studienausgabe. Stuttgart: Klett.

Piaget, Jean (1976): Die Äquilibration kognitiver Strukturen. Stuttgart: Klett.

Rüegg-Stürm, Johannes (2003): Organisation und organisationaler Wandel. Eine theoretische Erkundung aus konstruktivistischer Sicht. Opladen: Westdeutscher Verlag.

Schirmer, Werner (2008): Bedrohungskommunikation. Eine gesellschaftstheoretische Studie zu Sicherheit und Unsicherheit. Wiesbaden: VS Verlag für Sozialwissenschaften.

Singelnstein, T. \& P.Stolle (2006). Die Sicherheitsgesellschaft. Soziale Kontrolle im 21. Jahrhundert. Wiesbaden: VS.

Tyler, Edward Burnett (1871): Primitive Culture. London: John Murray.

Wæver, Ole (1995): "Securitization and Desecuritization." In: On Security, edited by Ronnie D. Lipschutz, 46-86. New York: Columbia University Press.

Weber, Burkhard (1996): Die fluide Organisation. Konzeptionelle Überlegungen für die Gestaltung und das Management von Unternehmen in hochdynamischen Umfeldern. Bern, Stuttgart, Wien: Haupt.

Weick, Karl E. (1977): Organization Design. Organizations as Self-designing Systems. Organizational Dynamics, 6 (2), S. 31-46.

Wolfers, Arnold (1962): National Security as an Ambiguous Symbol. In: Wolfers, Arnold (Hrsg.): Discord and Collaboration. Baltimore: Johns Hopkins Press. 


\section{Autor}

Gebhard Rusch, 1954 in Magdeburg geboren; Studium der Linguistik, Literaturwissenschaft, Geschichte und Philosophie in Bielefeld und Siegen, Promotion 1985, Habilitation in Medienwissenschaft 1998, seit 2004 Professor für Kommunikations- und Medienwissenschaft am Institut für Medienforschung der Universität Siegen. Schwerpunkte der Forschung und Lehre liegen in der Kommunikations- und Medientheorie, dem Medienwandel, der Organisations- und der Sicherheitskommunikation. 

Aus dem Archiv 



\title{
BANANA PERIOD - Ein Lichtprojekt an den Nahtstellen von Medienkunst und Wissenschaftskommunikation
}

\author{
Jona Hoier, Markus Murschitz und Theo Hug
}

\begin{abstract}
Zusammenfassung
Die vielfältigen Zusammenhänge von Technisierungsschüben und Kulturwandel betreffen nicht zuletzt auch die Technologien und Ästhetiken des Lichts. Hand in Hand mit den digitalen Entwicklungen sind neue Spielräume der Programmierung von Beleuchtungskörpern sowie responsiven Infrastrukturen und Interaktionsräumen entstanden. Das Ernst-von-Glasersfeld-Archiv setzt mit seinem EvG Lightwindow bei diesen Entwicklungen an im Hinblick auf die Gestaltung neuer Formen der Wissenschaftskommunikation im Spannungsfeld von Technik, Wissenschaft und Kunst. BANANA PERIOD ist eine Medieninstallation von Jona Hoier und Markus Murschitz im Rahmen des EvG Lightwindow Projekts. Sie thematisiert die Bildsprache Yerkish, welche von Ernst von Glasersfeld in den 1970ern entwickelt wurde, und deren Anwendung in sprachwissenschaftlichen Experimenten mit Schimpansen. Die Lichtinstallation lässt die Symbole der Bildsprache mittels moderner LED-Technologie auf ästhetische Weise wieder aufleuchten und belebt so aus dem Schaufenster des Ernst-von-Glasersfeld-Archivs den Innsbrucker Stadtkern.
\end{abstract}

\section{Yerkish und das Lana-Projekt}

Lange Zeit galt die These als richtig, dass Affen nicht in der Lage sind, Sprachen zu erlernen. Die ersten Schritte in Richtung einer Mensch-Affen-Kommunikation wurden in den späten 1960ern von Allen und Beatrix Gardner durchgeführt (vgl. Gardner 1969). Sie lehrten einen Schimpansen namens Washoe die amerikanische Gebärdensprache und widerlegten damit die geltenden Thesen. Ernst von Glasersfeld entwickelte 1971 mit Yerkish eine Sprache aus Wortsymbolen - sogenannten Lexigrammen. Mit Hilfe von Primatologen des Yerkes Center in Atlanta erstellte er dazu eine Liste von Dingen, „von denen man annehmen konnte, daß sie eine junge Schimpansin interessieren und im Rahmen des Projekts eine Rolle spielen würden“ (von Glasersfeld 2008, S. 209). Die Sprache wurde von Duane Rumbaugh und Sue Savage-Rumbaugh von der Georgia State University eingesetzt, um am Yerkes National Primate Research Center mit Affen zu kommunizieren. Yerkish hat gegenüber der amerikanischen Gebärdensprache (ASL) den Vorteil, dass die strenge Syntax eine durch den Computer automatisierte Analyse und Interpretation ermöglicht. 
Der erste Affe, der die Sprache spricht, ist die Schimpansin Lana. Wie in Abbildung 1 dargestellt konnte Lana über Druckschalter Yerkishsymbole in eine Maschine eingeben. So konnte sie um Unterhaltung oder Nahrung bitten. Das Angebot bestand aus Filmen, Milch, Obst und M\&M (Lanas Lieblingssüßigkeit). Ein Computer prüfte auf korrekte Grammatik und reagierte ausschließlich auf richtige Eingaben, wobei jegliche Kommunikation zur späteren Analyse aufgezeichnet wurde (siehe Abbildung 1 rechts). Innerhalb von nur zwei Wochen erlernte Lana einige einfache Aufforderungen wie zum Beispiel PLEASE MACHINE GIVE M\&M oder PLEASE MACHINE MAKE MOVIE. Zuätzlich bot die Maschine den Forschern die Möglichkeit, mit Lana Yerkish zu „sprechen“.
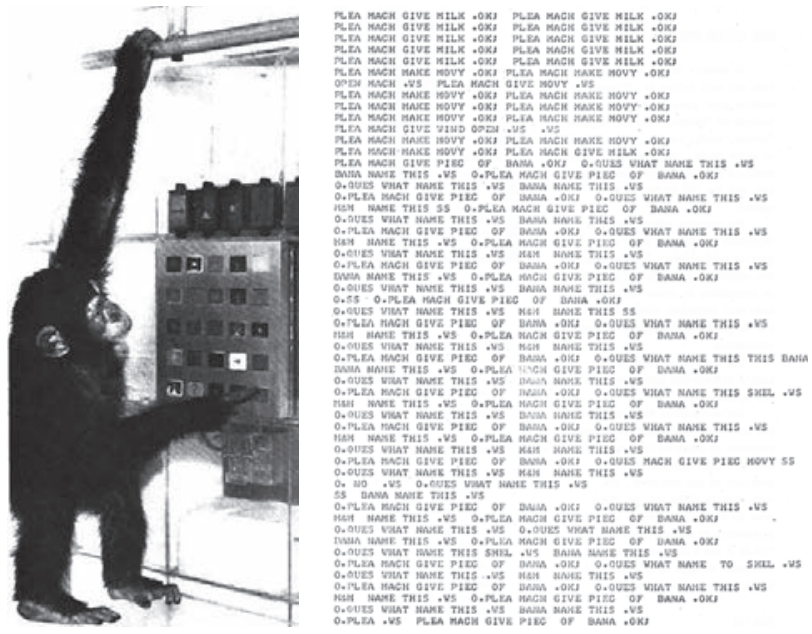

Abbildung 1: (links) Lana an der Lexigram Tastatur, Fotografie von Ernst von Glasersfeld (vgl. Bettoni 2007), (rechts) Auszug Protokoll (vgl. Cox 1973, S. 10).

Die Experimente mit Lana hatten zum Ziel, sowohl die linguistischen Fähigkeiten von Affen auszuloten als auch die Prozesse des Erlernens von Sprache an sich besser zu verstehen. Es gilt die Annahme, dass sich die Erkenntnisse auch auf den Menschen übertragen lassen (vgl. Cox 1973, S. 4). Yerkish wird nach wie vor weltweit in zahlreichen Forschungsinstitutionen "gesprochen" - heute sogar auch auf Touchscreens oder auf Tablet PCs.

\section{Die Installation}

BANANA PERIOD ist eine Interpretation der Maschine in Form eines überdimensionierten maßgefertigten LED-Displays im Schaufenster des Ernst-von-Glasersfeld-Archivs. Das Display ist in der Lage das gesamte Yerkish Vokabular abzubilden und die Symbolfolgen zeitbasiert darzustellen. Selektive Farben und Animationen ermöglichen die ästhetische Verschmelzung von geschichtsträchtiger Thematik, zeitgemäßen Technologien und der historischen Innsbrucker Altstadt. 


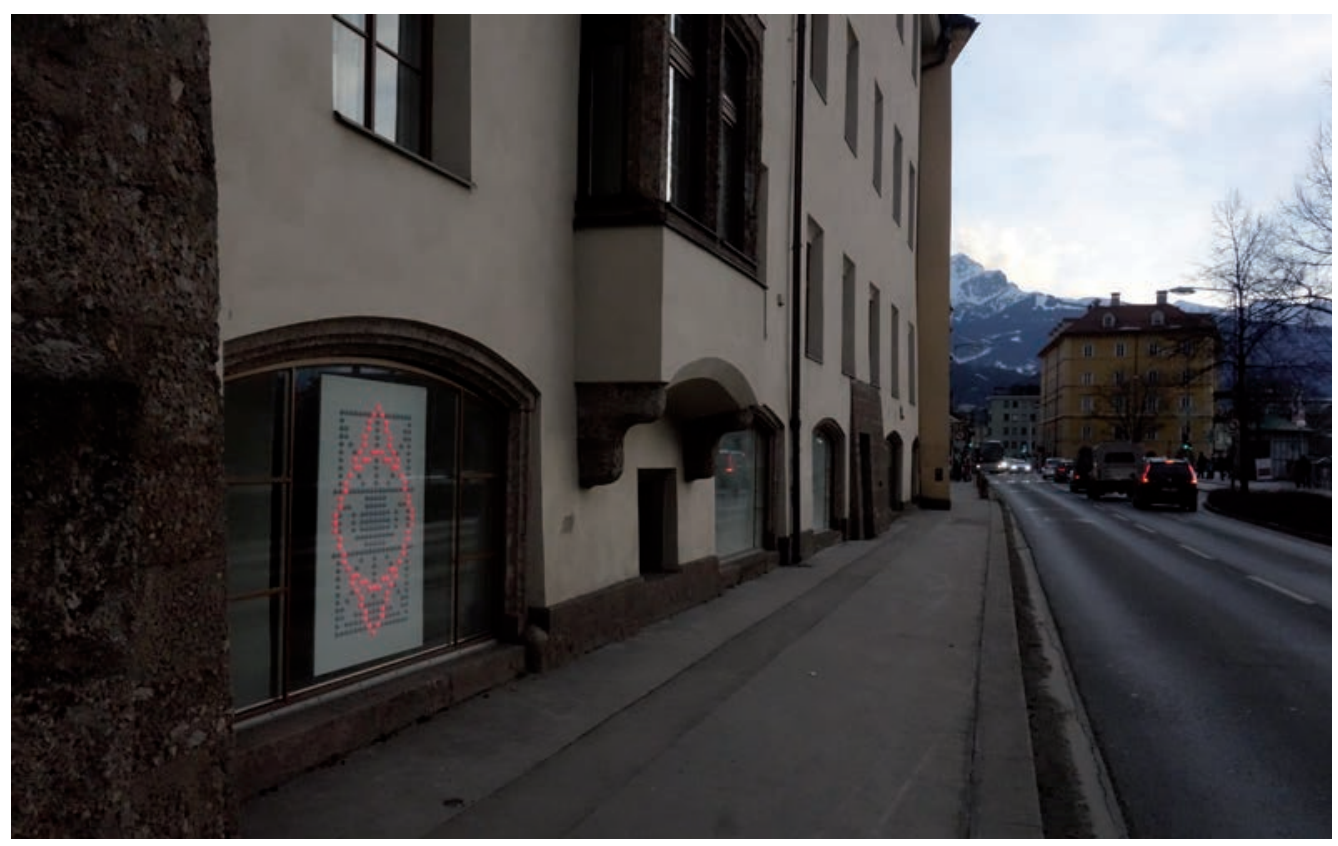

Abbildung 2: Ernst-von-Glasersfeld-Archiv Außenansicht mit BANANA PERIOD

Die Installation BANANA PERIOD reproduziert ein Protokoll zwischen Maschine und Lana (siehe Abbildung 1 rechts). Das Gespräch wurde über einen Zeitraum von ungefähr zwei Stunden aufgezeichnet. Es enthält neben einer Vielzahl von Wiederholungen von Essensanfragen auch Sätze, deren Bedeutung für uns Menschen zwar nachvollziehbar ist, aber von der Maschine aufgrund einfacher Syntaxfehler nicht akzeptiert wurde und so zu kuriosen Situationen in der Affen-MaschineKommunikation führte.

Ein Beispiel für so eine Situation ist, als Lana die Maschine fragte: QUESTION WHAT NAME THIS. Man kann sich beim Lesen des Protokolls vorstellen, dass Lana auf ein bestimmtes Objekt im Raum Bezug nahm und das zugehörige Symbol wissen wollte. Die Maschine akzeptierte die Frage jedoch aufgrund eines grammatikalischen Fehlers nicht, woraufhin Lana der Maschine erklärte: BANANA NAME THIS und schließlich die Aufforderung gab, dass die Maschine doch ein Stück Banane rausrücken soll: PLEASE MACHINE GIVE PIECE OF BANANA.

Das Protokoll spiegelt allgemein die der Sprache inhärenten und oft frustrierenden Eigenschaften wider - sie ist repetitiv und oft unzulänglich in der Mensch-Maschine-Affen-Kommunikation: manchmal einfach zum Verrücktwerden - just to go bananas. 


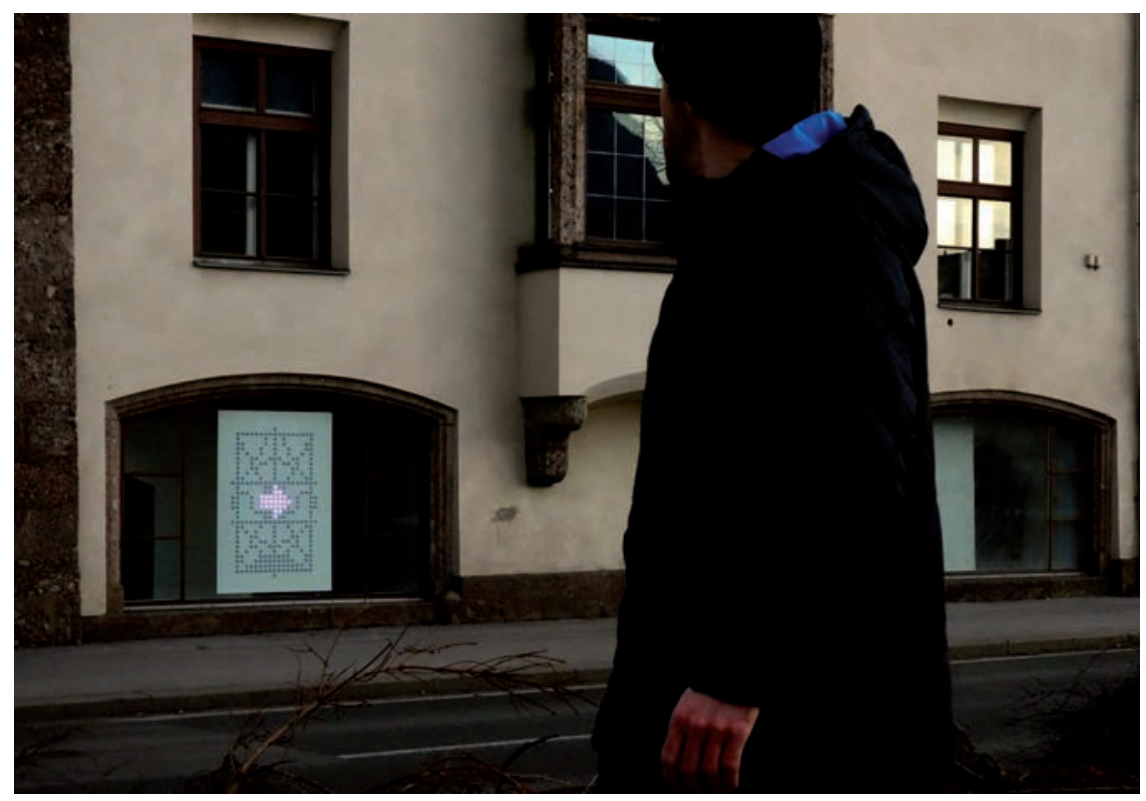

Abbildung 3: BANANA PERIOD bei Tag

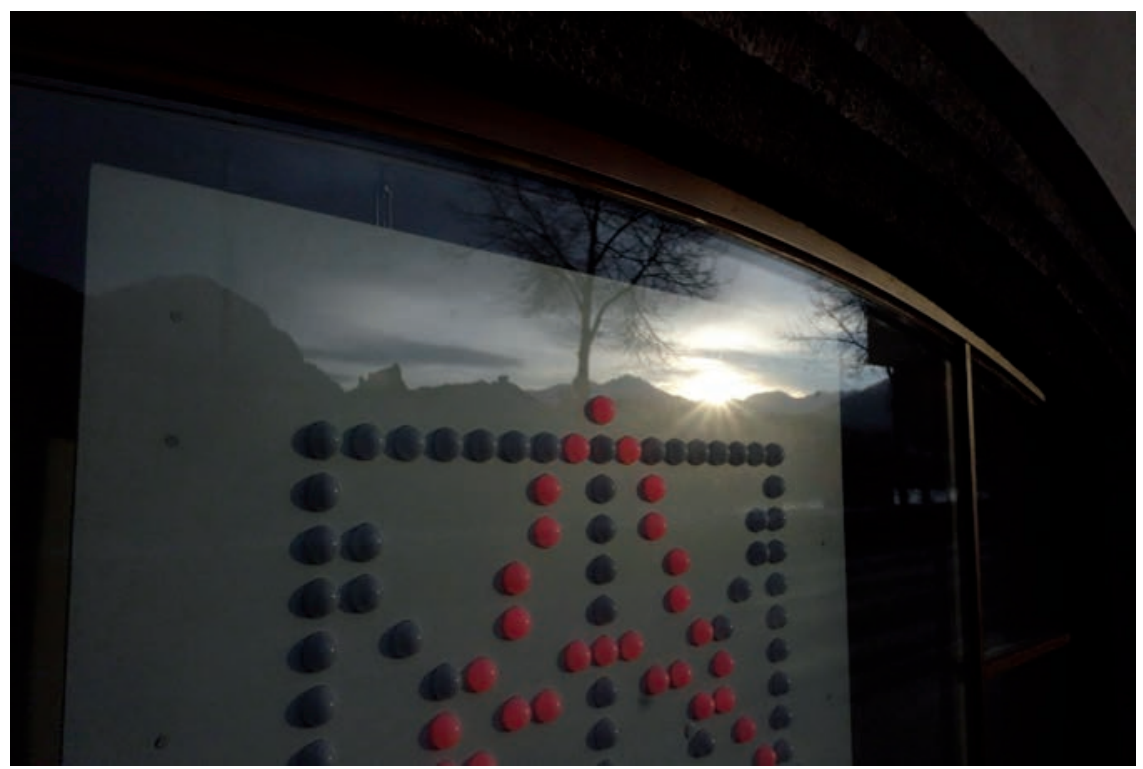

Abbildung 4: BANANA PERIOD bei Tag, Detailansicht 


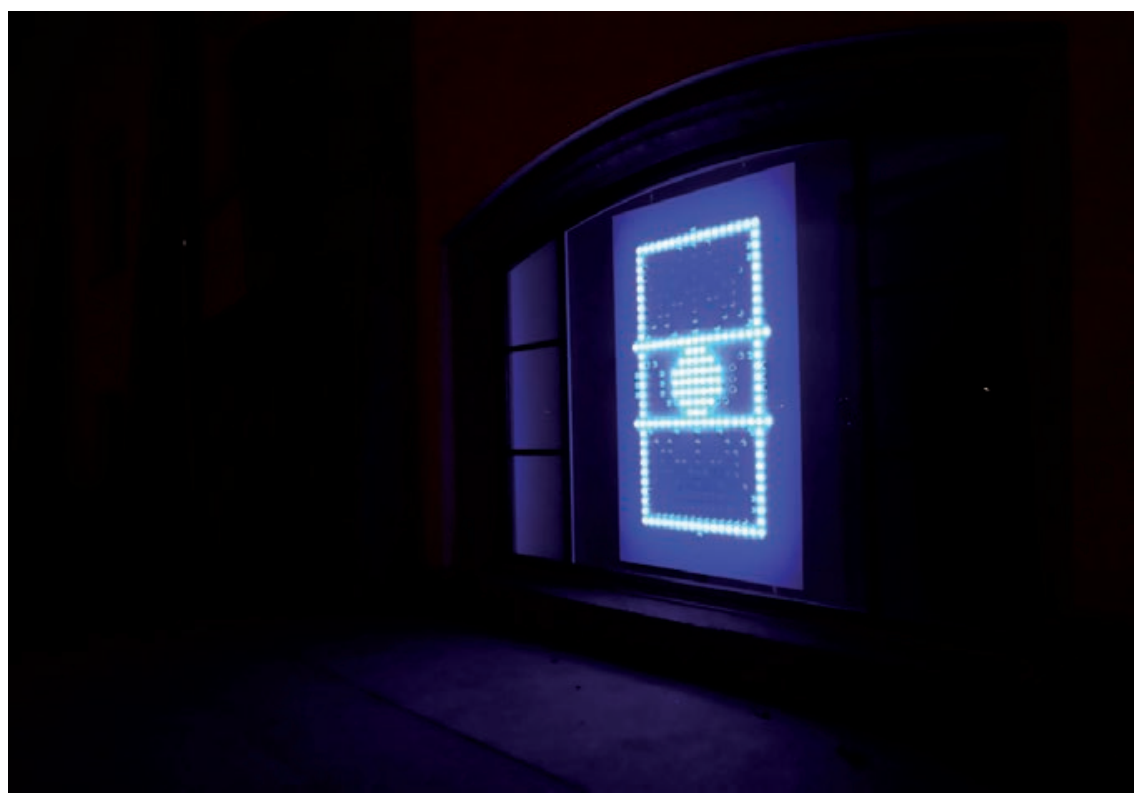

Abbildung 5: BANANA PERIOD bei Nacht

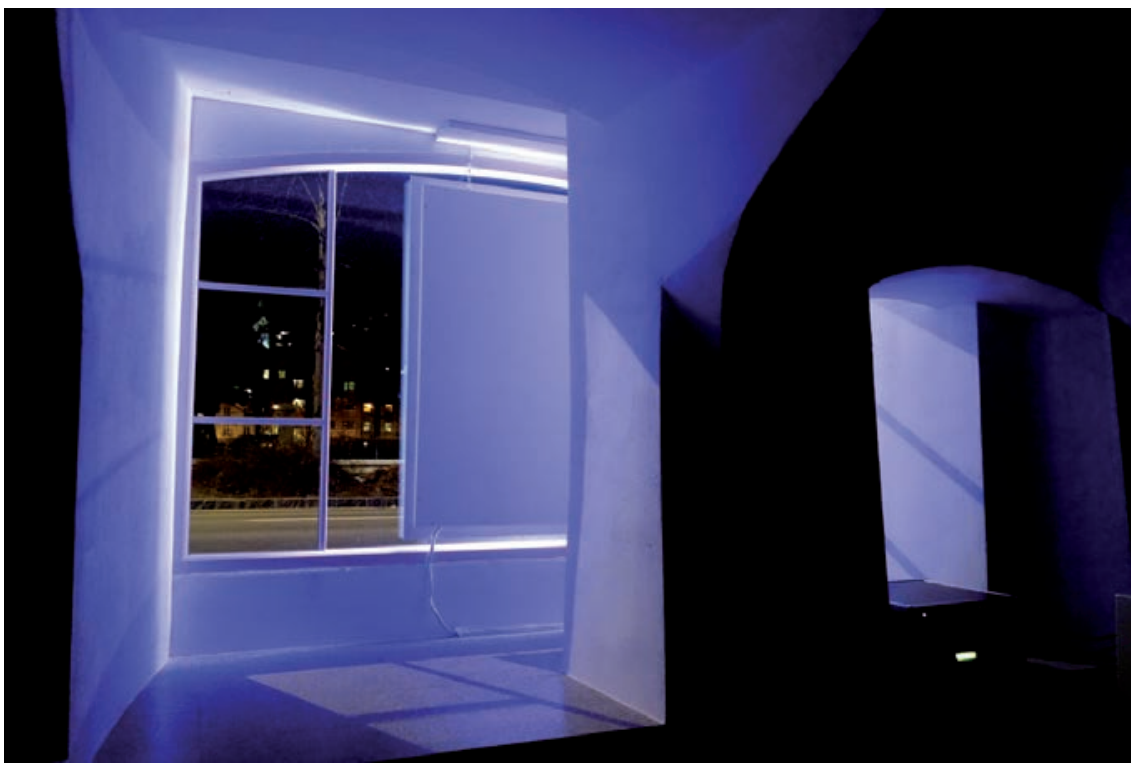

Abbildung 6: BANANA PERIOD bei Nacht, Innenansicht 

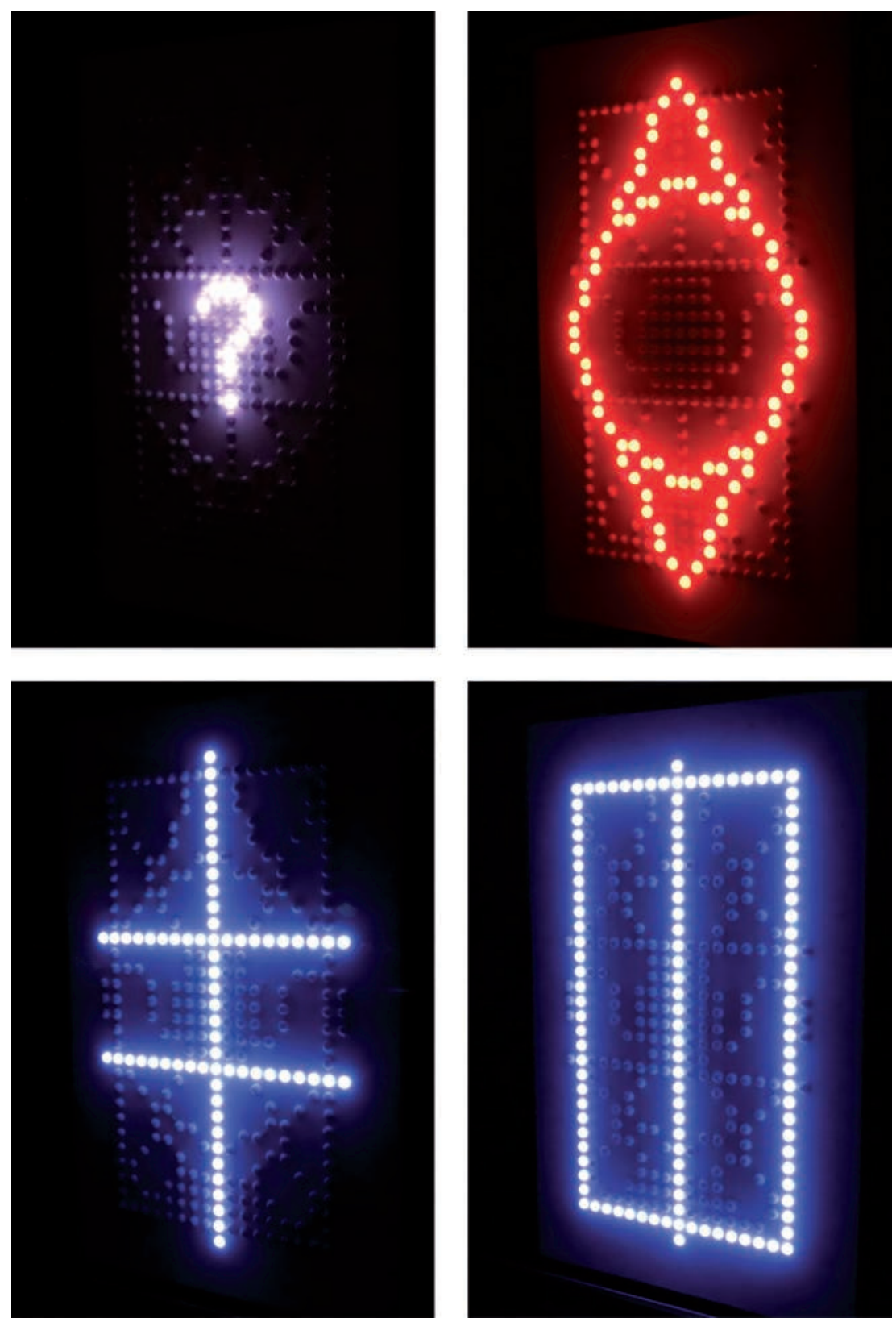

Abbildung 7: Yerkish Display mit Symbolen - Question, Banana, name-of, this 


\section{Kontext der Installation}

BANANA PERIOD ist Teil eines interdisziplinären Gesamtprojekts mit dem Arbeitstitel EvG Lightwindow, welches von den Medienkünstlern Jona Hoier und Markus Murschitz in Kollaboration mit Edith K. Ackermann, ${ }^{1}$ Susanne Seitinger ${ }^{2}$ und Theo Hug entsteht.

Das im Rahmen von BANANA PERIOD entstandene Yerkish-Display und die zugehörige Software stellen einen wesentlichen Bestandteil der Infrastruktur dar. Während BANANA PERIOD eine passive Lichtinstallation ist, geht das EvG Lightwindow darüber hinaus und fordert Passanten zur Interaktion auf.

Das Ziel des Projekts EvG Lightwindow besteht zum einen in der Sondierung und Weiterung konventioneller Formen der Wissenschaftskommunikation am Beispiel des Ernst-von-Glasersfeld-Archivs. Während traditionelle wissenschaftliche Archive in der Öffentlichkeit kaum wahrgenommen werden, bieten medienkünstlerische digitale Interaktionsformen neue Möglichkeiten sowohl der öffentlichen Wahrnehmung der dokumentierten Leistungen als auch der Anregung zum Neudenken derselben im Hinblick auf kontemporäre und künftige gesellschaftliche, technologische und medienkulturelle Entwicklungen.

Gerade die sprachwissenschaftlichen Experimente mit Yerkish eignen sich hier in besonderer Weise, da sie an den Nahtstellen von Natur-, Geistes- und Sozialwissenschaft angesiedelt sind und im Zusammenhang posthumanistischer sowie postanthropozentrischer Diskurse neue Aktualität erlangen. Nicht zuletzt machen die ethischen, anthropologischen und epistemologischen Fragestellungen der Human-Animal-Studies deutlich, dass wir die Grenzen des Menschen-Möglichen, der Viabilität medialisierter und kommerzialisierter Kommunikationsformen sowie der Gestaltbarkeit menschenwürdiger Habitate angesichts der biotechnologischen Entwicklungen neu ausloten müssen.

Als interdisziplinäres Kunstprojekt setzt EvG Lightwindow dort an, wo alltagsweltliche, künstlerische und wissenschaftliche Erkenntnisformen aufeinander treffen. In Form einer interaktiven Installation transportiert es diese Inhalte auf spielerische Art und Weise aus dem Schaufenster des Ernst-von-Glasersfeld-Archivs in den öffentlichen Raum der Stadt Innsbruck. Hierbei können sich Besucher_innen in die Rolle von Primaten versetzen und Teil eines sprachwissenschaftlichen Versuchs werden. Ziel des Versuchs ist es, dass Besucher_innen Fragmente der Sprache erlernen und von unbedarften Passant_innen zu interessierten Beobachter_innen bis zu aktiven Kommunika-

1 Edith K. Ackermann ist Honorary Professor of Developmental Psychology an der Université Aix-Marseille, Frankreich sowie Visiting Scientist am Massachusetts Institute of Technology, School of Architecture, und Visiting Professor an der University of Siena, Department of Communication.

2 Susanne Seitinger ist City Innovations Manager bei Philips Lighting in Burlington, MA. Sie erhielt ihr Doktorat am MIT Media Lab 2010 und studierte davor Architektur (Princeton BA 2001) und Städtebau (MIT MCP 2004). Sie kombiniert ihren technischen und anwendungsbezogenen Hintergrund zur Gestaltung innovativer Beleuchtungssysteme. 
tionspartner_innen werden. Die Inhalte erschließen sich den Besucher_innen über die Installation graduell - je mehr Interaktion, desto mehr Inhalt.

Das Projekt EvG Lightwindow zeigt am Beispiel der Experimente mit Yerkish auf, wie Aspekte der Mensch-Maschine-Interaktion, des Informationsdesigns und der Kommunikationskultur aufeinander bezogen und öffentlichkeitswirksam diskursiviert werden können. Die Sondierung von Möglichkeiten neuer Gestaltungsformen der Wissenschaftskommunikation im Spannungsfeld von Technik, Wissenschaft und Kunst deckt sich dabei mit dem Motto Light for Change - Licht für Wandel der Vereinten Nationen und soll auch über das „Internationale Jahr des Lichts“3 hinaus weiter geführt werden.

\section{Literatur}

Bettoni, Marco C. (2007): The Yerkish Language: From Operational Methodology to Chimpanzee Communication. Constructivist Foundations, 2 (2-3), pp. 32-38. Abrufbar unter http://www. univie.ac.at/constructivism/journal/2/2-3/032.bettoni.

Cox, Edie (1973): Lana and the Computer. The Bulldog Byte, 5 (3) September, pp. 4-11.

Gardner, R. Allen; Gardner, Beatrice T. (1969): Teaching Sign Language to a Chimpanzee. Science, New Series, 165 (894) (August), pp. 664-672.

von Glasersfeld, Ernst (2008): Unverbindliche Erinnerungen. Skizzen aus einem fernen Leben. Bozen: Folio-Verlag.

\section{Unterstützungshinweis}

EvG Lightwindow und das Team von BANANA PERIOD danken dem Kulturamt der Stadt Innsbruck für die großzügige Unterstützung.

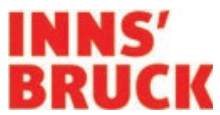

3 Vgl. die Informationen der UNESCO zum International Year of Light and Light-Based Technologies (IYL 2015), abrufbar unter http://www.light2015.org/ sowie http://www.unesco.de/wissenschaft/ingenieur-natur-wissenschaften/ mathematik-physik-chemie/jahr-des-lichts.html. 


\section{Autoren}

Markus Murschitz, DI - Freischaffender Medienkünstler und Forscher am Austrian Institute of Technology.

Jona Hoier, DI (FH) - Freischaffender Medienkünstler und Lehrender an der HTBLVA Ortweinschule und an der FH-Joanneum Graz.

Theo Hug, Dr. phil. habil - Professor für Erziehungswissenschaft mit Schwerpunkt Medienpädagogik und Kommunikationskultur an der Universität Innsbruck, Sprecher des interfakultären Forums Innsbruck Media Studies und zusammen mit Josef Mitterer Nachlassverwalter des Ernst-von-Glasersfeld-Archivs. 



\title{
Sprechen Sie Yerkish?
}

\section{Ernst von Glasersfelds Beitrag zum LANA Projekt - zwischen Operationalismus und Radikalem Konstruktivismus}

\section{Michael Schorner}

\begin{abstract}
Zusammenfassung
Yerkish, eine von Ernst von Glasersfeld Anfang der 1970er Jahre zur Kommunikation mit Schimpansen entwickelte und heute noch verwendete Symbolsprache, erscheint auf den ersten Blick wie ein erratischer Block im umfangreichen Gesamtwerk. Die Verortung von Yerkish im Kontext von (italienischem) Operationalismus und (Radikalem) Konstruktivismus ist Ziel dieses Beitrags.
\end{abstract}

\section{Yerkish}

Zwischen 1971 und 1975 widmete sich Ernst von Glasersfeld am Yerkes National Primate Research Center in Atlanta (Georgia) dem LANA Projekt zur Erforschung der kommunikativen Fähigkeiten von nicht-menschlichen Primaten, in dessen Rahmen er Yerkish, die erste Symbolsprache für Schimpansen entwickelte. Wie dieses kurze, aber richtungsweisende Intermezzo mit der Linguistik und Primatenforschung in Glasersfelds Gesamtwerk zu verorten ist, soll hier skizziert werden.

Nicht zuletzt angeregt durch die Herausforderung von Noam Chomskys nativistischem Modell einer generativen Transformationsgrammatik begann Mitte der 60er Jahre ein Reihe von Versuchen, die Sprachfähigkeit von Menschenaffen auszuloten. Die Schimpansin Washoe etwa wurde von dem Ehepaar Allen und Beatrice Gardner in der amerikanischen Gebärdensprache unterrichtet, während David und Ann Premack mit der Schimpansin Sarah mit Hilfe einer Magnettafel und Plastiksymbolen kommunizierten. Das von dem Tierpsychologen Duane Rumbaugh am Yerkes Zentrum für Primatenforschung angeregte LANA Projekt sollte das erste computerunterstützte und zudem interdisziplinär ausgerichtete Projekt in dieser Reihe werden. LANA ist ein Akronym für LANguage Analogue Project und zugleich der Name der als erste Probandin ausgewählten Schimpansin, die mit 2 1/2 Jahren ihr Sprachtraining begann. Glasersfelds Rolle als Linguist in diesem Projekt war seiner Bekanntschaft mit einem der Pioniere der amerikanischen Primatologie, Ray Carpenter, sowie seinen in Mailand begonnenen Forschungen zur Sprachanalyse und automatisierten Übersetzung für die US Air Force zu verdanken. Menschenaffen haben nicht die physiognomischen Voraussetzungen für eine gesprochene Sprache, deshalb entwickelte Ernst von Glasersfeld eine Zeichensprache. Yerkish, benannt nach dem Psychologen und Zoologen Robert M. Yerkes, der das Forschungszentrum gegründet hatte, baut auf geometrischen Zeichen auf, für die Glasersfeld den heute noch 
Aus dem Archiv I Michael Schorner

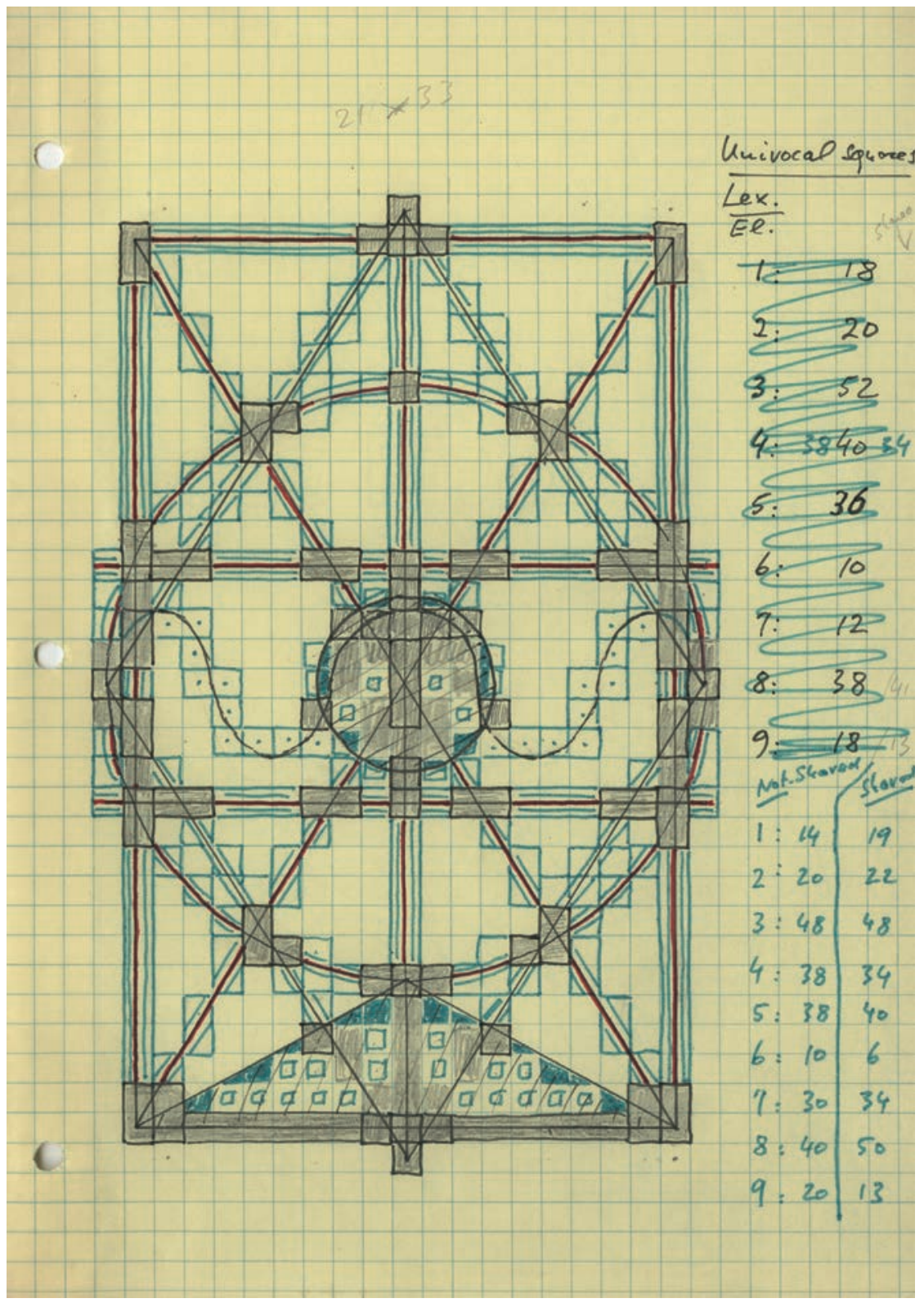

Abbildung 1: Ernst von Glasersfeld: Entwurf für Yerkish-Lexigramme zur Darstellung auf Projektoren.

Ernst-von-Glasersfeld-Archiv, Kassette 21, Mappe 6 
gebräuchlichen Namen „Lexigramm“ prägte. Es handelt sich dabei um Begriffszeichen, die mit wenigen Ausnahmen einzelne Wörter der englischen Sprache repräsentieren, ein Zeichen ist somit die kleinste Ausdruckseinheit. Lexigramme sind Ideogramme, also keine ikonischen Zeichen (Piktogramme). Damit konnte verhindert werden, dass Lana die Bedeutung der Zeichen aufgrund einer Ähnlichkeit mit den bezeichneten Objekten erlernte. Jedes der Lexigramme basiert auf einer Kombination aus neun Basis-Designelementen, die einen konstanten semantischen Wert haben und als kleinste bedeutungstragende Einheit den Morphemen der natürlichen Sprachen entsprechen. Die Herausforderung bestand darin, diese Elemente so zu entwickeln, dass sie eine möglichst große Anzahl von Kombinationen ermöglichten und diese zugleich für Lana leicht zu unterscheiden waren - tatsächlich hatte Lana mit der Unterscheidung der Lexigramme keine Schwierigkeiten. (vgl. von Glasersfeld 2008, S. 209) Eine Zeichenkette von sieben Lexigrammen war die maximale Länge eines Satzes, der immer mit einem Punkt abgeschlossen werden musste, um als gültig ausgewertet zu werden. Die Yerkish-Grammatik hat ein Genus und sieht drei Modi vor (Indikativ, Imperativ und Frage), die in Kombination mit den entsprechenden Satzzeichen („Please“ und Fragezeichen) eindeutig interpretierbar waren. Das Kommunikationssystem bestand aus einer mit den Lexigrammen belegten Tastatur, die mit einem PDP8 Computer verbunden war und einer Reihe von Projektoren, auf der Lana die eigenen Eingaben sehen und Nachrichten der Forscher empfangen konnte. Der Computer war zum einen mit einem Parser programmiert, der jede Eingabe speichern und auf ihre grammatikalische Korrektheit auswerten konnte, zum anderen stand Lana damit 24 Stunden am Tag eine Lernumgebung zur Verfügung. Es war ihr dadurch möglich, nicht nur mit den Forschern zu kommunizieren, viele ihrer Anfragen konnten automatisiert beantwortet werden - so konnte sie damit etwa Futter bestellen, Musik und Filme abspielen, Fenster öffnen etc. Für die automatisierte Analyse war zum einen die eindeutige Bedeutung der Lexigramme wichtig, was Lana das Erlernen von Yerkish wesentlich erleichterte, zum anderen die Grammatik, mit der die Lexigramme zu sinnvollen (und syntaktisch korrekten) Sätzen kombiniert werden konnten.

\section{Grammatik}

Die Yerkish-Grammatik geht zurück auf Silvio Ceccatos Untersuchungen von menschlichen Denkprozessen und seiner daraus entstandenen Theorie der „korrelationalen Bedeutungsnetze“. Laut dieser Theorie, die sich auf den Operationalismus von Percy Bridgman stützt, würden Wörter für Begriffe stehen und Definitionen müssen jene Operationen angeben, mit denen man diese Begriffe erzeugen kann. (vgl. von Glasersfeld 1996, S. 31)

Bereits in den späten 30er Jahren hatte sich Ceccato der Struktur und Dynamik von Denkprozessen, sowie dem Zusammenhang von Sprache und Denken gewidmet und eine Methode der operationalen Begriffsanalyse entwickelt. Bewusstsein wird dabei insofern als „operational“ aufgefasst, als mentale Inhalte wie Wahrnehmungen, Vorstellungen oder Begriffe als das Ergebnis von einzelnen 
Aus dem Archiv I Michael Schorner

oder mehreren Operationen angenommen werden. Eine Analyse des Denkens, bzw. eines Bedeutungsinhalts/Begriffs besteht demnach in der Rekonstruktion der mentalen Operationen. Ein zentraler Aspekt ist die „pulsierende Aufmerksamkeit“, ein Mechanismus, der Wahrnehmung selektiv fokussiert und Bewusstsein und kognitive Verarbeitung erst ermöglicht und konstituiert.

Mit seiner „Denkmaschine“ Adamo II versuchte Ceccato 1955 die Möglichkeit einer Mechanisierung des Denkens (und Sprechens) zu demonstrieren und leistete damit Pionierarbeit für die Computerlinguistik. Die erste größere Anwendung der operationalen Begriffsanalyse war ein von der US Air Force finanziertes Projekt zur Analyse von englischen Sätzen und automatisierten Übersetzung, an dem auch Glasersfeld beteiligt war.

In traditionellen Grammatiken werden Lexikoneinträge von natürlichen Sprachen nach ihren morphologischen Charakteristika und syntaktischen Funktionen klassifiziert. Die korrelationale Grammatik, auf der Yerkish basiert, klassifiziert diese Lexikoneinträge ausschließlich entsprechend der jeweiligen Rollen, die sie in Satzstrukturen spielen können. Diese Rollen werden hinsichtlich der Begriffe, die das Wort bezeichnet und der Beziehung, in die diese gesetzt werden, unterschieden und beschrieben. Der erkenntnistheoretische Hintergrund liegt dabei in der Verlagerung des Schwerpunkts von angeblich objektiven Entitäten auf die aktive kognitive Konstruktion durch Individuen in Erfahrungssituationen, die mit anderen geteilt werden. Es handelt sich dabei um eine interpretative Grammatik, die nicht beansprucht "generativ“ oder „transformativ“ im Sinne Chomskys zu sein. Im Gegensatz zu dessen Beschreibung der Verbindung von Tiefen- und Oberflächenstruktur einer Sprache, liefert die korrelationale Grammatik ein Modell des Sprachbenutzers und eine Abbildung der kognitiven Operationen, die den Begriffen zugrundeliegen. Dies wird erreicht durch eine Zuordnung der semantischen Verbindungen zwischen den Elementen und Strukturen der Sprache auf der einen und den entsprechenden Verbindungen der begrifflichen Repräsentationen auf der anderen Seite. Während der Aufwand an einer korrelationalen Grammatik für eine natürliche Sprache enorm ist (wie das Air Force-Projekt gezeigt hat), hat Yerkish den Vorteil, dass das Lexikon, die Syntax sowie die Grammatik gleichzeitig entwickelt werden konnten und für die Kommunikation mit Schimpansen somit „maßgeschneidert“ war. Die Satzstruktur von Yerkish ist so nahe wie möglich am Englischen angelehnt und ermöglicht somit eine Wort für Wort-Übersetzung.

Glasersfeld hatte ursprünglich eine Idealsprache im Sinn, deren Lexigramme nicht nur auf Begriffe verweisen, sondern anhand von Pleremen (in diesem Fall also bestimmten Designelementen) unterschiedlichen semantischen Kategorien zugeordnet werden können. (vgl. Glasersfeld 1975, S. 15) Er erhoffte sich damit Erkenntnisse über den Prozess der Begriffsbildung und die Fähigkeit zur Klassifizierung bei menschlichen und nicht-menschlichen Primaten. Aufgrund von technischen Beschränkungen und eines begrenzten Budgets konnte das nur teilweise umgesetzt werden: Auf den Projektoren musste jedes Lexigramm dargestellt werden können, sie erlaubten jedoch nur eine limitierte Zahl von Kombinationsmöglichkeiten. Die grafischen Elemente der Lexigramme wurden durch Hintergrundfarben ergänzt, mit denen die wichtigsten Begriffsklassen ausgezeichnet werden konnten. Diese wurden in Hinblick auf die funktionalen Charakteristika der Begriffe definiert und 
nicht nach morphologischen Gesichtspunkten und ihrer Verwendung im Satz (Substantiv, Verb, Adjektiv, etc.). Beispiele für diese semantischen Klassen sind etwa „autonome Akteure“, Körperteile oder relationale Begriffe (of, name of, which is). (vgl. Bettoni 2007) Die zentralen Elemente der Yerkish-Grammatik sind die etwa 30 „Korrelatoren“, jene Operationen, die mentale Operanden (bzw. Begriffe) in Beziehung bringen und in natürlichen Sprachen Wörter oder Wortfolgen verbinden und somit eine neue Sinneinheit („Korrelation“) erzeugen. Ein Korrelator erzeugt etwa eine Prädikation („Banana black“), verbindet einen selbstständigen Akteur mit einer ortsgebundenen Tätigkeit („Lana drink“), ein anderer verknüpft einen beweglichen Akteur mit einem Positionswechsel („Tim move“).

Durch die Programmierung eines automatischen Parsers, einer reduzierten Version des von Glasersfeld und Pier Paolo Pisani bereits in Mailand entwickelten „Multistore parser for English sentences“, war es nicht nur möglich, alle sprachlichen Äußerungen zu kontrollieren und zu speichern, Yerkish war so angelegt, dass durch die zwar einfache, aber rigide Grammatik die Auswertung automatisiert werden und somit auch der Interpretationsspielraum drastisch reduziert werden konnte. Das Problem der Voreingenommenheit bei der Interpretation war durch die vorangegangenen Kommunikationsversuche mit Affen deutlich geworden. So hatten etwa die Äußerungen der Schimpansin Washoe in der Gebärdensprache ASL einen zu großen Interpretationsspielraum geboten. Dass Menschenaffen in der Lage sind, eine einfache Grammatik zu verwenden, wurde in diesen ersten Versuchen von vornherein ausgeschlossen.

\section{Kommunikation und Sprache}

Angesichts der „unklaren und widersprüchlichen Auffassungen des Phänomens der Kommunikation“, die Glasersfeld vor allem in der Literatur über tierisches Verhalten vorfand, setzte er für die Beantwortung der Frage, ob Primaten und andere Tiere eine Sprache haben bzw. erwerben können, zunächst eine hinreichende Definition von „Zeichen“, „Kommunikation“ und „Sprache“ voraus. Versuche dazu finden sich in mehreren seiner Arbeiten, etwa in dem Aufsatz Signs, communication, and language (1974, dt. von Glasersfeld 1987b). Die darin genannten Abgrenzungskriterien bilden nicht nur die Grundlage für Yerkish, sondern waren auch unerlässlich, um von der Beobachtung des Verhaltens auf Sprachfähigkeit zu schließen. Für seinen Gegenentwurf zum „Tabu des dogmatischen Behaviorismus“, das eine wissenschaftliche Beschäftigung mit zielgerichteten bzw. zweckorientierten Handlungen verbietet, fand Glasersfeld die Grundlage in der Rückkopplungstheorie der Kybernetik und in der Symbolphilosophie Susanne Langers. Die Rückkopplungstheorie ermöglicht nicht nur die Anwendung des Zweckbegriffs in der Verhaltensanalyse, sondern auch eine präzise Abgrenzung der Kommunikation von anderen Interaktionsformen. Zu seinen Beiträgen zum LANA-Projekt gehören mehrere Arbeiten, die sich mit Kommunikation und Sprache auseinandersetzen und dabei die vom Behaviorismus „geächtete“, hingegen für die Kybernetik entscheidende 
Aus dem Archiv I Michael Schorner

Rolle von Zweck und Teleonomie betonen. Neben dem Gründungsdokument der Kybernetik Behavior, Purpose and Teleology von Rosenblueth, Wiener und Bigelow (1943) stützt sich Glasersfeld auf Colin Cherrys Studie On Human Communication (1957). Zielgerichtetheit wird dabei als Ergebnis von Mechanismen in informationsverarbeitenden Systemen verstanden; mit der Erklärung des Verhaltens durch einen Rekurs auf operative Rückkopplungsschleifen wird jeder Bezug auf die Frage eines freien Willens, eines Bewusstseins oder Geistes und somit auch ein Anthropozentrismus vermieden. Als Kriterium für Kommunikation gilt die Spezifizierung des Referenzwerts (des Ziels), das heißt „nur dann, wenn wir die instrumentelle Relation zwischen einem Zeichen und einem Ziel angeben können, das der Sender des Zeichens erreichen will, können wir von ,Kommunikation' sprechen". (von Glasersfeld 1987b, S. 59) Kommunikatives Verhalten wird somit als Versuch einer Minimierung der Diskrepanz zum Referenzwert (Rückkopplungsausgleich), anstatt als bloße Reaktion auf einen Stimulus verstanden. Damit ist für Glasersfeld auch jegliche Erforschung von Kommunikation, die im engen Rahmen des behavioristischen Stimulus-Reaktions-Modells bleibt, zum Scheitern verurteilt.

Die Unterscheidung von zufälligen und zielgerichteten Handlungen geht Hand in Hand mit der Zeichenklassifikation Susanne Langers, die zwischen „natürlichen“ und „künstlichen“ Zeichen unterscheidet. Natürliche Zeichen sind lediglich „Symptome eines Sachverhalts" (Langer 1948, zit. nach von Glasersfeld 1987b, S. 57), also Anzeichen, die entstehen, ohne dass kommunikative Absicht vorliegt (z. B. ist Rauch ein natürliches Zeichen für Feuer). Kommunikation im Sinne einer instrumentellen Absicht liegt dann vor, wenn der Sender künstliche Zeichen verwendet, also etwas erzeugt wird, das absichtsvoll mit wichtigen Ereignissen, deren Bedeutung dargestellt werden soll, korreliert wird und vom Empfänger dahingehend interpretiert werden soll. Erst kulturelle Überlieferung oder Übereinkunft machen die Sinnzuschreibung durch Sender und Empfänger kompatibel. Während Kommunikation von anderen Formen der Interaktion abgegrenzt werden muss, bedarf es auch einer Präzisierung des Begriffs Sprache, um dieses Phänomen von einfachen Signalsystemen zu unterscheiden. Eine solche Präzisierung schien bis weit in das 20. Jahrhundert kein Bedürfnis zu sein. Es gab in der Linguistik zwar eine Reihe von Definitionsversuchen, die Ergebnisse waren jedoch unbefriedigend bzw. widersprachen einander. Gemeinhin galt (und gilt für viele nach wie vor) Sprache als Anthropinon, also als spezifisch menschliches Charakteristikum. Dass Sprache in der Regel mit (menschlichem) Sprechen gleichgesetzt wurde, lag an der Dominanz des Strukturalismus von Leonard Bloomfield, in der für die Funktion und die kognitiven Aspekte von Sprache eine „militante Blindheit" entwickelte wurde. (von Glasersfeld 1987b, S. 64) Nachdem man sich in behavioristischer Manier nur auf das direkt Beobachtbare stützte, stand in der Linguistik die Phonologie hoch im Kurs, während semantische Untersuchungen nur peripher betrieben wurden. In seiner Kritik an diesem linguistischen Paradigma beruft sich Glasersfeld auf Edward Sapir, für den ein Sprachlaut, insofern er nicht mit Elementen der Erfahrung verknüpft ist, weit davon entfernt ist, Element einer Sprache zu sein. Im Unterschied zu Glasersfeld hatte Sapir jedoch nie die geringsten Zweifel daran, dass Sprache „a purely human and non-instinctive method of communicating 
ideas“ ist. (Sapir 1921, S. 8) Nur ein Gesamtkomplex aus Signalen (dazu zählen auch visuelle oder taktile Signale), semantischem Nexus und Bedeutung kann als Sprache bezeichnet werden. (von Glasersfeld 1987c, S. 65) Wie andere Formen der Kommunikation muss Sprache „instrumentell, zielgerichtet und zweckorientiert" sein. Das liefert jedoch lediglich eine notwendige, aber noch keine hinreichende Bedingung für Sprache.

Zwei der einflussreichsten Versuche, die Spezifika von Sprache zu formulieren und somit von nichtmenschlichen Kommunikationsformen abzugrenzen, kamen in den 60er Jahren von Charles Hockett und Noam Chomsky. Hockett erstellte einen Katalog von 13 Differenzkriterien (Hockett 1960), die später um drei weitere ergänzt wurden (Hockett/Altmann 1968). Während Spezialisierung (specialization), Bedeutungshaftigkeit (semanticity), Willkürlichkeit (arbitrariness) und Weitergabe durch Tradition (traditional transmission) bedingt auch nicht-menschlichen Primaten bzw. Hominoiden zugestanden wird, sieht Hockett Distanzfähigkeit (displacement), Produktivität/ Offenheit (productivity/openness), doppelte Gliederung (duality of pattern), Täuschung (prevarication), Reflexivität (reflexiveness) und die Erlernbarkeit von anderen Sprachen (learnability) als Spezifika an, die nur die menschliche Kommunikation aufweist. Für Hockett ist die Entwicklung der menschlichen Sprache ein soziales Phänomen, während Noam Chomsky eine Theorie der biologischen Fundierung von Sprache entwickelte. Nur die menschliche Spezies ist laut Chomskys Modell der generativen Transformationsgrammatik mit einem „Spracherwerbsorgan“ (language acquisition device) ausgestattet, Spracherwerb ist nach dieser Theorie nur aufgrund von angeborenen Prädispositionen möglich. Nach Chomsky hat nur der Mensch ein limitiertes Repertoire von Kommunikationsregeln, die es ermöglichen, noch nie zuvor verwendete Satzgefüge zu bilden und zu verstehen.

Glasersfeld übernimmt Hocketts Charakteristikum der Dislozierung, erweitert dieses jedoch um die Symbolizität. Das bedeutet, dass uns die Sprache erlaubt „zu reden, und zwar nicht nur über Dinge, die in Zeit und Raum entfernt sein mögen, sondern auch über Dinge, die nirgendwo und nimmer sind." (von Glasersfeld 1987c, S. 76) Damit aus einem Zeichen ein Symbol wird, muss es „semantisch mit einer Repräsentation verknüpft werden, die unabhängig ist von den zu irgendeiner Zeit verfügbaren perzeptuellen Signalen.“ (ebd.) Ein Symbol liegt also vor, wenn das Bezeichnete nicht mehr in der Erfahrungssituation auftreten muss, sondern allein durch das Zeichen aufgerufen werden kann. Symbole sind in erster Linie mit Vorstellungen verknüpft, können unabhängig vom Erfahrungskontext eingesetzt werden und „es sind diese Vorstellungen, nicht die Dinge selbst, die Symbole direkt, bedeuten“". (Langer, zit. nach von Glasersfeld 1987b, S. 60) Damit wird auch die Rolle der Sprache als ein Instrument der Reflexion (im Unterschied zu ihrer Rolle als Instrument des Handelns) deutlich. Ebenfalls als essentiell sieht Glasersfeld Hocketts Merkmal der „Offenheit" (Produktivität). Damit werden die Erzeugung und das Verstehen von noch nie dagewesenen sprachlichen Äußerungen ermöglicht. Erreicht wird dies durch eine Grammatik, die von Mustern und Konventionen gebildet wird, nach denen die elementaren bedeutsamen Einheiten (wie etwa Morpheme oder bedeutsame Signale) zu größeren Sequenzen verbunden werden können und die 
Aus dem Archiv I Michael Schorner

zugleich festlegen, welche Bedeutung sich aus der neuen Anordnung ergibt. Zur Bedeutung einzelner Zeichen (lexikalische Semantik) kommt somit die Grammatik als zweite Menge von Konventionen dazu, die eine syntaktische (bzw. relationale) Semantik erzeugt und fixiert.

Sprache ist somit für Glasersfeld ein semiotisches System mit drei definierenden Merkmalen:

1. Ein Lexikon von (künstlichen) Zeichen, deren Semantizität durch Konvention und nicht induktiv konstituiert wird.

2. Die Zeichen müssen Symbole sein, also mit Repräsentationen verknüpft sein.

3. Eine Menge von Regeln (Grammatik), die neue semantische, über die Inhalte der Zeichen hinausgehende Inhalte ermöglicht.

Sprachliche Kompetenz kann einem Tier gemäß Glasersfeld nur dann zugeschrieben werden, wenn es in der Lage ist, ein erlerntes Zeichen auch unter neuen Bedingungen und in Hinblick auf nicht konventionelle Reaktionen anzuwenden. Nur somit wird aus dem Zeichen ein Symbol. Ein Zeichen, das nur in Zusammenhang mit einer einzigen Verhaltensreaktion verwendet wird, ist kein Symbol. Der Tanz der Bienen ist zwar eine komplexe Form der Kommunikation, die auch Dislozierung beinhaltet, es fehlt ihr allerdings die Symbolizität. Kurzum, ein Kommunikationssystem ,that allows for imperatives only - no matter how sophisticated and accurate they might be - should not be called a language“. (von Glasersfeld 1977a, S. 65)

\section{Das Erkennen von Sprache}

Kriterien für eine Sprache anzugeben ist eine Sache. Eine andere ist es, anhand von beobachtbaren Verhaltensmanifestationen zu bestimmen, ob diese Kriterien sämtlich erfüllt sind. Ob es sich bei einem bestimmten Verhalten um eine Äußerung eines künstlichen Zeichens handelt, beziehungsweise ob dieses Zeichen symbolisch verwendet wird, ist im Zuge der Beobachtung eines Individuums, mit dem kein gemeinsames Kommunikationssystem geteilt wird (etwa eines Schimpansen in der freien Natur), kaum festzumachen. Die Situation im Labor ist eine andere, das Drücken von bestimmten Tasten auf dem Keyboard, das zu Belohnungen führt, kann ohne Zweifel als Verwendung von künstlichen Zeichen mit dem Wissen um deren kommunikative Funktion interpretiert werden - unabhängig davon, ob die Verwendung der Zeichen das Ergebnis von Konditionierung ist. Auch die Fähigkeit, ein Zeichen repräsentativ einzusetzen, kann im Labor getestet werden. Sobald eine gemeinsame Kommunikationsbasis aufgebaut ist, kann jede neue Frage nach einem Gegenstand, der sich nicht im Wahrnehmungsbereich befindet, nur richtig beantwortet werden, wenn eine eindeutige repräsentative Vorstellung des genannten Gegenstands vorliegt. Und steht einmal fest, wie einzelne Zeichen verwendet werden, ist es auch möglich herauszufinden, ob die Kombination von zwei oder mehreren Zeichen eine neue Bedeutung hervorbringt und ob sich diese Kombinationen wiederholen und von Regeln, also einer Grammatik, geleitet werden. Glasersfeld betont, dass dabei 
wie im alltäglichen Gebrauch von Sprache in erster Linie ein implizites Wissen von Regeln zählt. Man operiert (gemäß W. Sellars und J. Piaget) nach Regeln, ohne diese jemals formulieren zu müssen. Produziert ein Schimpanse genügend Zeichenkombinationen, die der Grammatik entsprechen, muss das als „Wissen“ um die Grammatik anerkannt werden. (vgl. von Glasersfeld 1977a, S. 67 f.) Für Glasersfeld haben die Versuche keine Zweifel hinterlassen, dass Lana auf dem besten Weg zu einer Sprache war. Obwohl Schimpansen außerhalb der Laborsituation keine Sprache anwenden - ein Indiz dafür, dass Sprache dieser Spezies offenbar keinen evolutionären Vorteil verschafft hat besitzen sie zumindest in Ansätzen sprachliche Kompetenz.

\section{Der theoretische Hintergrund}

Eine Einordnung seiner Beiträge zum LANA Projekt in das Gesamtwerk kann nur gelingen, wenn man Glasersfelds Auseinandersetzung mit dem Phänomen Sprache vor einem erkenntnistheoretischen Hintergrund sieht. Schon Ceccatos anti-realistischer Ansatz enthält Elemente, die später wesentlich für den Radikalen Konstruktivismus wurden. Der gemeinsame Nenner seiner Untersuchungen zur Begriffsanalyse war "Consapevolezza operativa“, das sich Bewusstwerden des eigenen mentalen Operierens. Wissen entsteht nicht aus passiver Erfahrung, sondern wird aktiv aus Elementen der Erfahrung aufgebaut - ein Ansatz, der auch Parallelen zu Giambattista Vico aufweist, mit dessen Werk Glasersfeld bereits in seiner Zeit in Irland Bekanntschaft gemacht hatte. Der Operationalismus in der Ausprägung von Ceccatos Scuola Operativa Italiana hat seine Wurzeln in der Kritik an der traditionellen Erkenntnistheorie mit ihrem Postulat einer Wahrheit als Abbild einer bewusstseinsunabhängigen Realität und ihrer für Ceccato unhinterfragten „Verdopplung des Objekts“. Der Einfluss Ceccatos wird in Glasersfelds Auseinandersetzung mit dem Problem der Referenz und Repräsentation deutlich. Üblicherweise wird die Frage nach der Referenz mit einem Verweis auf die entsprechenden Gegenstände oder Ereignisse in der Welt (den Referenzgegenständen) beantwortet. Dieser auf den ersten Blick unproblematischen Auffassung hält Glasersfeld entgegen, dass die Objekte und Ereignisse, die wir mit Sprache kommunizieren, immer aktiv erzeugte Konstruktionen und damit Ergebnis von mentalen Operationen sind. Semantische Analysen müssen demnach kognitive Analysen sein und sich auf die Begriffe und deren Relationen konzentrieren, nicht aber Objekte oder Wahrheitswerte suchen. Was unter einer solchen Analyse zu verstehen ist, veranschaulicht Glasersfeld etwa in einem Aufsatz zur „semantischen Analyse von Verben auf der Grundlage begrifflicher Situationen“ (von Glasersfeld 1987a): Um die Bedeutung eines Verbs zu analysieren oder für eine Übersetzung müssen sämtliche Charakteristika jener begrifflichen Situationen angegeben werden, auf die das Verb anwendbar ist. Unter „begrifflicher Situation“ wird dabei eine Struktur von Dingen und Relationen verstanden, die im Denken des Sprachbenutzers vorliegt - unabhängig davon, ob diese Struktur „der Wahrnehmung, der Phantasie oder sogar einer Illusion entstammt“. (von Glasersfeld 1987a, S. 26) Auch unter Repräsentation wird aus konstruktivistischer Sicht nicht 
etwas verstanden, das sich auf eine bewusstseinsunabhängige Außenwelt bezieht, sondern vielmehr eine Re-Konstruktion von etwas, das zuvor in einer Erfahrungssituation konstruiert wurde. Ein Ding oder eine Situation zu begreifen ist nicht dasselbe wie darauf zu reagieren oder sich lediglich dessen bewusst zu sein. Beim Sprechen über Dinge greift man auf Vorstellungen und Begriffe zurück und nicht auf die Dinge selbst, es sind letztlich unmittelbar die Vorstellungen, die Symbole „bedeuten“. Der entscheidende Schritt in der Interpretation (und damit auch einer Übersetzung) „geschriebener (und natürlich auch gesprochener) Sprache wiederum ist nicht der Schritt von einer linguistischen Struktur zu einer anderen, sondern der Schritt von einem sprachlichen Ausdruck zu einem nicht-sprachlichen begrifflichen Gebilde“. (von Glasersfeld 1987d, S. 23) Um von der Oberflächenstruktur einer Sprache in die einer anderen zu gelangen, führt also kein Weg daran vorbei, „in das Substrat begrifflichen Verstehens einzutauchen“. (Glasersfeld, 1987a, S. 25)

Während seiner Mitarbeit an dem LANA Projekt beginnt Glasersfeld sich mit Jean Piaget auseinanderzusetzen, der zu einer weiteren Inspirationsquelle für seine in großen Teilen bereits ausformulierte Wissenstheorie wird. Glasersfeld war bereits während seiner Zusammenarbeit mit Ceccato auf Piaget gestoßen, wegen Ceccatos Ablehnung des „Kinderfängers“ kam es jedoch noch zu keiner Auseinandersetzung mit dessen Werk. Dabei vertraten Ceccato und Piaget eine ähnliche erkenntnistheoretische Position und auch methodologisch gab es Berührungspunkte. Kurz vor Glasersfelds Ausstieg aus dem LANA Projekt taucht im Titel seiner Arbeiten erstmals der von Piaget stammende Name „Konstruktivismus“ auf, der von Glasersfeld durch das Attribut „radikal“ ergänzt wird. Piaget und Chomsky zählen zu den wichtigsten Wegbereitern der Kognitiven Wende, standen sich jedoch in einer Debatte gegenüber, die im Rahmen der von ihnen begründeten Denkschulen bis heute ausgefochten wird. Im Zentrum steht dabei die Frage, ob Sprache (zumindest teilweise) angeboren ist oder erst nach der Geburt erworben wird. Zu den Verfechtern der nativistischen Position zählen in jüngerer Zeit etwa Marc Hauser und Tecumseh Fitch, während Michael Tomasello eine adaptionistische Theorie vertritt. Hauser ist zu dem Ergebnis gekommen, dass Studien an nicht-menschlichen Primaten keine relevanten Parallelen zur menschlichen Kommunikation gezeigt haben. Tomasello, ein Schüler von Glasersfeld, bestätigt ebenso einen fundamentalen Unterschied, sieht die Entwicklung menschlicher Sprache jedoch als Ergebnis kumulativer kultureller Prozesse und hält Chomskys Annahme einer Universalgrammatik für unnötig.

Auch im LANA Projekt versuchte man, dieser Frage nachzugehen: Es wurde von den National Institutes of Health finanziert, weil man sich von den Versuchen auch neue Erkenntnisse über den menschlichen Spracherwerb erhoffte, die wiederum der Erforschung von durch Hirnschädigungen versursachten Sprachstörungen bei Kindern zu Gute kommen sollten. 


\section{Yerkish heute}

Das LANA Projekt machte weltweit Schlagzeilen, die in einem umfangreichen Pressespiegel in Glasersfelds Nachlass dokumentiert sind. Im Oktober 2015 feiert Lana ihren 45. Geburtstag. Die goldene Zeit der Sprachforschung mit Primaten war Ende der 70er Jahre vorbei, dennoch werden die Versuche bis heute am Language Research Center der Georgia State University und im Iowa Primate Learning Sanctuary (vormals Great Ape Trust) fortgesetzt. Zu Berühmtheit hat es dort der Bonobo Kanzi (geboren 1980) gebracht, der mit Hilfe von Tablet Computern und großformatigen Touchscreens kommuniziert und auch gesprochene Sprache versteht. Yerkish wurde weiterentwickelt, mittlerweile werden über 400 Lexigramme verwendet. Kanzi lernte Yerkish nicht mehr über das behavioristische Lernmodell, sondern spielerisch durch Beobachtung. Eines Tages griff er aus eigenem Antrieb zum Keyboard und begann mit den Forschern zu kommunizieren.

\section{Literatur}

Bettoni, Marco (2007): The Yerkish language. From Operational Methodology to Chimpanzee Communication. Constructivist Foundations, 2 (2-3), pp. 32-38.

von Glasersfeld, Ernst (1975): The Yerkish Language for Non-Human Primates. American Journal of Computational Linguistics.

von Glasersfeld, Ernst (1977a): Linguistic Communication: Theory and Definition. In: Rumbaugh,

Duane M. (Hrsg.): Language Learning by a Chimpanzee. The LANA Project. New York/San Francisco/London: Academic Press, pp. 55-71.

von Glasersfeld, Ernst (1977b): The Yerkish Language and Its Automatic Parser. In: Rumbaugh,

Duane R. (Hrsg.): Language Learning by a Chimpanzee. The LANA Project. New York/San Francisco/London: Academic Press, pp. 91-130.

von Glasersfeld, Ernst (1987a): Die semantische Analyse von Verben auf der Grundlage begriffli-

cher Situationen. In: von Glasersfeld, Ernst: Wissen, Sprache und Wirklichkeit. Braunschweig/ Wiesbaden: Vieweg, pp. 24-38.

von Glasersfeld, Ernst (1987b): Zeichen - Kommunikation - Sprache. In: von Glasersfeld, Ernst: Wissen, Sprache und Wirklichkeit. Braunschweig/Wiesbaden: Vieweg, pp. 52-62.

von Glasersfeld, Ernst (1987c): Sprache als zweckorientiertes Verhalten: zur Entwicklungsgeschichte. In: von Glasersfeld, Ernst: Wissen, Sprache und Wirklichkeit. Braunschweig/Wiesbaden: Vieweg, pp. 63-79.

von Glasersfeld, Ernst (1987d): Lesen, Verstehen und begriffliche Situationen. In: von Glasersfeld, Ernst: Wissen, Sprache und Wirklichkeit. Braunschweig/Wiesbaden: Vieweg, pp. 63-79. von Glasersfeld, Ernst (1996): Radikaler Konstruktivismus. Ideen, Ergebnisse, Probleme. Frankfurt am Main: Suhrkamp. 
von Glasersfeld, Ernst (2008): Unverbindliche Erinnerungen. Skizzen aus einem entfernten Leben. Wien/Bozen: Folio.

Sapir, Edward (1921): Language. New York: Harcourt, Brace \& World.

Schmidt, Siegfried J. (1999): Ernst von Glasersfelds Sprachphilosophie: Grundlagen, Konzepte, Perspektiven. In: Rusch, Gebhard (Hrsg.): Wissen und Wirklichkeit. Beiträge zum Konstruktivismus. Heidelberg: Carl Auer Systeme Verlag, pp. 111-126.

\section{Autor}

Michael Schorner, Mag. phil. - Universitätsassistent am Forschungsinstitut Brenner-Archiv/ Ernst-von-Glasersfeld-Archiv. Arbeitsschwerpunkte sind Wissenschaftstheorie und Wissenschaftsgeschichte. 
Der vorliegende Band dokumentiert die Ernst-von-Glasersfeld-Lectures 2015 an der Universität Innsbruck. Neben den Vorträgen von Siegfried J. Schmidt und Gebhard Rusch sind zwei weitere Beiträge aus dem Ernst-von-GlasersfeldArchiv abgedruckt. Diese befassen sich in dokumentarischer und medienkünstlerischer Absicht mit dem Lana-Projekt und "Yerkish", der ersten Zeichensprache für Primaten, die der Philosoph und Kommunikationswissenschaftler Ernst von Glasersfeld (1917-2010) zusammen mit Piero Pisani Anfang der 70er Jahre an der University of Georgia entwickelte.

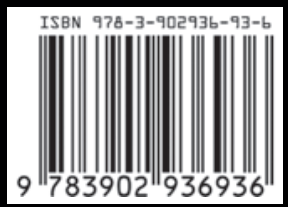

